\title{
Women's Traditional Knowledge and Sustainable Development in Rural Sialkot, Pakistan
}

\section{By Sadia Munawar-Ishfaq}

A thesis presented to the Faculty of Science of the Victoria University of Wellington in partial fulfilment of the degree of MASTER OF DEVELOPMENT STUDIES

School of Geography, Environment and Earth Sciences

Victoria University of Wellington

Wellington, New Zealand 


\begin{abstract}
Sustainable development has become a global imperative in recent times that needs to be taken seriously more than ever before. While it is globally acknowledged that sustainable development is indispensible to holistic global development, inadequate attention has been paid to alternative modes of achieving sustainability, examples of which exist in traditional knowledge systems of many rural and indigenous communities. This research tries to explore the intricate link between traditional knowledge studies and sustainable development, with a particular focus on the environmental, economic and socio-cultural aspects of human welfare. This is done by placing the concepts of 'traditional knowledge' and 'sustainable development' in the wider development framework, and by analysing their theoretical and practical underpinnings at the global and local level. Drawing upon a research carried out in Pakistan, the study adds to an existing body of literature that confirms that traditional knowledges of rural women are a valuable resource, which can constructively contribute to sustainable development objectives. The evidence is collected from four villages in rural Sialkot, where elderly women were interviewed about their knowledge systems and changing social roles in the context of local socioeconomic and environmental change. A major finding of the study is that local women's traditional knowledge, which has for long provided the foundation for sustainable living, is being displaced as globalisation invades rural life. This is indirectly resulting in a loss of sustainable livelihoods and local biodiversity. The problem is aggravated by the low value that is attached to indigenous know-how and practice at the community, and national and international level. The thesis concludes that women's indigenous knowledge needs to be recognised and mainstreamed in important development strategies in Pakistan for a more inclusive development.
\end{abstract}




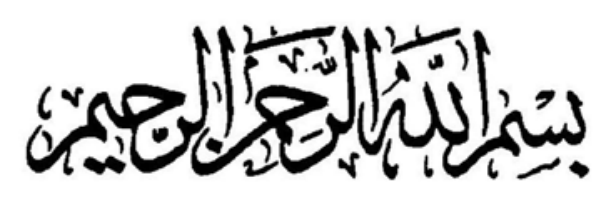

In the name of God, the most Beneficent, the most Merciful

Dedicated to my loving parents from

whom I draw my inspiration 


\section{ACKNOWLEDGEMENTS}

I am overwhelmed by the cooperation and hospitality I received from the locals in rural Sialkot, especially those who volunteered to participate in this study. I am grateful to them for taking out time from their daily routines to add richness to this research. I would like to thank Chachi Allahrakhi, Chachi Amna, Chachi Arshad, Chachi Bushra, Farzana, Chachi Fatima, Chachi Iqbal, Chachi Nusrat, Chachi Naseem, Razia, Phuphi Rasheedan, Phuphi Rehmat, Chachi Salima Nasim, Chachi Shabiran, Chachi Sharifan, Phuphi Sharifan and Chachi Sughran of Madhopur Vaince. I would like to thank Bashiran, Khatijan and Rashida of Gulokot, and Sughran of Kadiyanwali. I would also like to thank Allahrakhi, Ghulam Zara, Hamidan, Shamim and Rabia of Jajopur. Among the men, I would like to thank Mohammad Malik and Ashraf of Madhopur Vaince and Muhammad Khan of Gulokot. I thank them all for participating in this project and for enriching me (and my readers) from their diverse experiences.

A very special thanks to Namo Bibi of Kadiyanwali whose unfortunate death in August, 2009, came as a sad shock. She holds a special place in my heart, not only for representing her minority Christian community in this research, but also for facilitating my mother, in her capacity as a midwife, during my birth.

I am also grateful to my key informants -Tehseen, Tehmina and my Aunt Kokab - who helped me during the field research.

I would like to thank my friends both in Pakistan and New Zealand for cheering me up with occasional coffee and chaaye during this time. I would especially like to thank my friend Ishfaq, and uncle Irfan, for reading through boring first drafts and providing me with insightful feedback and support for this thesis.

Last, but not least, I would like to thank my family, especially Ami and $A b u$, who endured me with patience, love and support during the never-ending thesis-writing process. I am grateful to my brothers, particularly Zabby who slept uneasy nights wearing his magical 'terminator goggles', while I worked on this thesis in his room overnight.

It goes without saying that this huge task would not have been possible without the help, support and guidance of my research supervisor, John Overton. He has made this huge 
task easy and enjoyable even when I wrote from Pakistan. I thank him for patiently standing my countless deadline extensions, monotonous drafts and frequent naggings. 


\section{PREFACE}

This research is inspired from my personal experiences and childhood memories of my village, Madhopur Vaince. As I grew up, I saw it transform drastically over a span of 25 years: from a village clustered with indigenous houses, dependent on a single well for water supply, to a village that now is lined with modern houses, each having its own supply of water and electricity. There were changes in household practices as well. Take the example of a native Acacia tree, locally known as desi keekar (Acacia nilotica).

Acacia nilotica had traditionally been cultivated or naturally-grown alongside farms and travel paths. Its wood was used for making natural 'toothbrushes', and as fuel-wood in indigenous mud-stoves. The young, soft wood of the tree would be cut into pen-sized twigs to make a 'chewing stick' (miswak), which would be soaked overnight and used for brushing teeth the next morning. The villagers had followed this oral hygiene practice with a common-held belief that miswaak prevented plaque and gum disease, which has now been attested by scientific inquiry elsewhere (see Wu, Darout \& Skaug, 2001).Sadly, this practice is no longer in use now locally.

The reason for this may be that the tree is nowhere to be found in this area any longer. But then, how could a native tree so useful (medicinally, domestically and ecologically in controlling drought and salinity) disappear from the local landscape? This was not only bewildering, but also alarming for me. The tree had disappeared from the local landscape even though there was a decrease in local dependence on it. Was not the 'environmentpoverty nexus' supposed to be broken and the environmental condition expected to improve in this village since there had been an improvement in rural prosperity and socioeconomic development? These were questions which intrigued me and inspired me to carry out my postgraduate research work in this area. It is hoped that the reader will find this study insightful and useful for further research or inquiry. 
Table of Contents

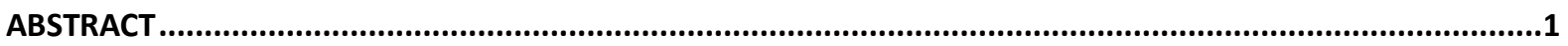

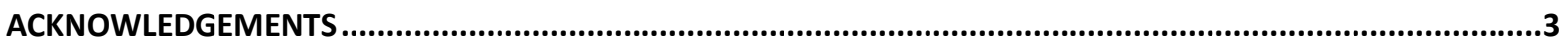

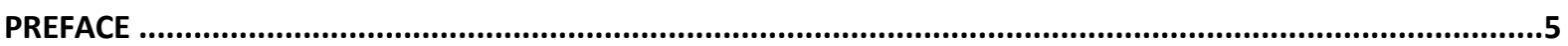

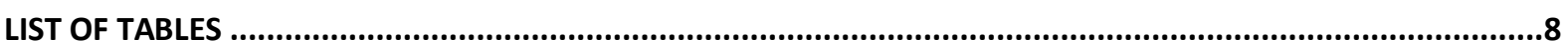

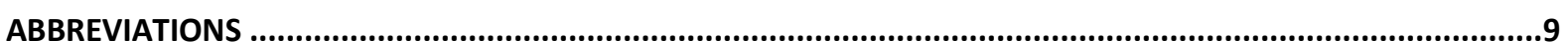

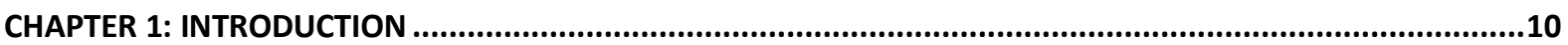

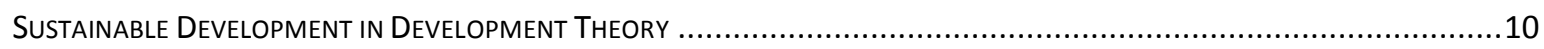

Sustainable DeVelopment, Traditional Knowledge And DeVElopment .................................................... 11

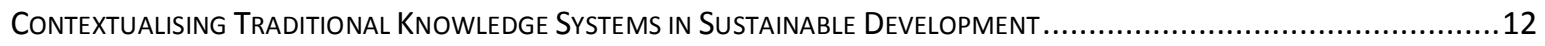

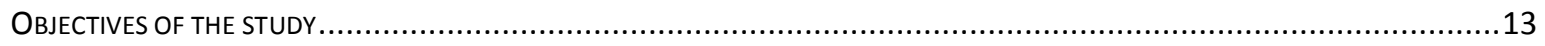

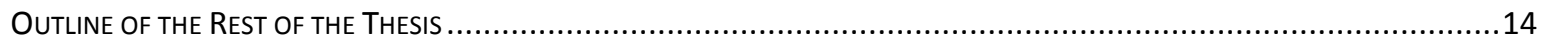

CHAPTER 2: RESEARCH SCOPE \& METHODOLOGY..........................................................................16

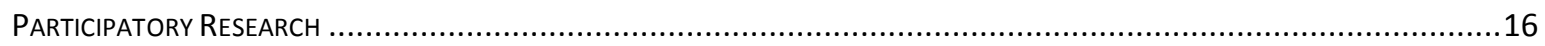

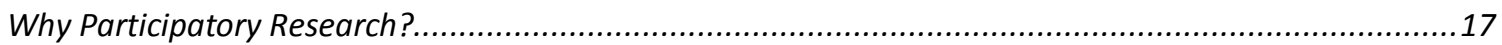

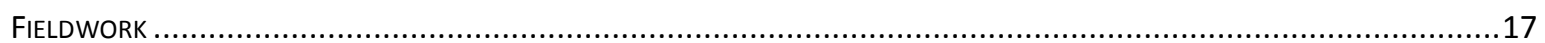

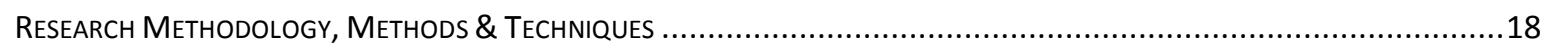

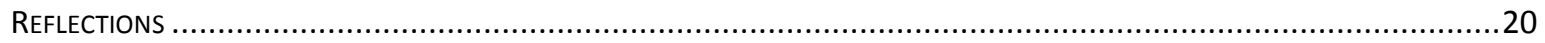

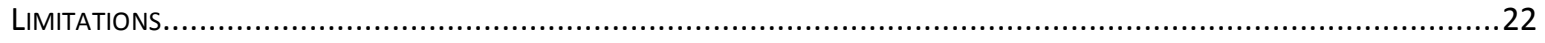

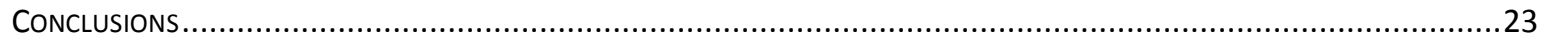

CHAPTER 3: TRADITIONAL KNOWLEDGE IN SUSTAINABLE DEVELOPMENT DISCOURSE: CONCEPT, THEORY \&

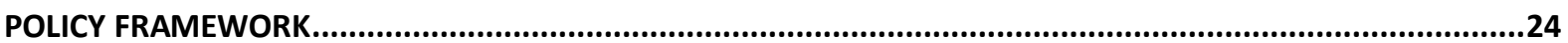

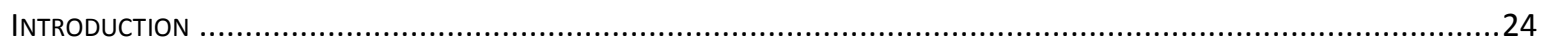

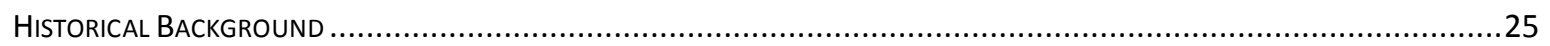

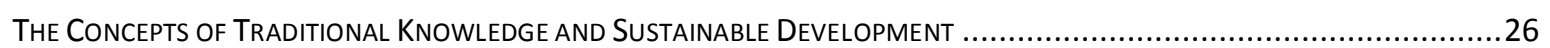

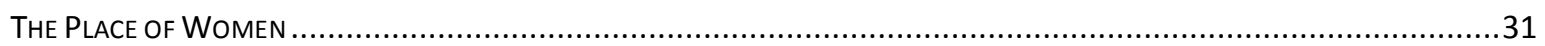

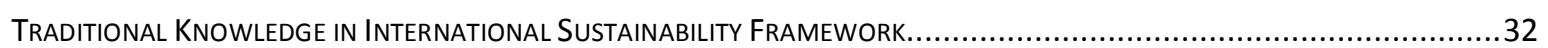

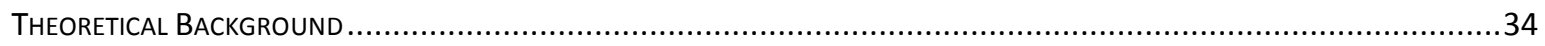

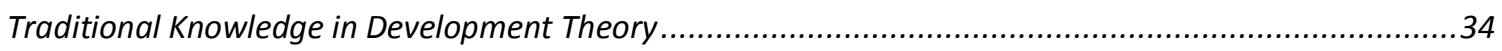

Traditional Knowledge in Sustainable Development Theory .................................................................36

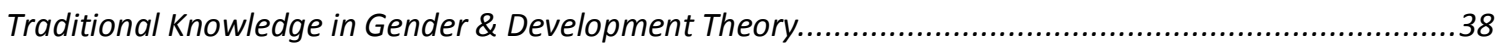

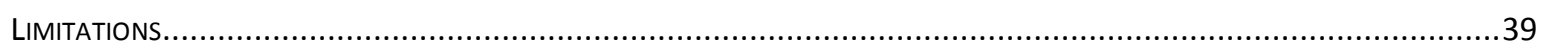

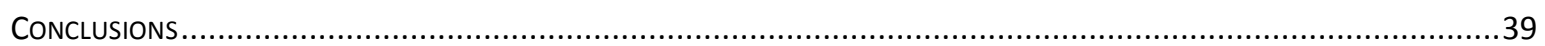

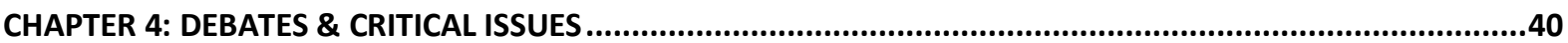

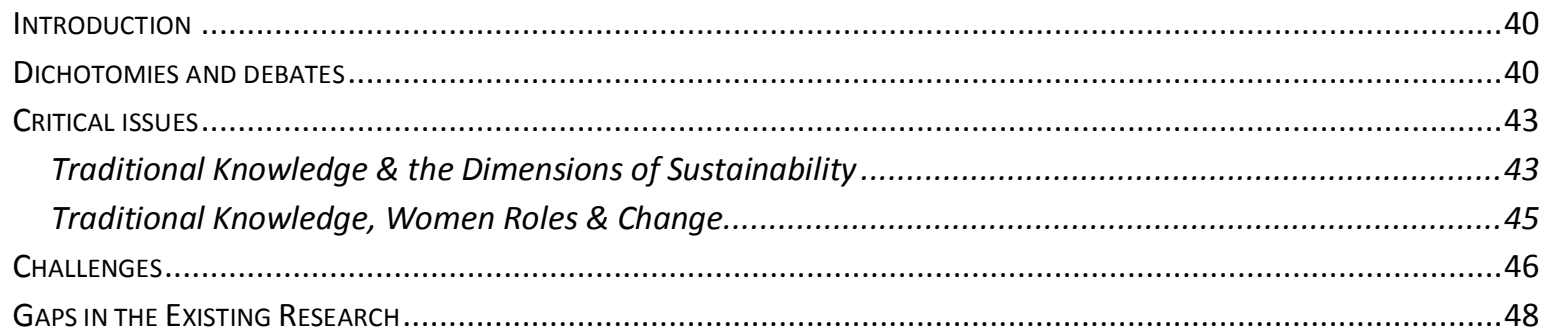




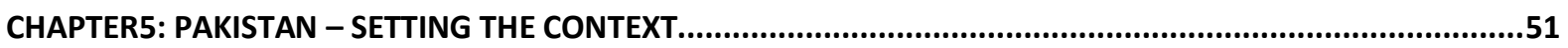

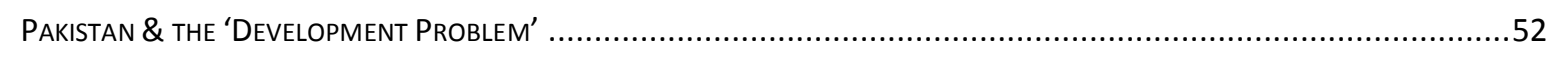

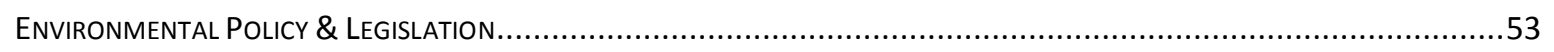

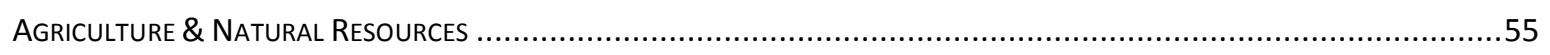

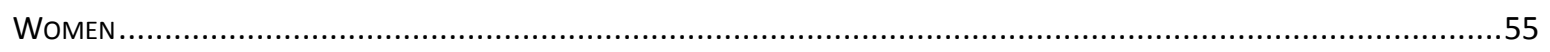

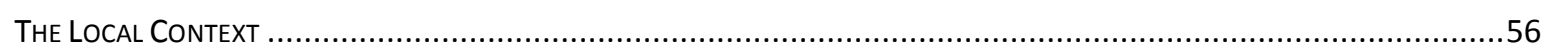

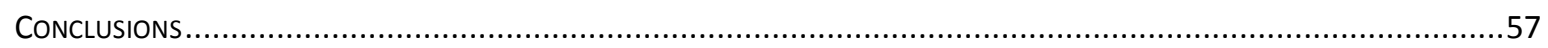

CHAPTER 6: WOMEN'S TRADITIONAL WISDOM \& SUSTAINABILITY IN RURAL SIALKOT, PAKISTAN ................58

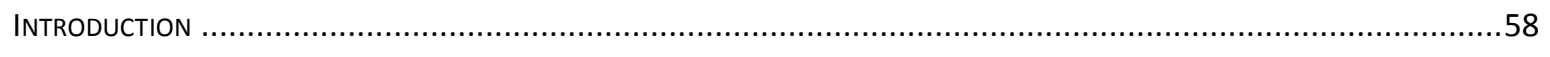

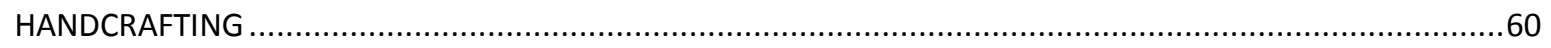

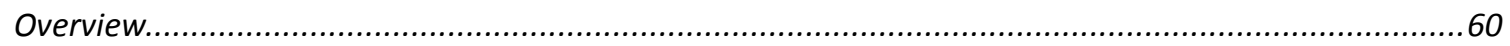

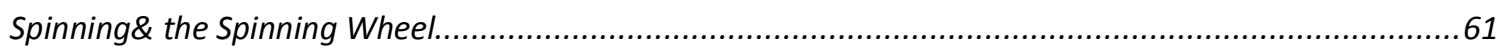

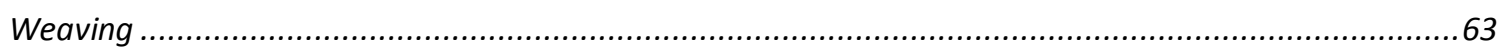

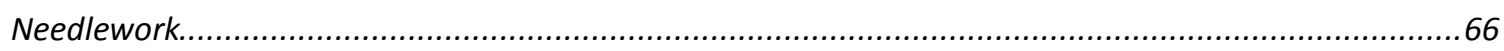

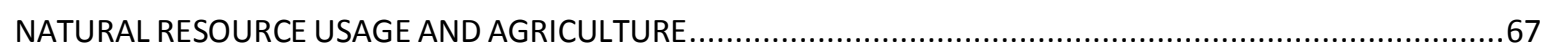

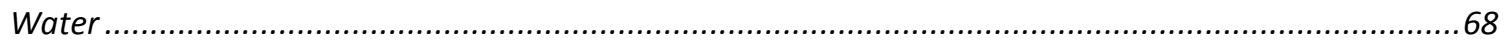

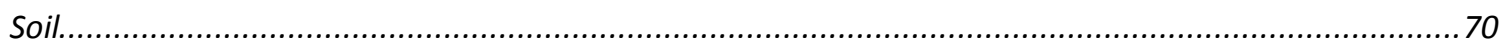

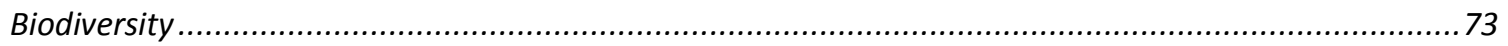

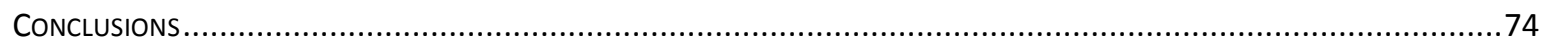

CHAPTER 7: INTERPRETING THE RESULTS - SIGNIFICANCE, CHALLENGES \& IMPLICATIONS ..........................76

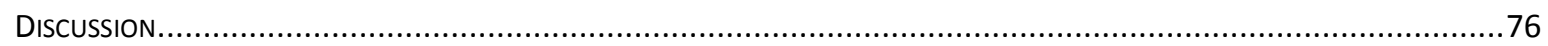

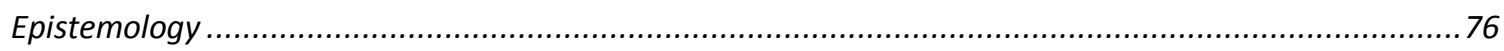

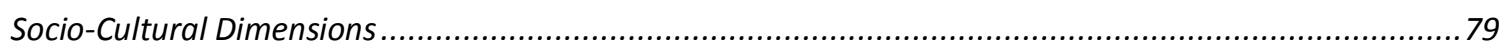

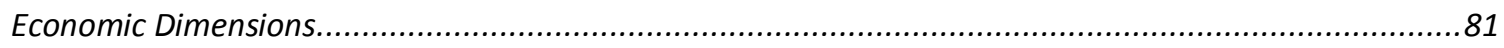

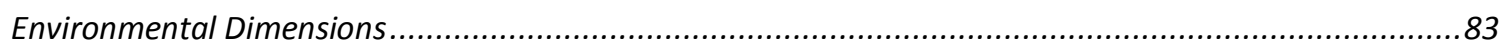

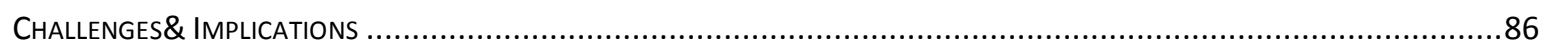

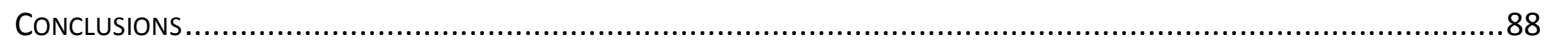

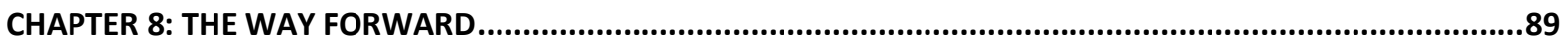

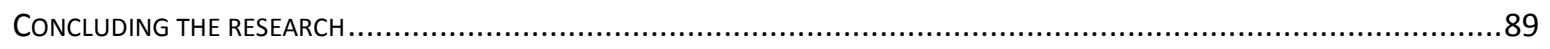

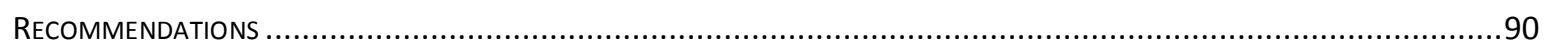

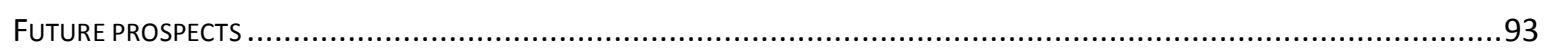

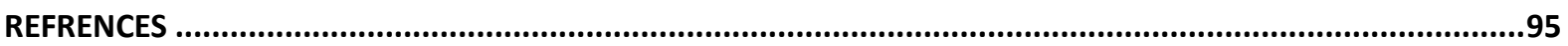

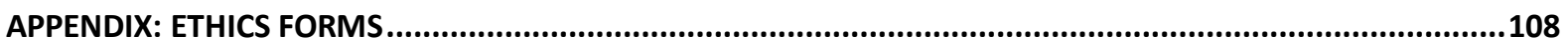




\section{List of Figures}

Figure 1: Iterative Cycle of Action and Reflection in Participatory Research ............................. 17

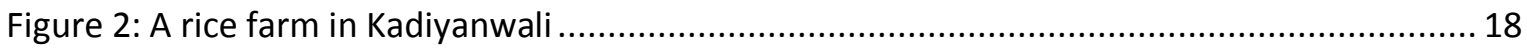

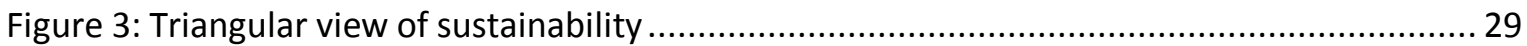

Figure 4: The parallels and differences between Traditional and Western knowledge systems ... 42

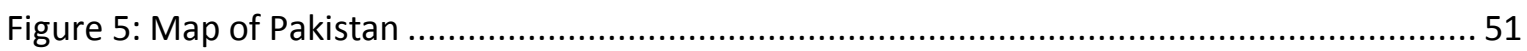

\section{List of Tables}

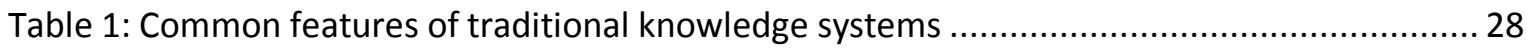

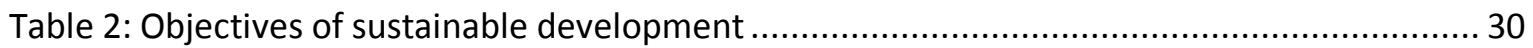

Table 3: Major international treaties on traditional knowledge and sustainable development.... 32

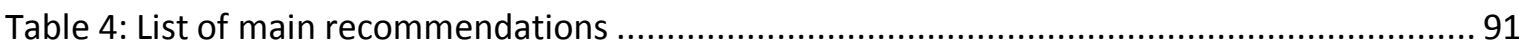




$\begin{array}{ll}\text { ABBREVIATIONS } \\ \text { CBD } & \text { Convention on Biological Diversity } \\ \text { DRIP } & \text { Declaration on Rights of the Indigenous Peoples } \\ \text { DDRIP } & \text { Draft Declaration on Rights of the Indigenous Peoples } \\ \text { ECOSOC } & \text { Economic and Social Council } \\ \text { FAO } & \text { Food and Agriculture Organisation } \\ \text { GAD } & \text { Gender and Development } \\ \text { GDI } & \text { Gender Development Index } \\ \text { GDP } & \text { Gross Domestic Product } \\ \text { GoP } & \text { Government of Pakistan } \\ \text { HDI } & \text { Human Development Index } \\ \text { IDS } & \text { Institute of Development Studies } \\ \text { IFAD } & \text { International Fund for Agricultural Development } \\ \text { IK } & \text { Indigenous Knowledge } \\ \text { IUCN } & \text { International Union for Conservation of Nature } \\ \text { MDGs } & \text { Millennium Development Goals } \\ \text { NCCR } & \text { National Centre of Competence in Research } \\ \text { NCS } & \text { National Conservation Strategy } \\ \text { NEP } & \text { National Environmental Policy } \\ \text { NEAP } & \text { National Environment Action Plan } \\ \text { NGO } & \text { Non-Governmental Organisation } \\ \text { NSDS } & \text { National Sustainable Development Strategy } \\ \text { OECD } & \text { Organisation for Economic Co-operation and Development } \\ \text { SDPI } & \text { Sustainable Development Policy Institute } \\ \text { UNCED } & \text { United Nations Conference on Environment and Development } \\ \text { UNDP } & \text { United Nations Development Programme } \\ \text { UNEP } & \text { United Nations Environment Programme } \\ \text { UNIFEM } & \text { United Nations Development Fund for Women } \\ \text { WAD } & \text { Women and Development } \\ \text { WED } & \text { Women, Environment and Development } \\ \text { WID } & \text { Women in Development } \\ \text { WB } & \text { World Bank } \\ \text { WCED } & \text { World Commission on Environment and Development } \\ \text { WSSD } & \text { World Summit on Sustainable Development } \\ & \end{array}$




\section{CHAPTER 1: Introduction}

Sustainable development has become a global imperative in recent times after international realisation about the vulnerability of earth's ecosystems (Lammerink, 2006). A number of international organisations, such as the United Nations (UN) and the World Bank (WB), are realising that local and indigenous knowledge systems offer valuable insights on how people interact with their environments and contribute to sustainability (Lammerink, 2006; Briggs, Sharp, Yacoub, Hamed \& Roe, 2007; Bicker, Sillitoe \& Pottier, 2004), and can serve as the 'foundation for new participatory approaches to development that are both cost-effective and sustainable, and socioculturally sound' (Bicker et al., 2004, p. xi). Given these concerns, it is important for us to investigate how local examples of traditional knowledge operate in a rapidly changing world and how these systems of knowledge might be maintained and utilised to achieve more sustainable livelihoods.

\section{Sustainable Development in Development Theory}

Sustainable development could not have been more appropriate at a time when looming environmental crisis threatens the survival of mankind and biodiversity alike. The global shift towards sustainable development came after the failure of previous theories and approaches to solve many of development's problems (Sillitoe, 1998a, 1998b).This was partly due to the cornucopian view of earlier international approaches that regarded the environment only as resource to be exploited for achieving economic growth. Thankfully, this assumption was challenged, especially after the publication of Brundtland report of 1987, and the environment came to be seen as another important dimension of development which needed to be managed and conserved sustainably.

Ironically, recent trends in the sustainability literature have once again been predominantly inspired by the economic models (such as carbon pricing), and there is concern in some quarters that sustainable development is being conveniently glossed over by the dominant neoliberal paradigm (Elliott, 1999). Doubts are raised about whether the United Nations Millennium Development Goals (MDGs) will be able to eradicate poverty, gender and economic inequality, and sustain environmental 
sustainability by 2015 , as set out in 2000 . Such doubts are redoubled after the recent international financial crisis (of 2008-2010) that has shaken the foundations of dominant development thinking, and has raised serious questions on the global blind faith in development approaches which overlook important dimensions of human life (such as the environmental, social and political). Clearly, such doubts need to be resolved by calling in line a more holistic sustainable development approach which is integrated in all future development endeavours as well (Desai \& Potter, 2008).

\section{Sustainable Development, Traditional Knowledge and Development}

Although sustainable development is a relatively recent concept, the idea of sustainability has existed in indigenous and traditional communities for thousands of years. For centuries, human beings have relied on traditional knowledge systems and know-how for survival, and have, in fact, co-existed in relative harmony with their environments. The intricate relationship that human communities have had with their environment can be symbolised in the 'egg of sustainability' metaphor, developed by International Union for Conservation of Nature(IUCN), where the yolk represents the society and white represents natural ecosystem (IUCN, 1997, as cited in Grenier, 1998, p. 51), symbolising the interdependence of the two. Certainly, there is a lot to be learned from such communities which have until recently been overlooked, and confined to the protected, rural and indigenous areas mostly, despite having negotiated their ways of knowing with their natural environments for centuries. What these indigenous communities have to offer to the concept of sustainable development is different from that which the Western-dominated scientific thinking presents.

The integration of traditional know-how in development projects can certainly prove useful to development agendas (Bicker et al., 2004). However, this does not imply that such a development model be detached from important development issues, such as poverty, hunger, illiteracy and insecurity (Kwa, 2005), almost all of which are locallydetermined. Indeed, many developing communities are wary of seemingly intrusive development projects which appear detrimental to local needs and values, and invade local cultures. It is hoped that by offering such a model, where development is rooted in the local context and knowledge systems, sustainable development can address important development concerns while also appearing more inclusive and integrated. 
The integration of traditional knowledge systems in sustainable development faces many theoretical and practical challenges that need to be addressed. The field of traditional knowledge studies is marred by theoretical incoherence and problematic contextualisation of TK in the local (which makes it all the more difficult for international sustainability objectives to be applied at the local level). Additionally, the inflexibility of sustainable development approaches becomes an impediment to their application at the local level (Kwa, 2005) after their 'translation' from the global level. Such challenges have made critics wary of indigenous knowledge studies and doubtful that they have anything positive to contribute to development thinking (see Dove, 2000; Agrawal, 1995).

\section{Contextualising Traditional Knowledge Systems in Sustainable Development}

In order for development to be successful, effective and appropriate, it needs to be grounded in the local context. Setting locally-appropriate and relevant development objectives (and achieving them) is not ideal, especially since local development policies are increasingly influenced by international guidelines. This is especially true for aiddependent countries like Pakistan that are often forced to compromise their national priorities in order to fulfil donor conditionalities. Although recent policy shifts in the international arena strive to bring the local to the forefront, especially after the Paris Declaration on Aid Effectiveness (2005), there is still a lot to be desired. Multi-donor organisations such as the WB and the International Monetary Fund (IMF), in search of quick and widely replicable results, come up with one-size-fits-all development strategies that have little local relevance. Clearly, there is a need for locally-appropriate development strategies that are guided by the international rhetoric, but at the same time, put local development needs at the forefront (rather than donors' preferences which are usually presented out of the local context). In other words, sustainable development strategies should be locally produced under limited international guidance, with input from local communities, and in consultation with local governmental, academic and non-governmental bodies. Because of their local rootedness, traditional knowledge systems can provide ideal basis for grass-roots decision making most of which usually takes place in indigenous community organisations where local problems are identified and solutions sought (Warren, 1996). 
Traditional knowledge systems can serve as storehouses of time-tested practices and know-how that can make global sustainable development efforts effective and meaningful at the local level. Studying how traditional knowledge systems have adapted to change and progress, while maintaining environmental sustainability, will enhance our understanding of how these bodies of knowledge have contributed to sustainability over the generations. It is hoped it will also provide us innovative insights and possible solutions to some of the modern-day development challenges faced in more developed communities. At the same time, it is hoped this research will help capture and document a small portion of what otherwise is a vast body of knowledge, similar to those existing in thousands of ethnic communities worldwide (Warren, 1996).

\section{Objectives of the study}

This research focuses on the environmental, social and economic aspects of sustainable development not only because these are the most basic and commonly recognised in international literature, but also because these are identified in the national sustainable development policies of Pakistan - the country under study.

Briefly, the research focuses on exploring out how traditional knowledge systems today contribute to sustainable development in rural Punjab, Pakistan.

The immediate objectives of the study are:

1) To develop a better understanding of ways in which rural women's traditional knowledge contributes to sustainable development (environmental, social, and economic)

2) To explore how rural women contribute to sustainability through the traditional roles they play in their households

3) To explore how traditional knowledge systems evolve over time with women's changing roles (and responsibilities) in context of socioeconomic and environmental change

The above research objectives are achieved by examining women's traditional know-how in the following major areas: cottage industry, agriculture and natural resource management. 
The second objective analyses the responsibilities women fulfill through their roles, which include meeting basic needs (of self and family), looking after welfare of the household, earning livelihoods, beside others.

It is hoped the research will help contribute to an enhanced understanding of and respect for traditional knowledge systems and cultural practices, and bring to light innovative sustainable practices that can possibly be promoted locally and adapted in other communities for a better, sustainable living.

\section{Outline of the Rest of the Thesis}

Chapter 2: Research Scope \& Methodology. This chapter describes the research design, the methodology and research techinques used in the research. It briefly overviews participatory research which inspires this postgraduate project. The chapter is summed up by reflecting on the field research, and by outlining the challenges and the limitations of the research.

Chapter 3: Traditional knowledge in Sustainable Development Discourse: Concept, Theory \& Policy Framework. This section examines the concepts of traditional knowledge and sustainable development within the wider development context, and discusses their place in the international legal framework. It discusses prominent theories and approaches in traditional knowledge studies, sustainable rural development, and gender studies.

Chapter 4: Debates\& Critical Issues. As obvious from the title, here prominent debates and critical issues are discussed which are of relevance to the current study. Scholarly research available on indigenous knowledge, women and traditional livelihood systems is analysed, before challenges in the field and gaps in the existing research are highlighted.

Chapter 5: Pakistan - setting the context. This chapter places the research in the local context. Pakistan's place in the world as a developing nation is discussed, and its national policies and programmes on sustainable development and traditional knowledge systems are overviewed. The place of women in Pakistan is also discussed, followed by a brief discussion on the local context (rural Punjab). It sets the background information for the next section. 
Chapter 6: Women's Traditional Wisdom \& Sustainability in Rural Sialkot, Pakistan. The findings from the field research are described in this chapter. The contributions of traditional knowledge systems to sustainable development are described by dividing women's acitivities into two major areas: handicrafts sector and natural resource usage ( $\&$ agriculture) sector. The findings reveal that women make important contributions to the rural community through active engagement in rural society, economy and environment, using their traditional know-how.

Chapter 7: Interpreting the results - Significance, Challenges \& Implications. Important findings from the field research are analysed and discussed in the light of the objectives of the research. The epistemological, social, economic and environmental aspects of traditional knowledge and rural sustainability are discussed. There are also challenges to be faced some of which are discussed along with their implications.

Chapter 8: The way forward. This chapter wraps up the research by summarising the thesis, and proposes recommendations for future directions. 


\section{CHAPTER 2: Research Scope \& Methodology}

This chapter briefly overviews the conceptual underpinnings of development research which inspire this study. The main aim of the chapter is to inform the reader about the research design and methodology employed in this research project. Later in the chapter, reflections are made on the field research, and some of the challenges and limitations of the research are briefly discussed.

\section{Participatory Research}

Development research is as much about research as practice. It differs from other research because of its unique position to directly impact local realities by influencing policy initiatives at the national and international level. In this regard, the most credible form of research that acknowledges local realities and tries to integrate them in development is participatory research.

Social science is 'socially constructed' and therefore 'subject to reinterpretation, revision and enrichment', just like other forms of science (Fals-Baroda, 2001, p. 28). Participatory research is a family of methods and approaches that allow people to 'share, enhance and analyze' their own realities (Kumar, 2002, p. 31) in order to bring about a personal or social transformation.

Unlike the positivistic approach of natural sciences, participatory research borrows heavily from values and subjectivity (Miller, Greenwood, \& Maguire, 2003) and tends to 'explore new paradigms of qualitative and humanistic experience' (Burgess, 2006, p. 425). Scientific reinterpretation relies on iterative cycles of action and reflection which involves self-inquiry, self-reflexivity and reflection, and self-awareness, (Burgess, 2006; Dowling, 2004; Kumar, 2002; Hanson and Hanson, 2001). 


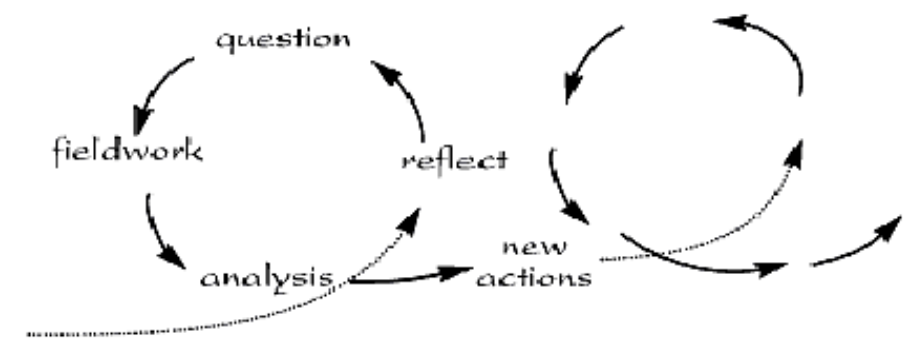

Figure 1: Iterative Cycle of Action and Reflection in Participatory Research

(Source: Wadsworth, 1998)

\section{Why Participatory Research?}

Science is knowledge, and knowledge is power (Dowling, 2004). Participatory research can also be used as a tool in development to weaken the dominant forces by empowering the locals, who in this case are the indigenous, marginalised rural women. Since it is perceived to be neutral, it can empower the locals by presenting their realities and grievances as valid scientific data. Participatory research is chosen over others because it allows the researcher to re-present local views using locally-adaptable research tools, which in other research approaches can become Western and hegemonic (Kincheloe \& Steinberg, 2008). The aim is to represent rural Sialkoti women and their opinions to accuracy, in pursuit of wider social (and personal) transformations.

\section{Fieldwork}

The field research took place in four adjacent villages in a relatively urbanised rural area of Sialkot. The fieldwork took place during March, 2009. Thirty-one semi-structured interviews were conducted, mostly of women (28 out of 31). Overall, men and women belonging to a total of 27 households were interviewed. During this time, I stayed at Madhopur Vaince, and usually visited the participants at their accommodations. This allowed me an opportunity to blend in the cultural context for the first time as a researcher; and to better understand the views, ways of doing and living in the local 
context. All interviews took place in the local language, Punjabi.

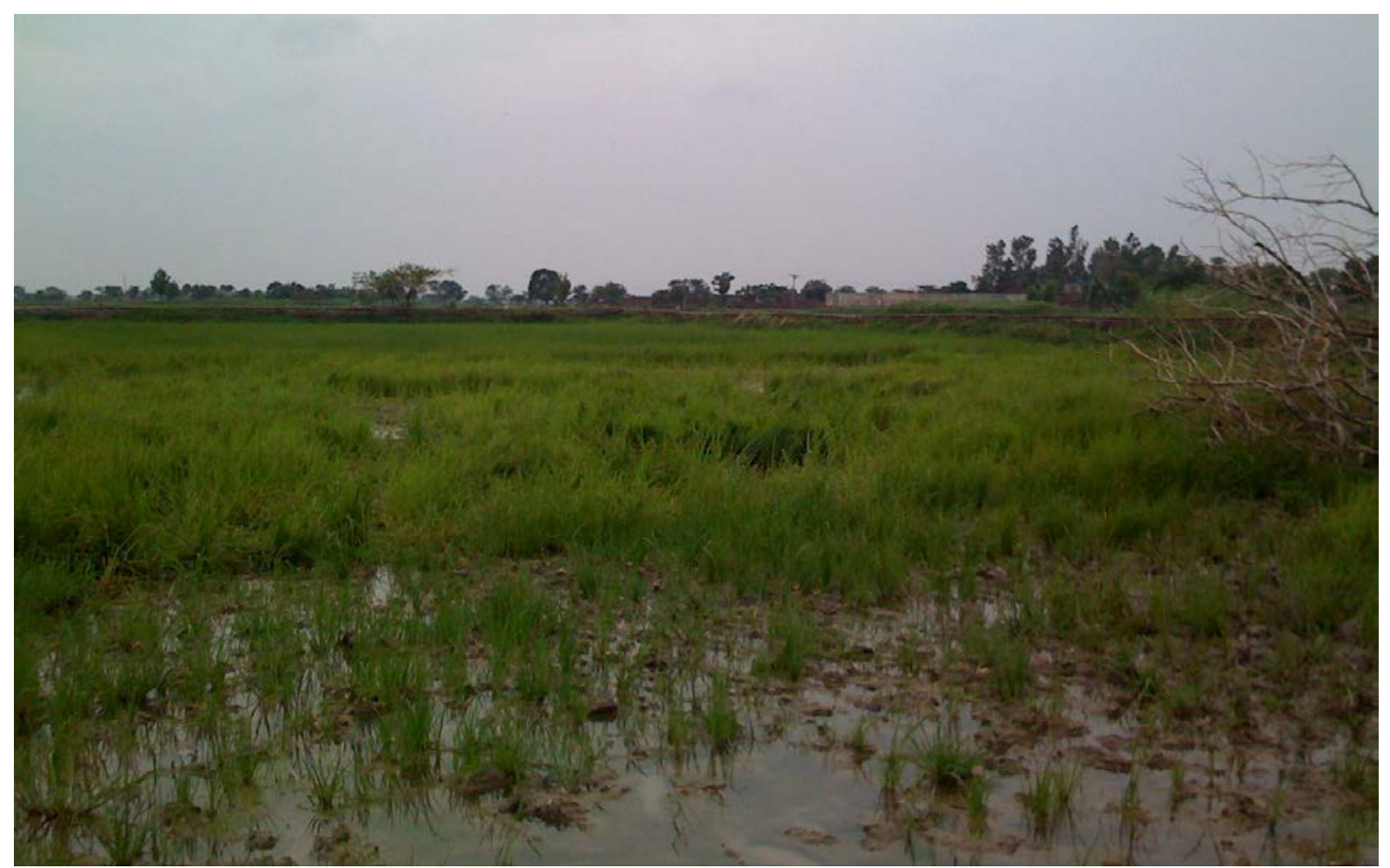

Figure 2: A rice farm in Kadiyanwali

I chose this particular rural locality because of a personal affiliation. I was born in Madhopur Vaince, and having spent part of my childhood there, I understood that these rural people had a rich heritage that conditioned them to adopt unique environmental attitudes and sustainable practices. I was disappointed to later find out that little research has been carried out in this area to study or understand traditional knowledge systems. In fact, to date there has been no known academic research that attempts to understand how rural Sialkoti women (particularly in this locality) have been adapting sustainable lifestyles in their own capacities, and how they interact with their environment using their traditional know-how.

\section{Research Methodology, Methods \& Techniques}

This research is purposely chosen to be cross-disciplinary because the 'richness of data' which results from the different perspectives (Mikkelsen, 2005, p.168) helps us better understand some of the gaps that exist in our current academic understanding. 
The methodology was primarily qualitative, as were the various methods and techniques used in the research.

An initial part of the research involved secondary data analysis. This was accomplished by analysing relevant literature that broadly covered academic research, institutional papers and reports, conference proceedings, and national and international policy frameworks.

The second part of the research involved fieldwork, which was inspired from participatory research and entailed: a) semi-structured interviews (individual and group), and b) participant observation. This methodology was chosen to help understand how the villagers' unique knowledge system informed their sustainable practices.

This research employed qualitative, semi-structured interviews as a research method because of the following features:
a. Openness, flexibility and adaptability
b. Participant engagement in research
c. Understanding the participant's perspective

Given the wide scope of the subject-area under study, the research was designed so to explore all possible dimensions of 'sustainable' traditional knowledge, including those that may have been missed out in the original research design. Semi-structured interviews were selected to keep the research focused, 'controlled and structured', while at the same time, to allow space for exploring unanticipated but relevant topic areas which could emerge during the course of the interviews (Mikkelsen, 2005, p. 169). Their openness, flexibility and adaptability made them ideal research method to suit the changing local contexts (of each village) (Mikkelsen, 2005), and the different levels of understandings of each participant. Research in this way would engage the interviewees as participants in the research, and not just as mere sources of information. Since the research was really about them, the village people (their way of living, thinking, and doing), it was desgined so that the participants coule be the guiding beacon of this research. 
The interviews were conducted in Punjabi, sometimes with the help of a fluent speaker (as my spoken fluency lasted only a few minutes, after which I reverted back to Urdu). Oral consent was sought after briefing the participants about the research and its possible implications. Interviews were audiotaped (with consent) and a written record was kept as well in the field journal. In total, 31 interviews were conducted, out of which 20 were individual interviews, each approximately 30minutes long. The other 11 participants were interviewed in groups of two or three (in total 5 group interviews).

The participant list was homogeneous with some diversity, where almost all the participants came from agricultural backgrounds. Potential participants were selected upon the recommendation of participants who had already been interviewed (partial snowball sampling). I cross-checked this list with my personal informants to ensure the credibility of recommended individuals. All participants, with the exception of one, were aged 35 or above. All had been residents of the village for at least ten years. Majority of the participants were women (28 out of 31). This was purposeful for two reasons: (i) the research was designed to find out how traditional knowledge was passed down, and since it was the mothers and grandmothers who had the responsibility of rearing children, they were the ones who passed on traditional know-how and ways of doing things to their younger ones; and (ii) because of the cultural sensitivities regarding gender segregation, interviewing men may have put them in an uncomfortable and even vulnerable position. Nevertheless, 3 men were interviewed, all of whom were farmers.

\section{Reflections}

Contrary to my expectations, the interviews when conducted proved quite similar to oral life histories, where detailed accounts of the participants' lifestyles, livelihoods, and previous ways of living were re-presented to the interviewer (Silverman, 2006). This was useful in some respects, because as a research technique, life histories reveal the ways in which social knowledge is passed on, and how the participants cope with changing lifestyles and culture over time (Marshall \& Rossman, 2006; Silverman, 2006). In this way, both the participant's life-story is analysed in context of the socio-cultural environment (Silverman, 2006). This helped because it allowed me to understand how traditional knowledge systems and rural sustainability had evolved in changing socioeconomic contexts over the generations. 
The interviews were conducted in informal environment, more like a conversation. I had expected the interviews to be one-on-one, but in reality they turned out to be conversations with (many) member(s) of the (extended) family and neighbourhood. This had an impact on how the respondents replied to questions - often agreeing with what the general consensus seemed to be.

Because I did not want to go to my interviewees with a pre-conceived idea of what the answers would be, I attempted to start each interview with a cognitive blank page. There were many issues that I could have enquired about - e.g. about the state of a dirty stream that washes past the village, now filled with industrial waste - but I did not because I wanted the villagers to highlight issues of importance to them. Unfortunately, many such issues were not discussed or even mentioned during the interviews. It may have helped to have a separate list of questions prepared as a questionnaire which would have served for the purpose of triangulation, and at the same time may have helped in understanding the villagers' perspectives that I thought needed to be addressed by the local government.

It was difficult to directly ask questions about sustainable development or traditional knowledge, because of two reasons: a) it was hard to translate the above terminologies in the local language; and b) the locals had little conceptual or theoretical understanding of 'sustainability', 'environment' and, surprisingly, even 'traditional knowledge'. As an outsider, it was easy for me to pinpoint and give examples of traditional practices. On the contrary, it took some time for the village women to understand what I meant by 'traditional' before they could elaborate upon their daily 'traditional' and 'sustainable' or 'environment-friendly' practises. Ironically, this exposed me to my own biased presumption of what the 'traditional' and the 'modern' meant, compared to what the locals meant by 'traditional', 'contemporary' and the 'modern'. Many of the interviewed villagers humbly denied that they held any useful 'knowledge' to elaborate on, when first questioned. Interestingly, most of the villagers interpreted 'knowledge' to be only formal and that which is attained in educational institutes. The community's apparent lack in self-confidence seemed similar to that found in other indigenous communities that are continuously bombarded with non-local values and compared against alien standards and ideals (Grenier, 1998). 


\section{Limitations}

Since the research was purely qualitative, it may be prone to subjectivity at the (a) participant level; (b) researcher level; and (c) audience level. At all the three levels different cultural understandings make it difficult to communicate universally a particular concept or a finding. The difficultly in translating local idioms, metaphors and, sometimes, local practices makes this job all the more challenging.

I belong to the culture where this research was conducted. Even though I have attempted to re-present the views of the villagers to the best of my objective abilities, there may have been issues, dilemmas which went unnoticed to my eye, but which may strike another researcher from another culture, as very different.

Interviews as a research method can be very subjective because human behaviour is unpredictable from person to person, and subject to bias and prejudice. Unlike pure sciences, human action, behaviour or saying cannot be quantified or scientifically tested for its credibility. However, I have attempted to tackle this problem by checking the credibility of the interviewees during selection process, and by carefully considering any statements (in the interviews) which seem dubious or unreliable.

Like any other social research, participatory research is subjective, and this can be its very limitation. A participatory research advocate cannot be expected to be absolutely neutral (O'Brien, 2001). Since the research process involved is 'deliberative' and 'interpretive' (Hoggart, Lees, \& Davis, 2002, p. 204), my interpretation of the research participants' histories and backgrounds may have impacted the way the results were produced. Critics of participatory research charge that it is shrouded in moralism (Mohan, 1999). Such concerns may raise serious questions about the validity of participatory research. However, it is important to acknowledge that no research can be completely value-free (Denzin, 1989, as cited in Stonebanks, 2008). As a participatory researcher, I was aware of this fallibility, and have consistently tried to counter such concerns by critically reflecting on my field research practices and results, by paying close attention to my own biases, and by being keenly aware of sensitivities throughout the research design, implementation and presentation process. 


\section{Conclusions}

This section places this research in the wider development research context. It argues that participatory approach is the most suitable to this kind of research where local realities need to be given credence to for integration into development work and research. The qualitative nature of participatory research, however, makes it subjective and prone to biases. Participatory research is, however, chosen because it brings local realities into focus, and explores issues of importance to the locals. This is suited to the scope of this thesis because traditional knowledge systems are indeed locally-formed, and in order to understand them adequately, it is important to understand them in the local environmental, social or economic context. We do this by analysing first the literature at the global level, and then focusing on a local case study in Pakistan, which is elaborated upon in the following chapters. 


\section{CHAPTER 3: Traditional knowledge in Sustainable Development Discourse: Concept, Theory \& Policy Framework}

This chapter explores and asserts that traditional knowledge systems are a valuable resource for sustainable development. The chapter begins by examining the concepts of 'traditional knowledge' and 'sustainable development', and how the two are intricately linked together in development theory and practice. This section aims to present a historical account of mainstream development approaches in the indigenous knowledgesustainable development discourse in order to inform the reader about the theoretical perspective that informs the research. The place of women's traditional knowledge in sustainable development is briefly discussed, with the argument that it has a potential to contribute to essential dimensions of sustainable development, i.e. environmental, sociocultural and economic dimensions.

\section{Introduction}

Numerous studies have emerged in the development field over the last $40-50$ years that argue that economic growth is not the only aim of development. International attention is drawn to more holistic models of development which integrate the economic, environmental and social dimensions of human life with the development needs of the present and future generations. 'Sustainable development' is one such model, which gained prominence in the late 1980s (Desai \& Potter, 2008) after international realisation that earth's resources are limited and may be exhausted soon. To date, however, sustainable development in policy and practice seems to have focused exclusively on the environmental and economic aspects, ignoring the social and cultural spheres of human development. Dissatisfied by this, a growing number of scientists and professionals are turning to non-conventional development models which can help devise more appropriate, effective and socio-culturally relevant sustainable development strategies world around.

A growing body of cross-disciplinary literature has been focusing on the role that traditional knowledge systems can play in participatory approaches to sustainable development (Boven \& Morohashi, 2002; Warren, 1996; Bicker et al., 2004). This growing 
interest is emerging after other models have failed to deliver the promise of development (Boven \& Morohashi, 2002; Agrawal, 1995; Nuffic-CIRAN, 1993).

Millions of people around the world still live in extreme poverty and deprivation. Yet, these poor possess something very rich (Ulluwishewa, 1993). Over centuries, indigenous and traditional communities have formulated their own locally-relevant and sophisticated know-how of forestry, agriculture, horticulture, fisheries, biodiversity, and resource management, among others (Warren, 1996; Nuffic-CIRAN, 1993; Ulluwishewa, 1993). Their rich knowledge systems helped them secure food and earn livelihoods in relative social accord. Recognising this, a greater number of development workers say that traditional knowledge systems have valuable contributions to make to sustainable development (Ulluwishewa, 1993), especially since they had previously been overlooked under the dominant Western paradigms of development.

Traditional knowledge indeed has a potential to play a very important role in devising development strategies, especially those aiming to enhance the 'sustainability' of a place (Ellen \& Harris, 2000). Undoubtedly, there is a need for a deeper understanding of how traditional knowledge systems contribute to sustainable development, and how women may differently contribute to it. This research seeks to address this in the coming sections.

\section{Historical Background}

Few can deny that traditional knowledge can make important contributions to the field of sustainable development (Ellen \& Harris, 2000). Although interest in this area is relatively recent (Sillitoe, 1998b), extensive research work has proved it to be an appropriate and useful partner in development, that is not only locally rooted but also deeply embedded in the local socio-cultural contexts (Ellen \& Harris, 2000; Sillitoe, 1998a; 1998b).

Academic interest in indigenous knowledge studies initiated with ethnographic studies in the field of anthropology, and later in ethnoscience and ethno-ecology (Sillitoe, 1998a). In more recent times, interest in the field has its roots in the farming systems approach and in participatory development approaches (Sillitoe, 1998a). Today, there are a number of disciplines contributing to the field, which are not limited to anthropology, 
botany, forestry, ecology, agriculture, resource management, medicine, and organisational management. We will attempt to briefly review the literature in these fields.

Interest in traditional knowledge studies has evolved from initial concepts such as 'indigenous technical knowledge', (Howes \& Chambers, 1979), to later studies on soil and vegetation research (Briggs et al., 2007). Some of the earliest exploratory studies in this field include a special issue dedicated to traditional knowledge systems by the Institute of Development Studies (IDS), University of Sussex, in its January 1979 IDS Bulletin that originally popularised the term 'indigenous technical knowledge'. It included Howes's article, 'The uses of indigenous technical knowledge in development' (Howes, 1979), which explored traditional knowledge's potential role in development fieldwork. A joint publication by him and Robert Chambers, 'Indigenous Technical Knowledge: Analysis, Implications and Issues (Howes \& Chambers, 1979), presented the concept of indigenous knowledge while it was academically still in its embryonic stages. The work was shortly followed by a landmark study, Indigenous Knowledge Systems and Development (Brokensha, Warren, \& Werner, 1980). Richards's 1985 work, Indigenous Agricultural Revolution: Ecology and Food Production in West Africa was another contribution from the field of agriculture. Richards is credited for acknowledging the objectivity of African farmers' agricultural traditional knowledge and practices, which previously had been overlooked (Richards, 1985, as cited in Briggs, 2008).

\section{The Concepts of Traditional Knowledge and Sustainable Development}

Debate about traditional knowledge begins with attempts to define it. The term has various synonyms, including indigenous knowledge, local knowledge, folk knowledge, traditional ecological/environmental knowledge, among others. Few writers agree on what the most appropriate term is. 'Indigenous knowledge' is most widely used in the current rhetoric, given its apparent cultural neutrality. However, its political connotations make it unlikely to be 'morally neutral or apolitical' (Ellen \& Harris, 2000, p. 3). Worldwide, indigenous groups have been associated with politically-marred activist movements for rights over natural resources, territories, and intellectual knowledge bases, which makes the term all the more controversial. There is also the difficulty in calculating how indigenous a community is (Ellen \& Harris, 2000) especially when the 
claim is made by conflicting groups. In the same breath, there is difficulty in deciding who the indigenous are, knowing that similar knowledges may exist in non-indigenous groups too (Johnson, 1992; Swift, 1979), rendering the term less useful in otherwise 'nonindigenous' development research.

'Local knowledge' is a more politically-neutral term, but becomes hackneyed by expanding to include all other knowledges that lay beyond our scope. Similarly, 'folk knowledge' too sounds commonplace and trite. 'Traditional ecological/environmental knowledge' seems to confine it to the environmental realms only, whereas in reality the knowledge under study is holistic, containing information about all spheres of traditional life, including beliefs, value systems and worldviews (Nakashima \& Roue, 2002).

Of all the terms, 'traditional knowledge' is most appropriate and relevant. It appears to be more credible, 'despite its implications of anachronism' (Ellen \& Harris, 2000, p. 3). Many writers feel uncomfortable using 'traditional' because of its apparent rigidity and association with the past, (Nakashima \& Roue, 2002). It becomes problematic to gauge how 'traditional' a knowledge system is, which is constantly evolving and renewing with social change (Johnson, 1992). The term is also inclined to invite often-dreaded comparisons with the 'modern', thus opening the binary debate on 'traditional' versus 'modern' (see Nakashima \& Roue, 2002; Dove, 2000; Ellen \& Harris, 2000; Agrawal, 1995) similar to that constructed by Swift (Swift, 1979). Misgivings about the term date back to the colonisation era and 'modernisation' era, when 'traditional' was derogatorily associated with such terms as 'backward', 'savage', 'primitive', and 'unprogressive'. Despite all these arguments, traditional knowledge is preferred and used here as it is appropriate to the context of this study. It is used interchangeably with indigenous and local knowledge and their acronyms (TK, IK and LK) without implying different meanings.

Traditional or indigenous knowledge is a 'complete body of knowledge, know-how and practices maintained and developed by peoples, generally in rural areas, who have extended histories of interaction with the natural environment' which are part of their 'cultural complex' (Boven \& Morohashi, 2002, p. 1). It is embedded in the community and unique to its locality, culture and society (Warren \& Rajesakaran, 1993 in Becker \& Ghimire, 2003; Guchteneire, Krukkert, \& Liebenstein, 1999). It is passed on between 
generations in the form of 'rituals, in religious observations, and in the cultural practices of everyday life' (Redclift, 1992, p. 402), using expressions which are unfamiliar to outsiders (Sillitoe, 1998b). It is non-formal, seldom formally recorded (Becker \& Ghimire, 2003; Boven \& Morohash, 2002; Guchteneire et al., 1999; Grenier, 1998; Sillitoe, 1998a).

It forms the basis of local-decision making about everyday life, including aspects such as food security, health, education, natural resource management, and the like (Warren \& Rajesakaran, 1993 in Becker \& Ghimire, 2003; Boven \& Morohashi, 2002; Guchteneire et al., 1999; Grenier, 1998). This is evident in a research carried out by Briggs and coresearchers in Egyptian valley (2003) which analysed how nomadic Egyptian women used their traditional environmental knowledge and skills to earn livelihoods.

Traditional knowledge systems generally share some common features and values which concern their interrelationship with their natural environment. According to Posey and Dutchfield (in Posey, 2000), these are:

Table 1: Common features of traditional knowledge systems

\begin{tabular}{|ll|}
\hline \multicolumn{2}{|l|}{ Common Features \&Values of Traditional Knowledge Systems } \\
\hline i) & Cooperation \\
\hline ii) & Family bonding and cross generational communication \\
\hline iii) & Concern for well-being of future generations \\
\hline iv) & Local in scale, self-sufficiency, reliance on locally available natural \\
& resources \\
\hline v) & Collective (and inalienable) ownership of rights to lands, territories \\
& and natural resources \\
\hline vi) & Respect for nature and restraint in resource exploitation \\
\hline
\end{tabular}

Traditional knowledge is dynamic and constantly evolving (Posey, 2000). The holistic nature of traditional knowledge systems makes it naturally adaptable to the various dimensions of sustainable development. Before these are discussed in detail, it is more befitting to understand what is meant by 'sustainable development'. 
The term 'sustainable development' became popular after the publication of a report by the World Commission on Environment and Development (WCED), Our Common Future, in 1987, (also known as the Brundtland report). The report defined sustainable development as a 'development that meets the needs of the present without compromising the ability of future generations to meet their own needs' (WCED, 1987, p. 43). In a joint report by the IUCN, the United Nations Environment Programme (UNEP), and the World Wildlife Fund (WWF), sustainable development was described as a development that improves quality of human living without exceeding the carrying capacity of the ecosystem (1991, as cited in Ulluwishewa, 1993). However, the WCED's definition remained more popular and was picked up by subsequent international conferences, such as the UN Conference on Environment and Development (UNCED) that was held in 1992 (also known as the 'Rio Conference' or the 'Earth Summit').

A defining feature of the UNCED's conceptualisation of sustainable development was its adaptation of the triangular view of sustainability (see figure 2 ):

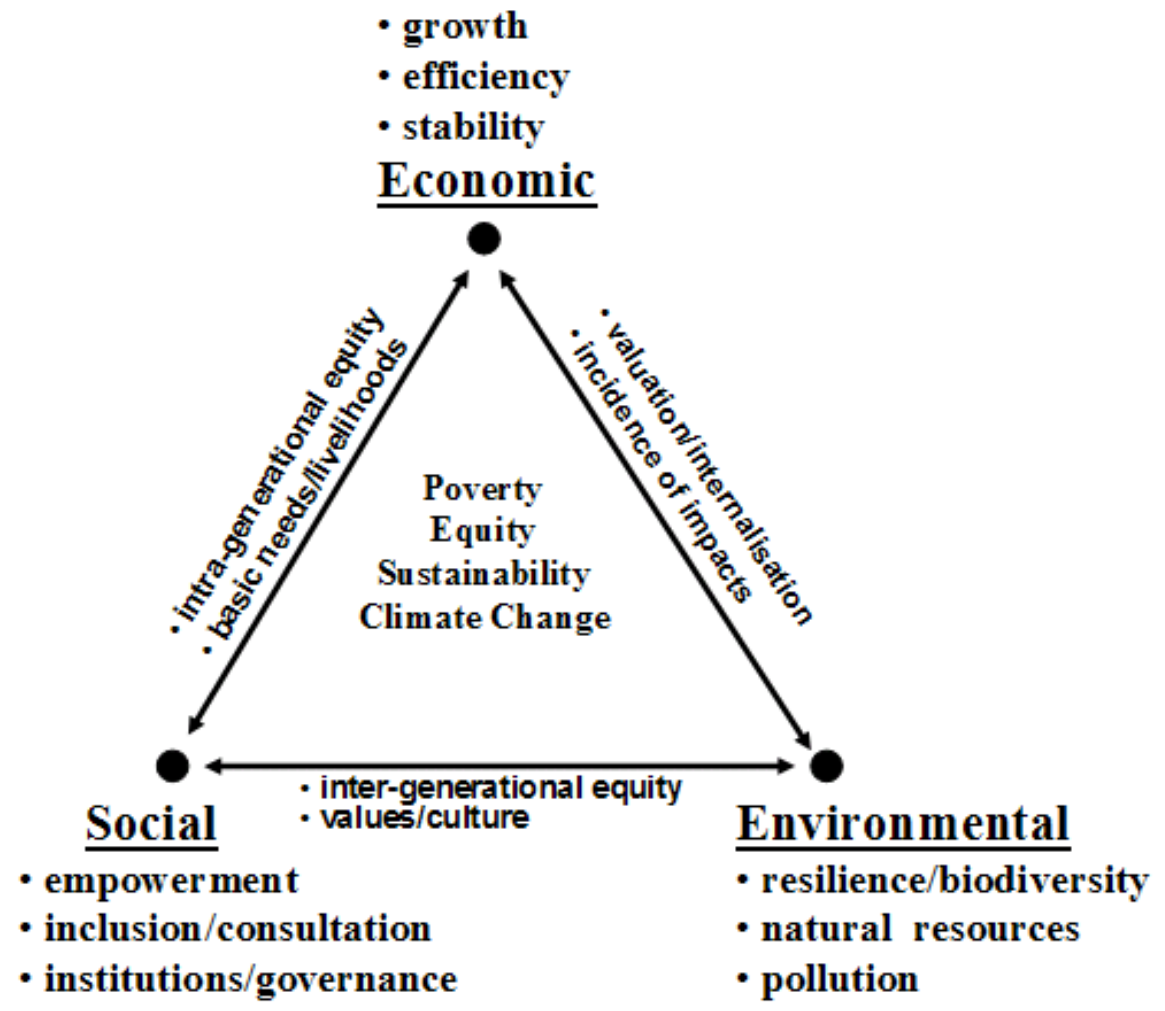

Figure 3: Triangular view of sustainability

(Source: adapted from Munasingha 1994) 
Much like the UNCED, most of the literature recognises the environmental, social, and economic dimensions of sustainable development to be the most important (Harris, 2000; Elliot, 1999; NCCR North-South, n.d.), even though there is support for the political and epistemological dimensions as well in some quarters (Redclift, 1992; Murdoch \& Clark, 1994). For the purpose of this research, we will look at the environmental, economic and socio-cultural dimensions of sustainable development.

The overall goal of sustainable development is long-term improvement in quality of life, and 'not just short-term improvements that disappear rapidly at the end of the project cycle' (Ulluwishewa, 1993, para 5). The objectives of sustainable development, according to the WCED (1987, as cited in Grenier, 1998), are:

\section{Table 2: Objectives of sustainable development}

\section{Objectives of Sustainable Development}

1. Reviving growth

2. Changing the quality of growth

3. Meeting essential needs for jobs, food, energy, water, and sanitation

4. Ensuring a sustainable level of population

5. Conserving and enhancing the resource base

6. Reorienting technology and managing risk

7. Merging environmental considerations and economics in decision-making

8. Reorienting international economic relations

9. Making development more participatory

Although most people accept WCED's definition of sustainable development, critics call it vague and ambiguous, allowing it to be interpreted differently to serve different interests (Redclift, 1992, 2008; McCright \& Clark, 2006; Ulluwishewa, 1993). Given this argument, the above objectives also become marred with ambiguity, especially since peoples' needs differ from one place to another, which may contradict peoples' needs in other societies (Redclift, 2008). The problem, hence, becomes a socio-cultural one.

Given the above difficulties, the most appropriate medium for the implementation of sustainable development objectives is a local one, where sustainability is designed to 
meet local needs while also respecting international protocols, which are discussed in more detail in the later sections.

\section{The Place of Women}

Before moving on to the next section, it is important to briefly appraise women's prominent role in bringing together indigenous knowledge systems and sustainable development.

Women's contribution to sustainable development is unique and should be recognised (Appleton \& Hill, 1994). Until recently, their traditional knowledge systems have largely been ignored or undervalued (Fernández, 1994; Mishra, 1994), despite having been recognised as a 'highly valuable resource' through the 1980s (UNEP, 2004, p. 21; Elliot, 1999).The lack of recognition led to the adaptation of insensitive policies which affected women and their livelihoods adversely. In many developing areas, for example, important subsistence crops that helped indigenous women generate incomes for the household were replaced by cash-crops, without realising their impact (Mpande \& Mpofu, 1995, as cited in Scott \& Foster, 2008).

Fortunately, women's contribution have come to be recognised in various fields, including agriculture and food processing, by international organisations like the WB, International Fund for Agriculture and Development (IFAD) and Organisation for Economic Co-operation and Development (OECD) (Appleton \& Hill, 1994). However, more research is needed to study women's roles as farmers, entreprenuers resource managers and craftspersons (Appleton \& Hill, 1994), and how their unique knowledge systems help contribute to sustainble development.

Women in many communities have contributed to the objectives of sustainable development in their own ways, using traditional know-how and practical skills worldaround. They are the primary resource managers and hold extensive knowledge about their environment (Mishra, 1994). Women play vital role in 'maintaining livelihoods, cultural continuity and community cohesion' (Mishra, 1994, para 2) especially when faced by a communal challenge, like environmental crisis or out-migration. Women have the capacity to directly influence both their natural and the intellectual resource pools. In many parts of the world, women are also the more vulnerable and marginalised 
segments of their societies. By serving as agents of socioeconomic and environmental change, they can not only close the wide gender- and poverty-gap that exists in many developing and communities, but also positively influence sustainable development rhetoric.

\title{
Traditional Knowledge in International Sustainability Framework
}

A number of international agreements recognise the importance of traditional knowledge systems in sustainability policy framework. To begin with, the 1992 UNCED summit held in Johannesburg was an important landmark conference that recognised the essentiality of traditional knowledge systems to sustainable development discourse:

\begin{abstract}
"Indigenous people and their communities and other local communities have a vital role in environmental management and development because of their knowledge and traditional practices. States should recognize and fully support their identity, culture and interests, and enable their effective participation in the achievement of sustainable development"
\end{abstract}

UNCED, 1992

The UNCED, or the Earth Summit, brought to light a broad and ambitious agenda that sought to achieve worldwide sustainability while reducing poverty and environmental degradation. Although many critics believe that it failed to live up to its outlined objectives (Pelling, 2008), it nonetheless remained successful in coming up with important international declarations, some of which are outlined in the table below, among others:

Table 3: International treaties on traditional knowledge \& sustainable development

\begin{tabular}{|c|c|c|c|}
\hline Declaration & Signed & Signatories & Scope \\
\hline $\begin{array}{l}\text { Convention to Combat } \\
\text { Desertification }\end{array}$ & 1992 & 193 & $\begin{array}{l}\text { Sustainable development. } \\
\text { Good governance. }\end{array}$ \\
\hline $\begin{array}{l}\text { Convention on } \\
\text { Biological Diversity } \\
\text { (CBD) }\end{array}$ & $\begin{array}{l}1992 \\
\text { at UNCED }\end{array}$ & 188 & $\begin{array}{l}\text { Biodiversity. Women. } \\
\text { Sustainable development. }\end{array}$ \\
\hline $\begin{array}{l}\text { United Nations } \\
\text { Framework Convention } \\
\text { on Climate Change } \\
\text { (UNFCC, or Kyoto }\end{array}$ & 1992 & 192 & $\begin{array}{l}\text { Climate change. Carbon } \\
\text { regulation. }\end{array}$ \\
\hline
\end{tabular}




\begin{tabular}{|llll|}
\hline Protocol) & 143 & Indigenous knowledge. \\
\hline $\begin{array}{l}\text { Declaration on Rights of } \\
\text { the Indigenous Peoples } \\
\text { (DRIP) }\end{array}$ & $\begin{array}{l}2007 \\
\text { at UN } \\
\text { General } \\
\text { Assembly }\end{array}$ & & $\begin{array}{l}\text { Sustainable development. } \\
\text { Indigenous rights. }\end{array}$ \\
\hline $\begin{array}{l}\text { Millennium } \\
\text { Development Goals } \\
\text { (MDGs) }\end{array}$ & 2000 & 189 & $\begin{array}{l}\text { Poverty reduction. } \\
\text { Sustainable development. } \\
\end{array}$ \\
& & $\begin{array}{l}\text { Women. Education. } \\
\text { Health. Global } \\
\text { development partnership. }\end{array}$ \\
\hline
\end{tabular}

Out of these, the Convention on Biological Diversity (CBD) remains the most widely supported legally-binding international agreement to date (Posey, 2000) with a total number of 188signatory countries. Despite that, a majority of indigenous people feel that the agreement is a 'sovereignty grab' by nations who wish to keep control over tribal, indigenous resources and territories (Posey, 2000, p. 38). With regards to the place of women, the CBD acknowledges women's contributions to sustainable development through their biodiversity management and conservation efforts (Zweifel, 1996).

The Rio Declaration recognises that 'women have a vital role in environmental management and development', and hence their participation is 'essential in achieving sustainable development' (United Nations Environment Programme [UNEP], 2004, p. 21). The Agenda 21 of UNCED 1992 is also another important plan of action which recognises indigenous communities' contributions and advocates their participation in local natural resource management and conservation activities (UNEP, 2004). It also recognises women's contribution to environment, but makes little mention of women's indigenous knowledge and its contribution to environmental sustainability (Appleton \& Hill, 1994).

Although the first UNCED summit made commendable progress in recognising traditional knowledge systems, the second UNCED conference, or the World Summit on Sustainable Development (WSSD) 2002, remained largely silent on this. It primarily focused on meeting economic goals for achieving sustainability, making little mention of traditional knowledge systems. The WSSD 2002 overlooked innovative resource management and conservation solutions that indigenous communities have adapted over centuries to sustain their ecosystems. Hoppers (2002) highlights the danger in this by emphasising 
that 'a major threat to the sustainability of natural resources is the erosion of people's knowledge, and the basic reason for this erosion is the low value attached to it' (Hoppers, 2002, p. 7, as cited in Breidlid, 2009).

Other declarations that recognise the importance of indigenous epistemological heritage include the Declaration on Rights of the Indigenous Peoples (DRIP), which was developed by UN's Economic and Social Council's (ECOSOC) Working Group on Indigenous Populations in 1982 and finally adopted in 2007. The two decades it took to debate and reach common grounds on the issue of indigenous rights is clearly indicative of the contentious nature of indigenous issues. The DRIP, which was formerly well-known as Draft DRIP (DDRIP) before it was ratified, is considered an important UN document that gives guidance on indigenous issues, and emphasises the importance of indigenous and local knowledge systems which are integral to human development and well-being (Posey, 2000).

Clearly, the UN has played an important role in drafting international agreements on sustainability and indigenous knowledge. The UN's Permanent Forum on Indigenous Issues (UNPFII) has declared 2006-2015 as the Second International Decade of the World's Indigenous Peoples. Despite this, indigenous knowledge systems are hardly mentioned in one of the most talked about UN agreements, the Millennium Development Goals (MDGs). The MDGs are a set of eight development goals, set out in 2000 , which the signatory countries seek to achieve by 2015 . These include poverty eradication, environmental sustainability, universal primary education and gender equality, among others. Considering that the MDGs are the most ambitious development objectives ratified by as many as 189 countries, it is disappointing that indigenous knowledge systems have gone largely unnoticed (International Fund for Agricultural Development [IFAD], 2009).

\section{Theoretical Background}

\section{Traditional Knowledge in Development Theory}

Interest in indigenous knowledge studies rose after a dissatisfaction with grand development theories, all of which espoused greater economic growth (Agrawal, 1995), 
while little attention paid to other important dimensions of human welfare, such as the environment and social well-being (Desai \& Potter, 2008).

Development theorists in the decades immediately following the end of World War II and the end of the colonisation era (1950s-60s), perceived indigenous knowledge to be 'inefficient, inferior, and an obstacle to development' (Agrawal, 1995, p. 413). The modernisation theory that became popular during this time was largely influenced by Western capitalist ideals, where the state enjoyed top-down control of the economy and the development process (Isbister, 2003; Sillitoe, 1998b). Human necessities such as food and shelter, (and social idles such as justice, opportunity, rights), were seen as natural byproducts of economic development. The modernisation school of thought saw developing societies' traditional knowledge systems as barriers to development (Isbister, 2003; Agrawal, 1995), which needed to be replaced with modern and technological know-how. Since most of this 'modern' knowledge was emerging from the Western societies at that time, modernisation became synonymous with Westernisation. The unilinear view of the theory clearly ignored the socio-cultural and environmental dimensions of development which are so crucial to human well-being. The theory also undervalued indigenous knowledge systems by seeing them as 'part of the problem, being nonscientific, traditional and risk-adverse, even irrational and primitive' (Sillitoe, 1998b, p. 212).

The Dependencia (or dependency) school of thought, that rose as a challenger to modernisation theory, similarly overlooked traditional knowledge as a 'view of the powerless' and exploited poor (Sillitoe, 1998b, p. 212). Like its predecessor, the dependency theory supported the state's top-down hierarchy of control over the economic, political and development resources. In their politico-economic view of development, underdevelopment was as a result of the marked inequalities between the North and the South, which needed to be addressed by rebalancing the unequal power structures. Like the modernisation theory, the dependency theory was 'blind to local knowledge issues' (Sillitoe, 1998b, pg. 211).

The neo-liberal discourse took a subtler position towards non-Western cultures and knowledge systems. The dominant development ideals were now democracy, liberty, 
freedom, individualism, free speech, free markets, and the like. A prominent approach belonging to the neo-liberal school of thought is the market-liberal approach that pays greater attention to local knowledge systems, albeit from a market- and technologyfocused perspective (Sillitoe, 1998b). Similar to some extent to the modernisation approach, the market-liberal approach subtly blames poor farmers for being ill-informed, and argues for educational and extension programmes for the farmers so they can make better informed choices (Sillitoe, 1998b). It recognises indigenous practices and knowhow on the one hand, while at the same time suggests that they are somehow inferior and that the farmers need to acquire more useful knowledge from the 'outsiders' through training.

The more recent alternatives approaches belonging to the neo-populist school of thought emphasise the importance of the local (and the indigenous) in enhancing the development process (Agrawal, 1995). Dominant grass-root approaches like the bottomup development and participatory development approaches have popularised and prompted the inclusion of neo-populism in mainstream development. The theory is that by localising development, the outcomes will be more relevant, effective and long-lasting as a consequence of endogenous efforts. The participatory approach to development pays serious attention to traditional knowledge systems, which are seen as important in identifying local problems and research (Sillitoe, 1998b; Agrawal, 1995). It seeks to solve local peoples' problems employing their traditional know-how and skills (Kumar, 2002), while it also advocates the empowerment of the poor through their participation in local decision-making. Ironically, the same 'grassroots-focused paradigm' (Sillitoe, 1998b, p.224) has been used by the neo-liberals to advance their agendas.

\section{Traditional Knowledge in Sustainable Development Theory}

Numerous discourses exist on sustainable development, often in contradiction to one another (Desai \& Potter, 2008; Redclift, 2008; McCright \& Clark, 2006), reflecting the different ideologies that people are committed to, and the diverging interests that people have in sustainable development (Redclift, 1992; 2008; McCright \& Clark, 2006).

As this research is set out in a rural context, we will begin by briefly reviewing some of the most widely accepted approaches in rural development. 
In the 1950s, the 'Green Revolution' was very popular with its underlying principle that agricultural output and rural prosperity increased as a result of scientific input, mechanisation and irrigation (Zoomers, 2008). Although the approach was discontinued in the 70s-80s, its remnants are still apparent in poor areas where fast and easy cash appeals more to the locals than environmental sustainability.

The Integrated Rural Development approach of the 70s and 80s drew inspiration from 'appropriate development', basic needs and 'bottom-up' development approaches. Unlike its predecessor, it engaged non-governmental and government sectors in the development process. More recent approaches in sustainable development include the neo-liberal 'pro-poor growth' model that emerged in the 1990s. At about the same time, alternative approaches from neo-populist school of thought became popular, such as participatory development, agropolitan development and bottom-up theory, among others.

An interesting model to consider is John Friedman's agropolitan development approach which proposes radical concepts based on a participatory, locally-rooted and self-reliant development (Parnwell, 2008). The approach however is somewhat utopian, failing to offer any innovative, practical solutions to rural environmental problems.

Sustainable rural livelihoods approach, popular since the 1990s, is a more holistic model which seeks to fulfil the material and non-material wellbeing of rural people (Zoomers, 2008). It views poverty as having economic, social, environmental and cultural dimensions, reflecting the multidimensionality of poverty that Amartya Sen and Jules Pretty also allude to (Pretty, 2008; Sen, 2000). It focuses on what people have ('capital') and what they are capable of ('capabilities'), which can help them shape their own destinies (Zoomers, 2008) (the approach has resonance with Amartya Sen's Human Capabilities approach that became popular after his Development as Freedom, 2000). The approach offers interesting insights on the fluidity of 'assets' between the different dimensions. A poor farmer having limited financial resources cannot be seen as entirely poor as long as she has social, cultural and environmental assets to capitalise on. She can utilise her traditional know-how and skills to generate sustainable incomes through natural resource use with the support of social networks. In other words, the poor may 
indeed be rich despite their economic deprivation. The approach however fails to find solutions for those poor who have little access to environmental, economic, social or cultural 'assets', like the shudras, or the 'untouchables', of India. In addition, it measures human well-being in economic terms as if human welfare can be easily converted into economic values, and human well-being be neatly divided into interchangeable dimensions - the absence of one being compensated by the presence of another.

\section{Traditional Knowledge in Gender \& Development Theory}

Since the 1980s, a number of theories and approaches have attempted to explain women's relationship with their natural environment. Earlier approaches like the Women in Development (WID), Women and Development (WAD), and Women in Environment and Development (WED) focused exclusively on women's contribution to the economy, household and environment as being unique and different from that of men. Because of their different gender-based social roles, women were in closer proximity to their environment, and generally inclined to be more empathetic towards nature (Briggs et al., 2003; Mishra, 1994). The approaches also implied that women's traditional knowledges were different from those of men, or at least laid emphasis on different aspects of the same knowledge system (Briggs et al., 2003). Although the approaches were engaging and convincing, their scope was narrow as they exclusively focused on only one half of the population (i.e. women), as if they existed in a socio-cultural vacuum. The approaches treated women as a homogenous group (Mikkelsen, 2005), despite the many differences and the diverse roles that women played in their daily lives (Briggs et al., 2003). The WID, WAD and WED approaches, still in practice today, stand in danger of romanticising women's roles and their traditional knowledges in sustainable development.

Ecofeminism, popular since the 1970s, viewed the relationship between women and environment in 'ideological terms' (Mishra, 1994, para 3), comparing the domination of environment to the domination of women (Mebratu, 1998). It viewed environment as an 'integrated entity', where any action on one part affects all other parts of the environment, which is in contrast to the reductionist scientist approach (Mishra, 1994).

Successor to the women-environment-development approaches was the Gender and Development (GAD) approach that recognised men's valuable contributions as well along 
with women in sustainable development. Supporters of GAD emphasize that women's close relationship with their environment is not because of their biological makeup, as ecofeminism may have proposed, but because of their poverty, lack of opportunities outside the households, and their social relations (Elliott, 1999).

\section{Limitations}

Although much international attention has been paid to indigenous knowledge research and sustainable development, the 'sustainable indigenous development' agenda has been slow-moving somewhat. Critics charge that the WCED and UNCED proposed a sustainable development agenda that is more reformist than radical, unlikely to challenge the current hegemonies of neo-liberalism and market economy that have become the dominant paradigms in development since the 1990s (Elliott, 1999). Rather than devising strategies that incorporate innovative alternative solutions, such as those found in traditional knowledge systems, sustainable development has sadly been reverted to economise on environmental problems, for example by devising 'carbon tax' strategies to curb green house gas emissions. Indeed, advantage should be taken of the 'heightened awareness of the central importance of indigenous knowledge systems in the construction of sustainable strategies for rural development' (Marsden, 1990, p.267 as cited in Pottier, 2003, p.4; Ellen \& Harris, 2000). However, this has been made difficult by a lack of common agreement on any one theory by the indigenous knowledge advocates (Sillitoe \& Marzano, 2009; Sillioe, 1998a, 1998b; Agrawal, 1995).

\section{Conclusions}

Although there has been a lot of interest in traditional knowledge studies since the 1970s, the academic literature available on the gendered nature of traditional knowledge is far from exhaustive. A review of sustainable and indigenous development framework suggests that indigenous knowledge systems have come to be recognised as having important solutions to offer in sustainability rhetoric, but are yet to be acknowledged in development practice. The problem is worsened by theoretical incoherence that mars indigenous knowledge studies. The next chapter draws attention to the gaps that exist in current traditional knowledge research, after it addresses prominent debates and critical issues that are of relevance to this research. 


\section{CHAPTER 4: Debates \& Critical Issues}

This chapter overviews important debates and dichotomies that exist in the field of indigenous knowledge research. This is followed by an analysis of issues that are of critical importance to this research. The chapter concludes by highlighting some of the gaps that are present in existing research.

\section{Introduction}

Critics are weary of the dichotomous debates between indigenous and Western knowledge, traditional and scientific or modern knowledge, and between local and global knowledge that have become entrenched in indigenous knowledge discourse (Agrawal, 2002; Dove, 2000). Absence of universal parameters against which to compare such contentious concepts undermines the credibility of the whole debate, and indirectly, of indigenous knowledge research, which thrives on these dichotomies. Agrawal (1995) compares such a dichotomous line of thinking to that found in modernisation theory. Michael Dove, once a devoted advocate of indigenous knowledge, re-thinks the place of indigenous knowledge research in development if such debates continue to haunt indigenous knowledge studies, as they have done in the past (Dove, 2000). Notwithstanding the criticism, it is asserted that 'some distinction' is necessary in order to distinguish between scientific and indigenous knowledge (Sillitoe, 1998b, p. 206), in order to discuss their relative place in development. Here, we take a brief look at some of these binary debates.

\section{Dichotomies and debates}

There are many debates on the place of indigenous knowledge studies in the development discourse. Experts argue whether indigenous knowledge is a 'technical knowledge' whose useful bits only need to be integrated into multi-donor development projects (Briggs, 2008), or whether it should receive a more prominent place as a partner among other renowned science disciplines in the development field.

Major funding agencies, such as the WB, see indigenous knowledge as complimentary to development by offering its 'technical, place-specific solutions', and consider that it should therefore be integrated into major development projects (Briggs, 2008, p. 108). A 
growing body of national and international organisations hold a similar view (Agrawal, 1995). However, Briggs cautions against accepting indigenous knowledge too readily in development programmes because the 'validity of [indigenous knowledge] needs to be confirmed' through the 'lens of formal science' before it is integrated into development programmes (2008, p. 108).

The apparent empathy for traditional knowledge in the above view appears to be superficial. The view clearly sees indigenous knowledge as a resource to be exploited, rather than a knowledge system to be acknowledged as an equal partner in development. It suggests that features of indigenous knowledge relevant to science should be extracted, while the useless rest be rejected through scientific validation based on scientific criteria (Nakashima \& Roue, 2002). The underlying assumption for Briggs's argument appears to be that scientific knowledge is superior to indigenous knowledge. Like in the past, traditional knowledge is indirectly being referred to as inferior and in opposition to science.

By claiming science to be 'objective', 'validated', 'rigorous', 'controlled' and 'tested', science is shown to be value-free, operating 'outside the society' in which it is rooted (Fernández, 1994, para 2). This attitude lowers the stature of traditional knowledge to innovate and experiment, consequently devaluating the role of 'grass-root innovators', especially women (Fernández, 1994, para 2).

Despite the differences and dichotomies, there are also similarities and parallels between traditional and Western/scientific knowledge systems, which need to be explored in order to advance the cause for a more integrated development (Sillitoe \& Marzano, 2009; Sillitoe, 1998a). There is clearly a need to build bridges between Western knowledge, science and traditional knowledges in order to understand how they can be employed together to aid development (Berkes, 2008; UNEP, 2004; Sillitoe, 1998a, 1998b; Agrawal, 1995). This however is made difficult by the power relations and powersharing issues that are inherent in development, and in traditional communities. 


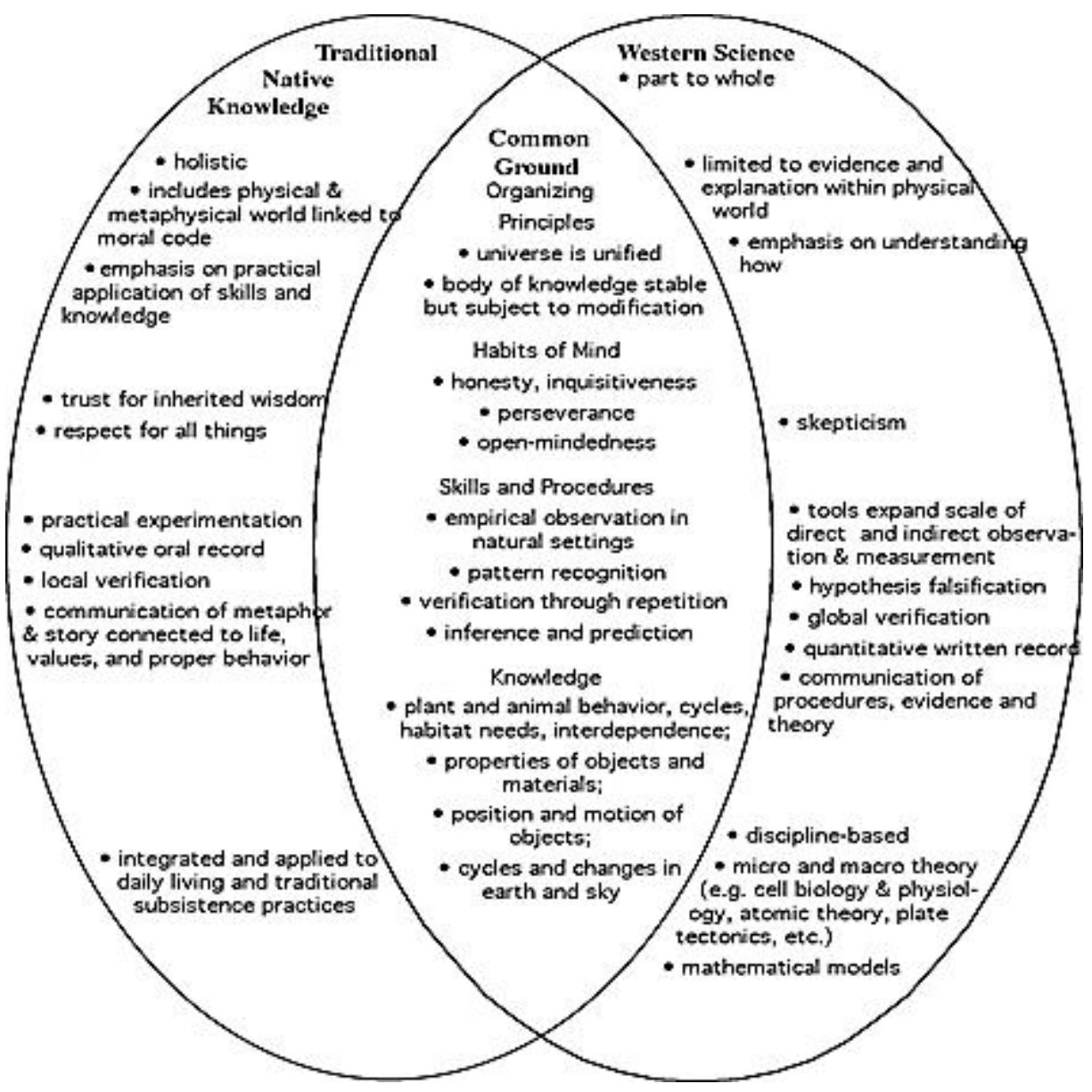

Figure 4: The parallels and differences between Traditional and Western knowledge systems

(Source: ANKN, 2008)

Power is a dominant player in development. Its influence cannot be ignored in indigenous communities and their knowledge systems. Power is also inherent in indigenous social hierarchies and structures. In most traditional societies, knowledge is gained with age and experience, and with it, power (Smith, Burke, \& Ward, 2000). Community elders are revered not only for the vast knowledge they hold but also for the power they exercise (ibid.). Scholars have tried to highlight the importance of the power relations that are at play in knowledge production, negotiation, dissemination and evolution (Nygren, 1999). Pottier argues that knowledge production involves 'social struggle, conflict and negotiation' (2004, p. 2), which is further explored in Nygren's (1999) case study among migrant peasant communities in Nicaragua. 
Based upon his research, Nygren acknowledges that power is a determining factor of who controls knowledge production or has access to the natural resource base. He claims that in an environment of conflicting and competing interests, knowledge is negotiated and politicised, hardly remaining 'indigenous' to a particular community. However, his assertions, although true to some extent, cannot be generalised for most indigenous communities, for not all are involved in a political struggle with migrant communities for access to protected resources, property and knowledge, as in Nygren's Nicaraguan case study.

What is obvious from the above discussion is that development needs to be seen as a holistic process, that engages not only science but also alternative forms of knowing for a sustainable, viable future (Sillitoe, 1998a). Science or indigenous knowledge may not effectively be able to contribute to development in isolation. Locals need to participate in sustainable development initiatives in order to harbour a sense of ownership, without which sustainability may not be achieved (Redclift, 1992). This will ideally be achieved through the recognition of indigenous peoples' knowledge systems not only in academic journals but also in development policy and practice, while remaining sensitive to the power dynamics within the local and global development contexts.

\section{Critical issues}

For centuries, people have relied on locally available natural resources to reap livelihoods using traditional know-how. This is evident from research carried out in fisheries, natural resource management, biodiversity conservation, agriculture, forestry, and textiles, for example (Briggs, 2005; UNEP, 2004; Warren et al., 1993, as cited in Agrawal, 1995). For the purpose of this research, we will take a brief look at the interdependent dimensions of sustainable indigenous development before we discuss traditional livelihood systems and gender in indigenous knowledge research.

\section{Traditional Knowledge \& the Dimensions of Sustainability}

Current research sponsored by international financial institutions, such as the WB, sees a linkage between economic deprivation and environmental degradation:

"Environmental degradation contributes to poverty...by constraining the productivity of those resources upon which the poor rely, while poverty restricts 
the poor to acting in ways that are damaging to the environment... The poor are...both the perpetrators and the victims of environmental damage..."

(Hope, 2008, p. 1, 5)

Not surprisingly, such a stance indirectly places the blame on the shoulders of the poor for the condition that they are in (i.e. their poverty), and consequently, blames them for their local environmental problems. It assumes that poor people's complex relationship with their environment is determined by economic desire alone. It also assumes that all poor communities behave alike; it generalises and ignores the vast diversity that exists between and within developing communities.

By focusing exclusively on what people are deprived of instead of what they have (Ulluwishewa, 1993), such development research ignores unique worldviews and value systems that are in place in many indigenous communities which, for example, restrict excessive environmental exploitation by way of social taboos and religious rituals. Although these value systems may not be able to prevent unsustainable behaviour altogether, as some studies suggest (Kalland, 2000), they may help discourage lifestyles that are driven by economic needs solely.

It is obvious that some degree of tension is always expected between human livelihood needs, social change and natural environment (Marx, 1954, as cited in Jacobs, 2008). The important point made is that poor and/or indigenous people do not earn livelihoods while remaining free from their environmental, social and cultural influences. Recognising the interdependence of the economic, environmental and social aspects of sustainable indigenous development, we briefly review traditional livelihood systems.

There is no doubt that economy is the most influential player in development and sustainable development policy and planning (Mazzucato, 1996). The 'concept of sustainability is embodied in indigenous and traditional livelihood systems' (Posey \& Dutchfield, 1996, as cited in Posey, 2000, p. 35). Understanding traditional livelihood know-how is important to appreciate how indigenous economies sustainably contribute to rural development. Consider, for example, the economic value attached to traditional material goods in communities that are not fully integrated with the local market. Local 
production and consumption behaviour is influenced by this different value system (Mazzucato, 1996), which in turn affects traditional patterns of resource production, usage and management.

In many developing and traditional communities, the crafts industry serves as an important source of livelihood for the poor masses. Crafts and handicrafts are artefacts that are a 'products of human behaviour and intent' which evolve and gain new meaning within changing cultural context (Wolff \& Wahab, 1995, para 2). Like indigenous lifestyle, traditional craft production is greatly affected by the introduction of new technologies, material and goods, where, it is estimated, crafts may change significantly within a single generation (ibid). In many communities, women hold extensive traditional knowledge about their local crafts industry, which can be gauged from the detailed taxonomic systems on crafts (ibid). In order to effectively understand how women's traditional know-how impacts this industry, it is important to study how women, their roles and traditional knowledge are affected by social, economic and environmental change.

\section{Traditional Knowledge, Women Roles \& Change}

Women's traditional knowledge is a socio-cultural construct that passes on from one generation to the next (Briggs et al., 2007; Fernández, 1994; Mishra, 1994). The knowledge and know-how is accessible to those members of the community who are primarily responsible for resource management and production duties (Fernández, 1994). Since the knowledge becomes socially specialised, the primary holders of it usually experiment and innovate (Fernández, 1994). Hence, traditional knowledge continuously evolves with the changing roles of those using it.

In order to understand how it evolves, it is important first to understand how knowledge is accessed and disemminated. Knowledge is usually orally passed on from one generation to the next (Bicker \& Sillitoe, 2004; Boven \& Morohashi, 2002; Ellen \& Harris, 2000; Appleton \& Hill, 1994; Kater, 1993). How it is accessed and passed on depends on time availability, education levels, mobility, access to media resources at the individual level, all of which are socially, economically and politically bound in the local context (Appleton \& Hill, 1994). Traditional knolwedge production is affected by the changing socioeconomic conditions and trends of a community (Briggs et al., 2007), which is why it 
is important to pay close attention to the sociocultural context within which such knowledge systesms exist (Briggs, 2005). A particular knowledge loses its relevance and is discarded when it stops being useful to the rural household, and becomes replaced by knowledge more useful and relevant to the changing trends (Briggs et al., 2007).

There is usually a sharp division of roles and responsibilities between men and women in traditional societies, which gives way to the gendered nature of indigenous knowledge (Appleton \& Hill, 1994). The extent to which knowledge is gender-specific within a community depends not only on the degree to which roles and responsibilities are gender-specified, but also to the amount of flexibility within these roles to carry out other responsibilities (Fernández, 1994). Moreover, the 'hierarchies of access, use and control' of knowledge and know-how depend on existing gender relationships within a community, which result in different perceptions, priorities for 'innovation and technology' by men and women (Appleton, 1993 as cited in Fernández, 1994, para 5).

Mishra's (1994) case study in India confirms that women's environmental knowledge is intricately linked with local economy and society. The study reveals that, as a result of depleting forest resources in rural Orissa, women were forced to travel farther and deeper into the forests to access scarce resources. This inconsequently resulted in renegotiation of gender roles, where women took over responsibilities previously ascribed to men. Mishra concludes that competetion for scarce resources gives way to community collapse, as a consequence of the 'individualism [that] creeps in, leading to the overall erosion of cultural identity of the community' (Mishra, 1994, para 9).

\section{Challenges}

There are a number of issues concerning the successful integration of indigenous knowledge research in development, which need to be addressed before discussing important issues critical to this research.

To begin with, there are a number of reasons behind why traditional knowledge has often been undervalued, misjudged and misunderstood for its potential role in development. Critics charge that part of the blame lies on the shoulders of 'Western scientific rationality' for its 'unreflexive' and biased analysis of traditional knowledge in development (Marsden, 1990, as cited in Pottier, 2003, p.3). Others recognise the 
demands that development work puts on traditional knowledge in order for it to be effectively integrated into international programmes: cost-effective, time-efficient, relevant, and easily understandable to non-experts (Bicker \& Sillitoe, 2004; Sillitoe, 1998a).

Another problem with traditional knowledge is that it is deeply rooted in the cultural context (Sillitoe, 1998a). The place and cultural-specificity of traditional knowledge makes it difficult to translate it to outsiders in a language which is comprehensible, accessible, and relevant to them ( (Sillitoe, 1998a). Communicating traditional knowledge intelligibly to scientists becomes all the more difficult due to the local rituals, rites, superstitions, myths and cultural idioms (van der Ploeg, 1989, as cited in Sillitoe, 1998a), which make traditional knowledge appear beyond the objective, deductive realm of science. In addition, taking traditional knowledge out of its cultural context dislocates it (Ellen \& Harris, 2000). Because of its local context and local results, it cannot be effectively applied to global sustainable development endeavours.

It is agreed that traditional knowledge may not be the most financially feasible alternative development model (Briggs, 2008; Sillitoe, 1998a). Farmers, if given a choice, may prefer better financially rewarding solutions that offer greatest economic returns in the shortest time (Sillitoe, 1998a). It is also true that many farmers who rely on their traditional know-how continue to live in poverty (Briggs, 2005). A Tanzanian farmer in Briggs's study raises this point by questioning why his farm continues to remain poor 'if indigenous knowledge is so good[?]' (ibid, p. 99). Clearly, farmers may have different priorities from those of indigenous knowledge advocates and development workers.

There is also the problem of the low value that is attached to products of indigenous know-how within the development community:

"IIndigenous crafts and products] are neglected because of the old stereotype according to which handicrafts and local traditions...are considered to be of low quality or low economic value... As a result, [these have] been neglected in both cultural programmes and economic development strategies." 
Traditional knowledge research, while not economically the most rewarding, offers innovative insights to sustainable resource usage, management and conservation.

Not surprisingly, sceptics of traditional knowledge studies charge that traditional knowledge systems are a barrier to development. Others claim the opposite, that resistance to development and the reclamation of traditional values and tradition in many developing communities is in opposition to the negative impacts that aggressive development goals have had on developing societies (McGregor, 2004). Such contradictory assertions are short-sighted in that they overlook the fact that traditional knowledge systems are often in a dynamic relationship with modernity, change and development. They change and adapt to socioeconomic trends, sometimes offering unique examples of coexistence of modernity and tradition in a community. This is especially true in the context of globalisation, which has at times facilitated convenient co-habituation of the local and the global.

\section{Gaps in the Existing Research}

Extensive research work has been carried out in the Asia-Pacific (see Kwa, 2005; Nakashima \& Roue, 2002; Dove, 2000; Osseweijer, 2000; Sillitoe, 1996) and South America (Costa-Neto, 2000; Nygren, 1999; Escobar, 1998), which relates to indigenous use of natural resources, agriculture, fisheries, watershed management, forestry, and the like. Similar work has been carried out in the African region as well (Briggs et al., 2007, 2003; Richards, 1985).

In the neighbouring South Asian region, similar research studies have been carried out particularly in India, Bangladesh and Nepal (Sillitoe, Barr, \& Alam, 2004; Mishra, 1994; Rajasekaran \& Warren, 1994; Rajasekaran, Martin, \& Warren, 1993).

Unfortunately, there are very few good studies on Pakistan's traditional knowledge systems that cover the realms of resource management, biodiversity conservation, craftmaking, or sustainability. There has been some research to document ethno-botanical knowledge in Pakistan (Sardar \& Khan, 2009; Qureshi, Khan, \& Ghufran, 2007; Jabbar, Raza, Iqbal, \& Khan, 2006; Ibrar, 2003; Shinwari \& Khan, 2000), but no known attempt has been made to analyse it with reference to gender dynamics, or in context of sustainability and development. There is limited donor-funded research on traditional 
knowledge systems, and is generally confined to the Northern Areas of Pakistan, particularly the Kailash Valley (see Parkes, 2000).

One of the few significant studies in the Punjab region is that of Michael Dove's, which was carried out in the 1980s in the rain-fed areas of Punjab and NWFP (now Khyber Pakhtunkhwa, or KPK), where he surveyed farmers about their traditional knowledge in agroforestry (Dove 2003, 1994, 1992). In his work, he explains how the local farmers traditionally conceptualised trees in terms of their shades, or 'sayah', which they used as a criterion for deciding which particular tree to plant on a farm. It was found that the local farmers categorised trees, based on the tree-shade's density, temperature, taste and size (which in itself had length, width, height, and duration) (Dove, 2003). Dove believes that such a complex evaluation system inherent in the farmers' traditional knowledge manifested the farmers' deep concern for agricultural sustainability. Ironically, the research was initially carried out upon complaint of the Pakistani government officials who felt that the farmers had no knowledge about or concern for on-farm tree cultivation. The research draws attention to the misunderstandings that often emerge as a result of different perceptions, and the oft-ignored linkage between environment, knowledge and politics.

Although Dove's study is a positive step forward in that it uncovers issues previously unexplored in Pakistan, more research studies are needed to uncover and amend the many misgivings between development policy and practice. Additionally, more extensive studies are needed to find out how traditional knowledges have evolved over time in the Pakistani context. Limited literature is available on how gender differently affects and negotiates traditional knowledge at the household level. No relevant piece of scholarly research could be found on how women's traditional knowledge effectively contributes to rural sustainability and generates sustainable livelihoods.

\section{Conclusions}

Most of the literature available on indigenous knowledge is confined to traditional research areas such as biodiversity conservation, resource management and farming practices. Research has largely been silent on how women's traditional knowledge systems help contribute to sustainable development. On the national front, there has 
been marginal local or international scholarly interest in exploring indigenous sustainability and women's knowledge systems in Pakistan. Lack of similar academic or governmental research in the Sialkot region, and the need for greater recognition of indigenous women's contribution to rural sustainability, makes this study all the more significant and a pioneer in the area studied. The following chapter informs the reader about the local context in which the field research is set. 


\section{CHAPTER5: Pakistan - Setting the Context}

The chapter briefly introduces the country, Pakistan, as a developing nation. Pakistan's national policies on (or related to) environment, indigenous knowledge and women are reviewed. The later part of the chapter reviews Pakistan's natural resource, agriculture and handicrafts sector policies. This section concludes by introducing the local region where the field research takes place.

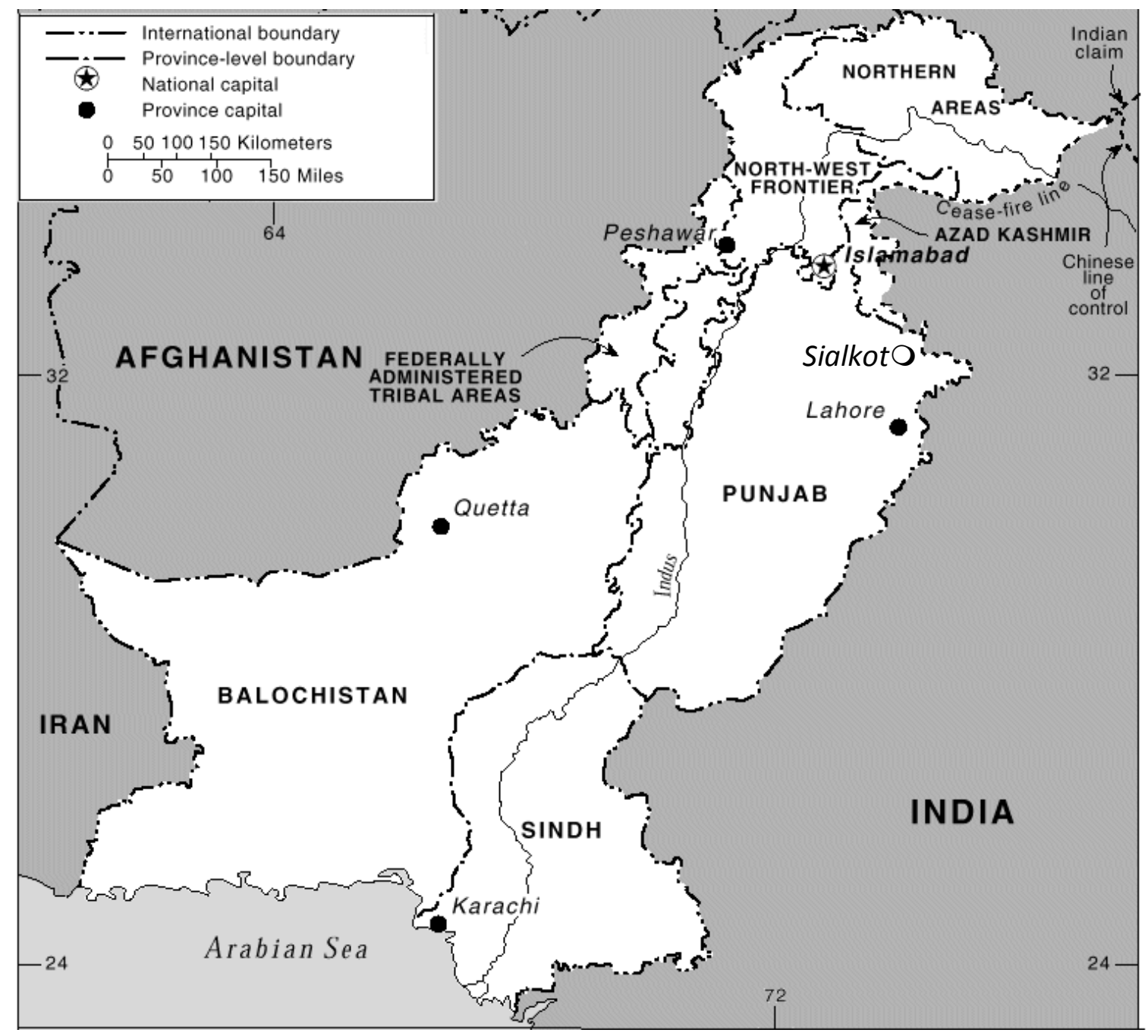

Figure 5: Map of Pakistan

(Source: adapted from Pike, n.d.) 


\section{Pakistan \& the 'Development Problem'}

The Islamic Republic of Pakistan is the seventh largest country in the world. With a population of almost 167 million people, it is the second largest Muslim country after Indonesia (World Bank, 2008). The population is predominantly Muslim, with a strong Islamic influence felt in the socio-economic, cultural and political spheres. Its borders touch China, India, Iran, Afghanistan and the Indian Ocean. Pakistan is home to two marvellous ancient civilisations - the Indus Valley and the recently-discovered Mehr Garrh civilisations - each more than 5,000 years old.

Pakistan's constitutional system is inspired from its former colonial power, the United Kingdom. The figurative Head of the State in Pakistan's parliamentary system is the President, while the actual power lies with the Prime Minister.

Pakistan transitioned to democracy in 2008, after an eight year dictatorship under the former military chief, Pervez Musharraf. The current government, headed by a coalition of political parties led by the Pakistan People's Party (PPP), faces a series of issues on the political, economic and social fronts, the most trying of which include: terrorism, sectarian violence, financial instability, governmental inefficiency, corruption, rising population and widespread poverty and economic disparity.

Pakistan's GDP stands at US\$168.2 billion, while its per capita income is about US\$1000 with a wide urban and rural poverty disparity (United States Department of Agriculture [USDA], 2009; WB, 2008). Pakistan is a highly aid-dependent country, the official development assistance and aid figures at US\$2.2billion in 2007 (WB, 2008).

In terms of development indicators, Pakistan has a low ranking especially on the Human Development Index (HDI). Its HDI stands at 0.572, making it rank $141^{\text {st }}$ out of 182 countries (United Nations Development Programme [UNDP], 2009). Additionally, out of the 155 countries that have a HDI and Gender Development Index (GDI) reading, Pakistan ranks the third worst in its GDI to HDI ratio comparison (UNDP, 2009). Literacy rate is low; only half the population can read and write, with a large gender disparity in education. This is not surprising, considering that Pakistan has one of the lowest GDP expenditures in health and education (WB, 2008). Almost one-fourth of Pakistanis are poor, most of them living in rural areas. Despite attempts by the government and 
international regulatory bodies, the gap between the rich and the poor seems to be widening, which has resulted in increased social inequalities (EC-Pakistan, 2007). Some analysts predict that the situation may not improve unless agricultural and landownership reforms are implemented (ibid). In spite of its weaknesses, Pakistan has a 'potential to develop into a prosperous, moderate and democratic state' (ibid, p. 21).

\section{Environmental Policy \& Legislation}

Sustainability is an important issue in developing countries like Pakistan where, according to World Bank estimates, the environmental degradation costs at least $6 \%$ of the national GDP (costing US\$4.4 billion per annum) (WB, 2008). It is estimated that by 2012, Pakistan will join a list of 80 other countries that are water scarce with a water level below 1000 cusecs per person (Government of Pakistan, Ministry of Environment [MoE], n.d.), which can seriously affect Pakistan's most important sector, agriculture (WB, 2008). Speculators fear that rising poverty and increasing environmental deterioration may further worsen the lot of the poor who are already dependent on the environment as their source of livelihood.

Pakistan's commitment to solve its serious environmental problems - such as pollution, deforestation, desalinisation of agricultural lands, lack of a proper sanitation systems, and depletion of natural resources - is evident from the many national and international environmental agreements that it has ratified on environmental protection and sustainable development, including those endorsed at the UNCED and the WSSD (UNEP, 2008). In addition, Pakistan has agreed to improve progress in development indicators, the most important of them being the MDGs.

According to the UNEP, Pakistan has made 'significant progress' in 'developing the environmental policy and regulatory framework, development of environmental institutions and raising awareness' (2008, p.1). In 1992, National Conservation Strategy (NCS) became Pakistan's first environmental policy to emerge, after the ratification of Agenda 21 of the Earth Summit, Rio de Janeiro. The NCS became the 'mother' policy framework for other environmental policies that were to follow. According to a MidTerm Review of the NCS completed in 2000, the NCS has helped in raising awareness about environmental issues (Hanson, Bass, Bouzaher, \& Samdani, 2000), while at the 
same time has helped establish environmental research and advocacy institutions (like the well-reputed Sustainable Development Policy Institute, SDPI) (EC-Pakistan, 2007). The Ministry of Environment believes that this has helped in strengthening the role of environmental institutions, civil society and media in environmental advocacy and protection (MoE, 2005).

The National Environmental Policy (NEP) of 2005 gives guidelines to the federal and local governments with an aim to 'protect, conserve and restore Pakistan's environment in order to improve the quality of life of the citizens through sustainable development' (NEP, 2005, p. 9). A UNDP-supported National Environment Action Plan (NEAP), now in its second phase, has been successful so far in helping to develop a number of policies and strategies, like NEP, Sanitation Policy, Clean Development Mechanism Strategy, Draft National Forest Policy and Energy Conservation Policy, among others.

Although there is a lack of policy coherence at the national level, sustainable development initiatives such as the National Sustainable Development Strategy of Pakistan (NSDS) offer a platform for the integration of not only environmental but also economic and social national objectives (MoE, n.d.). An example is the Public Sector Development Programme which targets water \& energy shortage, education, and agriculture sector for generating income and alleviating poverty (UNDP, 2009).

Even though Pakistan's environmental policy rhetoric is relatively well developed, it is yet to be converted into action (EC-Pakistan, 2007). What is more, none of the strategies explicitly recognise the role and contribution of traditional knowledge systems in sustainable development. There has been no known government-funded research on the linkage between traditional knowledge systems and sustainability (even though this has been recognised in international agreements such as the Agenda 21, which Pakistan has also ratified).

Pakistan's non-governmental sector is quite active in advocacy for environmental sustainability. The SDPI has collaborated with a number of other NGOs working for sustainable development, but has few, if any, partnerships with those working for indigenous knowledge systems. Only a limited number of NGOs are working to recognise and revive traditional art and know-how for sustainable development in the rural areas, 
like the Lok Sanjh Foundation. Another NGO, the Sungi Development Foundation has been actively working for the revival of handicrafts industry in order to alleviate poverty among women. It advocates for greater recognition of home-based women artisans. Unfortunately, there are few NGOs, if at all, that work towards similar objectives in Punjab.

\section{Agriculture \& Natural Resources}

The agriculture sector, comprising of crops, livestock, fisheries and forestry subcomponents, is the largest sector of Pakistan, contributing about $24 \%$ of the GDP to the national economy (USDA, 2009; Government of Pakistan, Federal Bureau of Statistics [FBS], n.d.), and providing livelihoods to more than 40\% Pakistanis (WB, 2008). It is also the source of largest foreign exchange earnings with the main cash crops being wheat, cotton, rice, sugarcane and maize (FBS, n.d.). Agriculture sector also provides raw materials for other industries (USDA, 2009), such as the cottage and textile industry. Pakistan is the fourth largest producer of cotton, most of which is consumed domestically (ibid). Pakistan is also the fifth largest milk-producing country in the world, highlighting the importance of the livestock and dairy sector in Pakistan's economy (Food and Agriculture Organisation [FAO], 2006). In fact, almost half of the income in agriculture is generated from the livestock sector (USDA, 2009).

Almost $67 \%$ of Pakistan's population resides in rural areas where the average farm size has decreased from 13.1acres in the early 1970s, to 7.7acres in 2000 (USDA, 2009). After Pakistan's independence in 1947, there were limited land reforms which led to less than half of the arable land being occupied by a majority of small-land holders, while most of the land went to a minority of large land holders (ibid). The land arrangements have not changed since. In fact, there exist a large number of landless farmers, who labour on others' lands for securing food and livelihoods. Given this, it is easy to see why Pakistan's agricultural policy, which is largely influenced by a powerful lobby, benefits the rich instead of the poor (USDA, 2009).

\section{Women}

In Pakistan, more than $70 \%$ of the women work in the informal sector, out of which $65 \%$ are in home-based work (compared to only $4 \%$ of men) (HomeNet Pakistan, n.d.). It is 
speculated that there are 12 million home-based women workers in Pakistan, but there is little official data to verify the figures (Review of National Policy for Home-Based Workers, 2008). Some of the major sectors that Pakistani women informally contribute to include: cottage and textile, agriculture, livestock, fisheries, forestry, leather, handicrafts, paperwork, food \& fruit preservation \& packaging (United Nations Development Fund for Women [UNIFEM], 2000).

Pakistan has recently come up with a draft National Policy on Home Based Workers, after a successful UNIFEM regional conference on Women, Work and Poverty in New Delhi, India. Advocates of the newly drafted policy suggest that absence of a prior legislation targeting home-based women workers reflects the lack of recognition that is granted to women's contribution in the economy (RNPHBW, 2008).

At the provincial level, the cottage and agriculture sector are important industries that rural Punjabi women informally contribute to. Ironically, these very two sectors are marred by low technological development, 'low productivity, limited investment, and inefficient resource use' (USDA, 2009, p. 2; Azid, Aslam, \& Chaudhary, 2001). The skills that home-based women workers employ in these sectors are usually an extension of their household skills (Azid, Aslam, \& Chaudhary, 2001).

\section{The Local Context}

The field research took place in a north-eastern district of Punjab, Sialkot. The region, located in the foothills of Himalayas, is well known for its rice fields, pharmaceutical instruments and world-renowned sports goods.

Four adjacent villages in rural Sialkot were selected for the study, which fall under the jurisdiction of near-by towns Pasrur and Chawinda. The focal point of field research was a medium-sized village, Madhopur Vaince, with a population of less than 1,000 inhabitants. It is adjoined by three neighbouring villages about a kilometre apart each: Jajopur, Gulokot and Kadiyanwali. Madhopur, lying in the centre of these villages, also served as the middle ground where the transition from the more urbanised (Jajopur) to the relatively less-developed (Gulokot and Kadiyanwali) took place. 
Over the years, the region has moved up on the socio-economic ladder. Agriculture remains as the main source of income generation, even though the region has seen a shift from previous subsistence practices. In recent times, the infrastructure has improved with well-connected roads leading to urban centres (especially in Jajopur). The villages have expanded in population and size, and there has been a shift from traditional mud-houses to more contemporary brick houses - an indicator of economic prosperity in the region. Currently, water and natural gas pipelines are being installed and it is anticipated that all four villages will have access to clean government-supplied water and natural gas in about 1-2 years. The region has seen a rapid loss of tree cover and vegetation which has contributed to serious soil erosion and decreased soil fertility. Lack of proper sanitation systems and unsustainable waste disposal practices put villagers at risk. Although a number of schools have been established in the vicinity and girls are acquiring formal education, elderly women are largely illiterate. Most of the women engage in home-based work for earning meagre livelihoods.

\section{Conclusions}

Over the years, Pakistan's development and environmental problems seem to have increased. Despite having made important national and international commitments to improve its state of environment, Pakistan has been slow in converting rhetoric into practice.

To an extent, what occurs at the local level is a replica of what goes on in the international arena. Traditional knowledge systems, and particularly those of women, are hardly recognised in national sustainable development rhetoric. A recently drafted policy on women-based workers is indicative of the little recognition granted to women for their informal contributions to the rural and national economy, especially in the handicrafts sector, cottage and textile industry, and agriculture and livestock sector. There is little or no literature available on the women's unique traditional epistemologies in rural Pakistan and their complex relationship with the natural environment. Considering this, the following chapter will explore how the rural women of Sialkot practice sustainability in their daily lives, and contribute to sustainable development, by utilising their traditional know-how in handicrafts, natural resource management and agriculture. 


\section{CHAPTER 6: Women's Traditional Wisdom \& Sustainability in Rural Sialkot, Pakistan}

The following section highlights the various ways in which women practice sustainability at the household level using traditional means, methods and knowledge. It is exemplified through women's ordinary lives: the roles they play, the responsibilities they fulfil, and the needs they try to meet. The chapter presents information about the interviewed women's traditional way of living, and how it has changed over time with their changing roles and responsibilities.

This section does not document all the data that was gathered during the field research. It tries to present important themes and aspects that emerged during the course of the interviews. It is hoped that these findings will help the audience better understand the various ways in which rural Sialkoti women help meet sustainable development objectives in their own traditional ways.

\section{Introduction}

The four villages that are under study are small-to-medium-sized, with an average population of about 500 - 1,000 residents per village. Jajopur is the largest. For generations, agriculture has been the primary source of food and income. The local villagers have lived on subsistence-farming, although the economic conditions have improved in recent years, especially after the 'Green revolution'. By profession, almost all the male members of these villages are part-time or full-time farmers. However, diversity in skills is present, as there are a number of carpenters, ironsmiths and artisans among the villagers. The social setup is largely patriarchal, where a woman joins her husband's (joint) family after marriage. The population is predominantly Muslim. Out of all the interviews conducted, only one was a Christian.

The women I talked to displayed traditional know-how in diverse fields, ranging from agriculture, livestock-husbandry and ethnobotany, to handicrafts, midwifery and traditional medicine. Women gained knowledge from their parents' home-place before marriage, and after marriage from their husbands' home-village. As a result, they passed 
on diverse knowledge to their children, not only about the place where their children lived, but also about the places where the women had spent their childhoods.

The rural community was relatively conservative. It was considered socially appropriate that men go out and earn a living while women engage themselves in household chores. In spite of this socio-cultural setback, women had made substantial contributions towards the economic betterment of their communities, albeit informally.

Few women interviewed had any formal education. Women traditionally fulfilled multiple roles, as house-wives, farmers, co-breadwinners, artisans, religious tutors, resource-fetchers, and the like. However, under changing socioeconomic contexts, women's roles, responsibilities and their activities appeared to have changed.

Compared to contemporary standards, women had spent a relatively independent, albeit difficult, and socially less-segregated life before. Women reported a decline in their social mobility over the years. However, they also reported an increase in relative prosperity and an improvement in access to basic facilities. Consider a remark by a 50 year-old man, Ashraf:

"[A generation ago], women and men used to work side by side without any segregation... Nowadays, even though women enjoy more independence, there is mistrust [in the community that discourages women from stepping outside their homes or from mingling freely with other men]."

Chachi Nusrat, of Madhopur Vaince, believed that women's decreased mobility was as a result of independent access to the media, interest in which 'has restricted women to their homes now'.

Communal ties and social networks were very important for women because they formed the basis of meeting personal needs. Communication was direct, live, and faceto-face, which helped in knowledge acquisition, exchange and dissemination.

Traditional knowledge appeared to pass on orally, through word of mouth, or visually through observation and practical demonstration, most commonly via family, friends or neighbours. Within families, knowledge relevant to one's family occupation was passed down. 


\section{HANDCRAFTING}

The term 'handicrafts' is loosely used here to refer to a wide range of handmade products domestically produced using arts such as spinning, weaving, knitting, netting, crochet, quilting, needlework (including embroidery, stitchery and sewing), and the like. The following section describes some of most common arts that the village women had engaged in, which are: spinning, weaving, and needlework.

\section{Overview}

Women play an important and dominant role in the informal handicraft industry in the area studied. They have played roles as weavers, spinners, fabric- and basket-makers, embroiderers, seamstresses, and much more. Traditional handicraft-making was reportedly the most common leisure activity. Out of the 28 women interviewed, at least 23 mentioned that they knew the art of weaving, spinning, and needlework. Women had learned it informally through their social network of relatives, neighbours and friends.

The handicraft-sector has played an important role in women's lives in various ways.

Socio-culturally, knowledge about handicraft-making was considered vital for all women. Girls were expected to learn these skills in order to secure their future (and have better marriage prospects). Additionally, handicrafts were given as dowry or 'gifts' to daughters upon marriage, symbolising the transfer of knowledge and skills from one generation (mother) to the next (bride).

Handicrafts have been used as a 'social resource' to help build and strengthen social ties. In the form of gifts, handicrafts served to express respect, affection and gratitude towards relatives and friends. This was particularly true of handmade products, which were seen to be of higher social value, because of the personal labour, time, and skill that went into making them. Handicrafts that consumed more labour and time to produce were gifted to closest relatives or friends.

Economically, the handicrafts industry was important to the local women, because it served as a major source of livelihood and income generation. All the resources used in preparing traditional handicrafts were natural, and local to the community, hence, relatively free of cost. This was a major advantage to the villagers, because they could 
own a basic necessity without having to invest hard cash, which was difficult to find anyway, especially a few decades ago.

Knowledge about handicrafts was disseminated either through family units, or through social network. Within the family system, know-how about weaving, crafting and needlework was generally passed on from the mother. Socially, friends or neighbours were the most reliable sources of informal knowledge. There appeared to be a degree of formality between the older and younger generations. Few women said they had asked their mothers how to make handicrafts (less than 10 out of of 28). Most said they had learned by observation, by 'watching' their mothers do the same, or by being instructed or taught how to make something.

\section{Spinning\& the Spinning Wheel}

Spinning in textile-making is a process whereby two or more fibres are twisted together to produce a yarn. In the villages surveyed, spinning usually involved either cotton or flax fibres using a traditional 'spinning wheel', locally known as 'charkha'. It was a traditional machine, made from local wood, which was operated by a single person - almost always a woman.

Historically, the charkha has played an important role during the Indo-Pak independence movement of 1940s, by becoming a symbol of protestation against imported goods of the then-colonising power. The charkha represented the preference of the local, indigenous textile and handicrafts over non-local goods. It eventually became a symbol of rebellion against British colonisation of India-Pakistan.

In the community under study, women used the charkha for spinning stem-fibre of a native flax plant (Linum usitatissimum). Thin twines or cords formed, as a result, were later used in making flax-rope for traditional beds and nets, among others.

The preparation of flax fibre, however, was no easy task in itself. Young, fresh plant stalks were cut and submerged in a nearby water body (usually a pond) for about 25 to 30 days. This was to separate the fibre from the plant stem. In scientific terms, the process is called retting, which relied on the 'action of bacteria and moisture on plants to dissolve 
or rot away much of the cellular tissues and gummy substances surrounding the bastfibre bundles [of plant stem], thus facilitating separation of the fibre from the stem' (Encyclopædia Britannica, 2009, para 1). Once the stalks dried after this natural water retting, the fibre was separated, and later spun in a charkha to make into a rope.

However, the charkha was more popularly used for spinning cotton and making cotton yarns.

Women collected cotton from their private farms or from the local market through a semi-barter system. In the case of barter, women would borrow cotton, for example a kilo, from a local merchant. Agreement would be made to return half of the cotton to the seller in the form of completed, spun bundle, while the other half would be kept by the women for their personal use. Women would use the 'earned' cotton for domestic use or sell it to others.

Charkha-spinning was usually carried out socially in small groups of friends or relatives, often during the night while the men cultivated the crops. In this way, a mundane chore (and a means of income generation) would become an opportunity for social networking, counselling, and knowledge exchange.

Consider, for example, the case of Madhopur Vaince's 80-year-old Sharifaan. During a group interview, Chachi Arshad, her junior, recalled how her neighbour Sharifaan's mother-in-law used to treat Sharifaan at home. [It came up while women were being interviewed about the charkha, its uses and how women used to work on it.] Sharifaan, who was sitting beside Chachi Arshad during this time, then recollected her story. All the women sitting in group nodded; presumably, they knew the story. It clearly indicated that, while securing their livelihoods, these women also shared their everyday grievances with fellow women.

This draws attention to the complicated role that socially-carried-out chores played in informally counselling the distressed. It clearly shows that such routine chores not only served to secure livelihoods and basic needs, but also helped to fulfil the women's social needs. 
The charkha, however, slowly fell out of use over the years, disappearing completely about a decade or so ago. Out of the many women I interviewed, only one mentioned that she had one at home. Asked why it was no longer used, a woman of Kadiyanwali, replied that it was no longer of use because "cotton is no longer available". Similarly, a 72-year-old Chachi Allahrakhi commented that, although

"I had learned [the art] from my mother, I did not pass it on to my daughter or daughter-in-law, because now cotton is nowhere to be found."

Others felt that it had been made redundant by the availability and affordability of cheaper fabrics and yarns in the market. Women also added that buying ready-made fabric from the market saved their time, which they could dedicate to the family. A few said it was not used because it had fallen out of trend or fashion.

Without doubt, knowledge about charkha appears to have been retained within the older generation only. No women that I talked to mentioned having passed on the knowledge about the charkha to any of the younger generations. Clearly, there appears to be a link between knowledge dissemination and its usability and relevance for the newer generations.

\section{Weaving}

Weaving is the art of fabric-making where two sets of yarns are interlaced in such a way that they cross each other, usually at right angles. It includes weaving of textile, apparel, baskets, traditional beds, carpets, and the like.

Almost all the women interviewed had practical knowledge about weaving. Women reported that, using this art, they made products for domestic consumption or for income generation. The most common products weaved were textiles, which included cloth and apparel, linens and blankets. However, hardly any of the ladies interviewed weaved textile nowadays. Knowledge about textile-weaving seemed to have been consciously retained within the older generation (especially those aged 50 and above). Like spinning, weaving appeared to have been more popular up till the late 80 s. 
Nowadays, weaving is confined to carpet- and charpoy-weaving only within the area studied.

Women reported that they used to weave textiles using home-spun yarns. Like other arts, women usually weaved in groups, in the company of friends or relatives. Most of them had learned the art from friends, while others had learned it by observing their mothers or close relatives.

Beside textile, women displayed their aptness in weaving traditional 'beds', or cot-like 'charpoy'. These were made by closely weaving a thick, tight and durable mesh of flax rope on a rectangular wooden frame.

Some women, like Chachi Bushra of Madhopur Vaince, made charpoys for a living to the day, (although less frequently now). She revealed that it usually took her one day to completely weave a charpoy; this was usually done after she had cooked, cleaned and looked after the children. Having thus worked from home allowed her to fulfil her responsibilities, and at the same time, earn a living.

Others, like Mrs. Munir of Madhopur Vaince, said that they weaved charpoys for household use only:

"All [such handmade products] are made for use in the household... Who sells them in the villages [after working so hard]? It is sufficient [for us] if it helps meet the needs of the household [members]."

Besides being an essential household item, the charpoy seemed to have a socio-cultural significance. Families 'gifted' special hand-woven charpoys to their daughter on their wedding.

There were environmental benefits too. The material resources that went into making a charpoy were natural and organic. Flax-fibre is said to be a durable natural fibre, which is stronger, and more resistant to harsh environmental fluctuations compared to cotton and jute (Pandey, 2009). It is biodegradable, unlike synthetically-prepared nylon yarns, which are now used in making charpoys. Additionally, flax plant has a high food consumption value as well. Its seeds (linseed) are a valuable source of food for both humans and livestock. There has been a lot of interest in the health properties of linseed 
oil because of its highly polyunsaturated fatty acids (Oplinger, Oelke, Doll, Bundy, \& Schulerl, 1997). Linseed (or its oil) also makes an excellent feed for the cattle because of its high crude protein (almost 35\%) (Oplinger et al., 1997). Understandably, villagers may not have been aware of the chemical and scientific properties of the plant, but they knew well the domestic, agricultural and industrial applications of the plant from the experience and passed-on knowledge of their ancestors, as indicative in their traditional practices.

Although charpoy-weaving is still very common today, the choice of raw materials used has been changed. Flax rope has been replaced with nylon and other synthetic yarns. The wooden charpoy frame has been replaced by a lighter metal frame, usually made of welded iron. This has had at least some impact on the rural economy which will be discussed in more detail later.

Interestingly, women also used 'recycled' fabric in charpoy-making. I came across the first instance of this at Mrs. Munir's house where she was working on a 'recycled charpoy' when I went to interview her. She briefly explained what she was doing:

"I have hand-made this rope [out of recycled yarn] to weave a charpoy. It is made it out of 'pasham' by unknotting [old, unwanted sweaters]."

When asked to explain how she did it, she replied:

"Different coloured [sweaters] were unknotted, their separated yarns collected and made into different coloured ropes which are now being used in weaving this charpoy. [All the rope used] is from 4-5 old [sweaters]."

[Other examples of recycling include the sale of used but unwanted household items (such as shoes, apparel, crockery, leftover bread, paper, plastic, metals, and glass items) which are collected by the local paupers in exchange for food edibles and/or snacks.]

When asked where Mrs. Munir had learned charpoy-weaving from, she explained:

"I did not know how to weave a charpoy [when I came here]. [A neighbour] taught me how to make these. I got all my charpoys made from [another neighbour], who used to make these for me on a wage." 
None of the women mentioned having taught their daughters how to weave a charpoy. It appears that passing on contemporary knowledge that addressed present needs was of higher priority. For example, Aroosa, the 17-year-old daughter of Mrs. Munir, knew how to "cook, clean [the house], and do the laundry, [but] [did] not know how to weave a charpoy," according to Mrs. Munir.

Interestingly, women believed that the quality of homemade crafts was better compared to market products. Mrs. Munir, while explaining how she weaved a charpoy out of recycled material, commented:

"Hand-made products are better compared to market products because they do not have synthetic material mixed in them. [Market fabric] has [comparatively] more synthetic yarn in it; it also has more spins in it, which makes it difficult to weave [a charpoy]... [I weave charpoy] primarily for a saving, but then, it is preferable [also] because it is better [in quality, compared to market products] as it is handmade... although it does take time to make it."

One family that I visited in Gullokot once used to stitch footballs and weave carpets for a living. Men of the family used to weave carpets (presumably part-time), while women used to recycle left-over wool material from carpets (called 'waddh') for household use. This was done by collecting and spinning the waddh in the charkha for it to be spun into a rope. This rope was used in weaving charpoys for home-use. In this way, an unused, leftover resource was recycled to make into something productive and useful.

\section{Needlework}

Most of the women knew the art of stitching, sewing, embroidery, crochet, knitting, and netting, among others. Like other handicraft work, knowledge about it was usually passed on from a female elder to a younger female, and in other cases, learned from female friends. However, unlike other arts, it seemed to be socially relevant even today, as it was still practised by the younger generation.

Women were savvy in the art of embroidery. Most women said they had learned it in the company of friends. One, 60-year-old Sughran of Kadiyanwali, said that she had learned it from her primary school. Generally, embroidery was pursued as a hobby or leisure activity, and was not limited to bed, linen, cushions and clothing only. 
Women also knitted apparels for household use and/or for earning livelihoods. These included cotton 'belts'. Some women, like Phuphi Rehmat of Madhopur Vaince, who had struggled financially in her early years, said that she used to knit these for a living. Although the profits were marginal, they helped contribute to the household income in some ways.

Interestingly, women aged 60 and above also talked about their knowledge of netting (net-making), which they employed during the Indo-Pak wars of 1965 and 1971 by making nets for the defence industry. After the wars subsided, they diverted their use of this art towards the sports industry by making nets for tennis, badminton and football.

Stitching was also an important craft. A 75-year-old Khatijaan and her three female descendents stitched footballs at home for a living. An agent supplied them the raw materials while the women worked from home. They were paid meagre wages based on the quality of needlework.

Women were also apt in sewing clothes and apparel. They stitched clothes for the self and family to save hard-earned incomes (as the cost of raw materials was relatively low compared to ready-made garments).

However, there were others who no longer used this knowledge. Mrs. Munir, a mother of five, said that she knew the art but her responsibilities kept her from practicing it now:

"I know the art of embroidery but I do not embroider any longer, because I do not have time for it now... I have to look after the [household and] our livestock as well."

\section{NATURAL RESOURCE USAGE AND AGRICULTURE}

Women have helped to secure food for their families. They worked beside men to harvest, cultivate and store crops, although the more intensive and laborious chores were carried out by men. At home, the women looked after their livestock and domestic animals, fetched fuel-wood and essential resources, besides managing their household. Village women valued their environment's biodiversity and natural resources such as water, soil and biota, and hence, took care to manage them in a way that would ensure future use. 


\section{Water}

Water is an important resource, central to the economic and social lives of village residents. In modern times, the quantity of water one can access is indicative of financial status of a household. The more the water one has access to, the more rich the person is perceived to be. Lack of access to water is seen as an indicator of poverty. This is particularly so in poorer households. Chachi Salima of Madhopur Vaince was of the view that,

"those who own lands and water can eat everything home-grown, like onions, chilli, tomatoes and potatoes... Crops grow only if there is moisture in the soil... Everything is really about water, and, secondly, about fertiliser. If you have access to water you can use fertilisers on your land to grow any crop."

Most of the houses that I went to had both a mechanical water hand-pump, and an automatic electric water motor. Mrs. Munir, a mother of five, agreed that water access at home was a blessing, but said that because of the electric water pump, a lot of water got wasted, because she did not have adequate storage or regulatory facilities (i.e. lack of a water tank to store water, and a water-tap to regulate its flow).

Water had traditionally been withdrawn from local wells (each village had at least one). The same well would be used for drinking, washing, cleaning, and irrigation. Chachi Nusrat, a resident of Madhopur Vaince, said that the benefit of using such water system was that the water would be used in limited amounts, and not be wasted away. She recalled that when the local well was the nearest source of clean water,

"Water was used in limited quantities and most of it was recycled. I used to draw water [from the well] in buckets and used to wash our dirty dishes with it. The relatively clean but already-used water [which had washed the dishes] was used for cleaning the mud-floor... That is why there were no over-running water sewage pipes, because no [usable] water was wasted."

She believed this conservative use of water made water usage very efficient at a time when water was available in very limited quantities. 
Local wells served as centres of social learning and knowledge exchange. Since the wells were the only source of fresh water in these villages, men and women congregated there to meet their basic needs, but in the process also strengthened community ties through informal socialisation. In some regards, this would also be a place of sharing social responsibility. For example, during a group interview organised at Madhopur Vaince, a 60 -year-old female resident recalled that often the first person to arrive at the well would fetch water for everyone standing behind in wait. This was done as a social courtesy. This indicates that social responsibility inculcated a sense of sacrifice among the villagers for the larger group, given that the principle of reciprocity was present.

Intriguingly, this social cohesion appears to have disintegrated with modern lifestyles. Chachi Meena of Madhopur Vaince felt that,

"In earlier times, people would share love and affection, but now, by accessing (and drinking) water from homes independently, people have lost that communal love and affection."

Water was accessed collectively when it was to be fetched from a distant source. Because well-water was scarce about two or more decades ago, women washed their linen and crockery at a local stream about 1-3 kilometres away from the villages. They felt that using water from and within a natural water body prevented water wastage. A 72-year-old Chachi Allahrakhi of Madhopur Vaince puts it well:

"Water was not wasted [as much] a generation ago, because we used to wash [clothes, utensils and ourselves] in the natural stream. Water would be recycled instead of getting wasted."

For the purpose of washing their laundry, women collected a white residual salt from the crop fields at dawn (kallarrh, or 'natural soda' as the women called it), which had accumulated overnight on the soil surface. At other times, women would collect a native, wild plant and use its soapy pulp for washing clothes. Shabiran, 62, mentioned how,

"Ash of burnt cotton plants was used for washing laundry. [In addition, we also used pulp of] a blue-flowered small 'chaananra' plant for washing linen."

Undoubtedly, washing became a social activity. Women would go together in groups, and on their way, would share daily-life stories with friends, neighbours and relatives. This 
also enabled them to establish a network of friends, where they could share their joys, grievances, innovations and experiences. In this way, women would exchange social information and knowledge, while doing a mundane chore. The social network was entrenched in daily routine, and so was the knowledge-network - as women learned from various sources on a daily basis.

This practice is no longer in use now, especially after women have gained access to handpumped or motor-pumped water in the vicinity of their homes. Detergents and soaps readily-available in the market have replaced 'organic detergents' (which, as a result, have either been ignored or slowly disappeared from the natural flora).

\section{Soil}

Soil was very important to this largely agrarian society in various ways.

Traditionally, soil, or mud, served as the foundation of all indigenously constructed houses. Traditional mud-houses were made from a durable mixture of clay and byproducts of wheat plant. The particular type of clay was secured from a nearby pond. One woman said she mixed in small proportions of cow dung in the clay-mixture so that dust would not rise after the clay-coating dried. Chachi Salima of Madhopur Vaince, felt that such houses

"do not get dirty easily, nor does any dust rise. If you clean the mud-floor once with a mop, it gets clean and becomes cool all of a sudden."

Like Chachi Salima, Chachi Shabiran of the same village also indicated that such houses had a temperature regulation effect:

"Mud-houses were better because they were cooler [during the summers] and were very economic, although they demanded a lot of hard work for maintenance."

When asked why she had moved from a mud-house to a modern (concrete) house, she responded:

"Because of social pressure and social status. I want to attract suitable proposals for my daughter because I want to get her married off. When people see someone living in a mud-house they think the person is poor." 
Her thoughts were similar to Chachi Salima's, which were shared in a separate interview:

"Who does not want to move [out of a traditional mud-house] to a modern, concrete house? Everybody wants to... but I do not have the financial resources."

In the neighbouring, more urbanised Jajopur, a relatively well-off grandmother of six said that her old mud-walled house was better because the temperature did not rise or fall as sharply as it did in her new double-storeyed, brick-house. Kausar of Madhopur Vaince said that she prefers her traditional house because it remains cool during the summer and warm during winters. In the same breath, she admitted she would like to live in a brick-house because 'everybody likes to enjoy things if they can afford them'.

This indicates that, for the villagers, such traditional dwellings are seen as an indicator of poverty. A few women who now live in brick-houses confided that they had moved away from their traditional mud-houses because those were looked down upon and considered 'unfashionable'. Over the years, as the streets of Madhopur Vaince have transformed from mud- to brick-laned, the nearby pond, from where women used to secure mud for their traditional shelters, has also disappeared as a result of neglect and disuse. Those with lesser economic means, like Kausar, the mother of a cancer patient, are content that the traditional shelters can be built and maintained at minimal cost. An added advantage, she felt, was that these houses were earthquake-proof.

Women also used natural soil to make traditional mud-stoves and traditional ovens. Almost all the women I talked to said they have a (functional) traditional mud-stove at home. These 3-walled mud stoves were made by recycling large, old pans or metal dishes, and ran on fuel-wood and dried cattle waste. Similarly, the traditional oven was made by lining bricks, plastered by mud, in a cylindrical shape on the ground with the oven's mouth facing the sky. Like the traditional stove, it ran on fuelwood and dried cowdung.

When requested to comment on where the women had learned such techniques from, two women of Madhopur Vaince replied:

"We saw our mothers do [such] work, and learned by observation. Similarly our children will learn by observing us perform [such] work." 
Naturally, soil has always been very important to the locals for its agricultural value. To ensure a good crop, women used to prepare organic fertilisers to increase soil fertility. Such fertilisers were domestically prepared by mixing cow-dung and ash (from traditional stoves) and household waste, such as left-over food and vegetable peels. This compost would take 6months-1year to prepare (estimates varied), and then fed to the soil to increase its fertility.

All the women interviewed unanimously agreed that the local soil fertility had declined over the years. Most attributed this decline to a switch to artificial fertilizers (which, the women felt, had ironically increased crop yields). A 75-year-old woman of Jajopur, also a local religious tutor, remarked:

"[Two decades or more ago] we used to dispose of our domestic [organic] waste [by mixing it] in [cow-dung] ash, and throwing it in the crop fields. It proved to be more efficient than artificial fertilisers. Now we just dump our household waste outside in the dump-field."

Women estimated that with an artificial fertilizer a crop area remained productive for 6 months in average. With traditional organic compost, the same cropland would remain productive for $1-6$ years, according to different estimates. Mohammad Malik, a 70-yearold father of five, while comparing the past and present soil fertilisation practices, reflected:

"About 15-20 years ago, villagers used to [fertilise their crops by using] cattle-waste and household [organic] garbage. This would keep the land fertile for about three years. It was also better because it produced better crops and [we consumed] better diet [as a result]."

Despite this, few locals used traditionally prepared manure on their crops today. The prime reason for this was the long duration it took for the manure to mature. Mohammad Malik said he used the traditional compost on his crops but he found it difficult to produce it in sufficient amounts for all of his sugarcane, wheat and rice crops. Instead, he used artificial fertilisers more frequently because they are "easily accessed".

Interestingly, the locals interviewed felt that the artificial fertilisers were the root-cause of illness and sickness in villages today. Salima of Madhopur Vaince believed that 
"People did not get sick a generation ago because of healthy diet. There were no artificial fertilisers used [then]. Home-prepared compost of cowdung was used in crops... Nowadays a lot of money is spent on [buying] artificial fertilisers... which are used on every crop."

Except one woman of Madhopur Vaince, who believed it was because of inactive and indolent lifestyles, all other participants were of the opinion that artificial fertilisers degraded the nutritious value of food crops and undermined human health.

There is a need to further study whether artificial fertilisers are the actual cause of reported declining health standards in the region. According to the locals, excessive use of artificial fertilisers, insecticides and pesticides have contributed to this problem. Changed, indolent lifestyles and unhealthy diets also add to the problem, some believe. No one pointed to the polluted, stagnant arsenic-laden waters that now stand in what was once a naturally flowing stream $15-20$ years ago.

\section{Biodiversity}

The women interviewed had a profound knowledge about their local flora. They revealed their knowledge about herbs, shrubs, plants, trees and crops which were of importance in the household and in the field. The most commonly grown crops were wheat and rice, which were also the common staple food. Lentils, mustard, sugarcane and sunflower were also cultivated to add variety to the diet.

A young woman of 40 , who had a terminally ill teenage daughter suffering from cancer, felt that local food crops and dietary intakes have changed over the years. She mentioned that crops such as black chickpeas and lentils, which were traditionally grown in the region, are no longer grown because they are risk-prone to unpredictable climatic conditions, and are commercially less viable. She concluded that 'when people can have rice and wheat to grow and eat, why would anyone want to grow other crops?'

According to the villagers, the local vegetation has also changed drastically over the years. The native flora seems to have been replaced by introduced species. Previously cotton was a very commonly-cultivated plant but it has disappeared in the local region especially after a decline in the local home-based cottage industry. A 65-year old woman of Madhopur Vaince remarked that, 
"Earlier there was no 'safaida' (eucalyptus) tree; there was 'darek', berry and 'keekar' (Acacia nilotica)... Now children no longer know the difference between a cotton plant and a potato plant".

Women usually used fresh leaves of the darek tree (Melia azedarach), as an insect repellent in grain storage containers. Its wood was used as fuel-wood, and the tree in general was used in agroforestry (on-farm tree cultivation).

Cattle are an important part of rural, agricultural life in Pakistan. The four villages surveyed were no exception to this. Cows and buffaloes have been of utmost importance to the village people: cow for its usefulness in the crop-fields (cultivation), as a means of transport, and also for its meat, dairy products, and by-products; and buffaloes primarily for their dairy products and to a lesser extend their meat and hide (Pakistan is a major exporter of leather products).

The usual dairy products domestically produced are milk, yogurt, curd, buttermilk, butter, and desi ghee (which is a kind of condensed butter, made by cooking milk-butter over low heat for long hours). Most of these products were consumed at home, while the rest sold to other residents for a livelihood.

Another reason why cattle are important to the rural household is their waste material, which is a major source of fuel for the traditional ovens and stoves. Villagers who did not own cattle had to purchase the 'dung-fuel'. Other sources of fuel-wood were the local keekar tree, and by-products of wheat, sunflower and cotton plants.

The wheat plant had various uses for the local women, besides it dietary input. It was used in making traditional handicrafts (such as baskets and mats), and was used as a raw material in local construction. Its by-products were used in preparing fodder for the cattle. In addition, women reported that mixing leftover wheat-bread in fodder increased the milk yield of the cattle. Women of Jajopur and Madhopur Vaince reported that mixing cotton seeds or by-products of mustard plant in the fodder increased both the yield and the cream content of the milk.

\section{Conclusions}

The local women have helped in uplifting the living standards of these communities in various ways by working informally from their homes. At a time when economic 
opportunities were limited, women depended on natural resources to produce items that were not only of use in the household but also those which they could sell in the market for an extra income. Women informally worked for the cottage industry by producing handicrafts and then selling these either in the market or within the local community for a livelihood. The income earned was directed towards household or personal use. Understanding, thus, the complex link between the natural environment, and their socio-economic well-being, women (and men) took care to manage their natural resources in a sustainable way, because those were the only ones they had (easy) access to for survival.

With new social and economic changes in the community, the villagers have adapted newer dietary habits, lifestyles and practices. This has had an impact on the natural biota as a result of decreased dependence and, hence, usage of natural resources. Whereas a generation ago diverse crops were grown for multiples uses (e.g. those for the crafts industry, such as flax and cotton, and those for securing food), now only food-crops are cultivated in the surveyed villages. Over time, village women have switched from resource management to resource negligence as a result of which a lot of naturallygrowing vegetation has disappeared from the landscape. Not surprisingly, traditional knowledge about natural resources has been significantly affected. Additionally, as the community has experienced relative prosperity in recent times, women no longer work in the informal cottage industry. In fact, women's lifestyles have become increasingly sedentary and their social mobility has been restricted. Socioeconomic and environmental changes in the community appear to have adversely impacted the local knowledge systems, since only a limited amount of traditional knowledge about the handicrafts, natural resource usage and agriculture is being passed on, while most of it has fallen into redundancy.

The next chapter discusses what these findings signify, and what implications they may have for the wider development rhetoric and practice. 


\section{CHAPTER 7: Interpreting the results - Significance, Challenges \& Implications}

As suggested in the previous chapter, traditional knowledge systems make vital contributions to the multiple dimensions of sustainable rural development. Women are active agents in fulfilling the aims of sustainable development. Engaging them along with the local communities through genuine participatory mechanisms will ensure a more holistic and appropriate sustainable development.

This chapter seeks to analyse and discuss some of the more important findings from the interviews with rural Sialkoti women. Analysis is made in the light of the previously outlined aims and objectives of the research. The introductory section of this chapter summarises the main findings from the research. This is followed by a discussion about the evolving nature of traditional knowledge systems and women's roles. The main part of the chapter discusses how women's traditional knowledges have contributed to the social, economic and environmental dimensions of sustainable development. The chapter closes by highlighting some of the challenges and their implications.

\section{Discussion}

The villages studied appear to be immersed in rapid socioeconomic change, which is challenging traditional norms, values and knowledge systems. Traditional knowledge systems have become increasingly vulnerable to change, as access to the market and the 'outside world' becomes easier and more affordable. Women's knowledge and practices in handicrafts, agriculture and natural resource usage are discussed below, with a central focus on how they help contribute to sustainable development.

\section{Epistemology}

In order to understand how traditional knowledge can positively contribute to sustainable development, it is important to understand how it is produced, disseminated, and used (Marsden, 1994). Knowledge is learned in various ways. In agreement with existing literature, knowledge in the communities-under-study was most often learned by non-conscious doing (Bicker \& Sillitoe, 2004; Kater, 1993). It was disseminated orally usually when the skill required some level of complexity (e.g. learning a particular 
embroidery pattern, compared to learning how to plaster mud-floors). Social and communal interaction was vital to traditional knowledge systems (Kater, 1993). Most of the learning took place in gender-segregated social groups (family unit or community group). Although traditional knowledge was collectively shared and owned, it was far from homogeneous. It varied within a community depending on age, experience, income, access to resources, household structure, among other things. Knowledge was most effectively retrieved when it was passed on in a socioeconomic context, rather than in abstract or out of relevance.

Some studies on traditional knowledge are marked with scepticism of traditional knowledge, because of its 'stagnant' and 'static' nature (see Sillitoe, 1998b). This is however far from true. Evidence from the research suggests that indigenous knowledge is indeed inherently dynamic, continuously evolving, and constantly adapting to socioeconomic context and changing environmental resource base, similar to what was found out in earlier studies (Briggs et al., 2003, 2007). The evolving social indicators of women in the villages surveyed attest to this (discussed in more detail later in the chapter). This shows that knowledge continues to evolve in a changing rural community that continues to re-negotiate its place in an increasingly urbanised, globalised, industrialised society. Women's roles and responsibilities, and their knowledges, evolved dynamically in negotiation with socioeconomic and environmental change. With changing roles their traditional knowledge has also evolved, adapted and re-negotiated itself.

Previous research indicates that utility of knowledge greatly determines whether the knowledge would be disseminated (Briggs et al., 2007). Findings from this research verify this. Relevant and useable knowledge appealed to rural women as more 'preservable' than knowledge which had lost its utility with changing resource base and socioeconomic trends. Besides that, knowledge dissemination was dependent on a number of other factors which included time availability, social mobility (Appleton \& Hill, 1994), and access to (and importance of) resources. As the women's lifestyles became increasingly sedentary, learning and dissemination patterns became spatially confined and less dynamic as a result of restricted social interaction. There patterns were drastically 
prominent when accompanied by socio-economic change (such as rural trend towards formal education).

Economic change seems to be the most dominant factor affecting traditional knowledge systems (Briggs et al., 2007). Traditional knowledge was modified when new sources of livelihoods replaced previous sources of income generation. In this process, less economically useful knowledge was discarded while more economically viable knowledge preserved. Additionally, when incomes from a particular industry (natural resource usage and agriculture) proved significantly profitable than others, interest and related traditional know-how in other, less profitable sectors eroded.

In earlier times, when income and food from agriculture were prone to risks, women invested the extra time they had in the cottage industry for extra income generation. With the advancement of agricultural technology, irrigation systems and greater mechanisation, rural communities have perennially been occupied in agriculture, with lesser time left for other activities. As a result, women had lesser time to invest in the cottage industry. Ironically, the same technological change and economic prosperity seem to have altered women's engagement in the most profitable sector (agriculture).

Women seem to have become less engaged in the agriculture sector compared to a decade ago. Handsome incomes and increased food security, as a result of intensification of agriculture, seem to have negatively impacted women's involvement in the agricultural sector - all of which significantly alter the local traditional knowledge base. (For example, the responsibility of preparing traditional fertiliser from organic waste was confined to women; and so was the related knowledge.)

Women's knowledge (and livelihoods) in agriculture have been displaced by the introduction of new technologies and knowledges which appear to have been economised by men more than by women (similar to Crewe and Harrison's findings, 1998, in Scott \& Foster, 2008). The reason for this lies in women's other duties and responsibilities. Most of the women's efforts are consumed in fulfilling their primary responsibilities (inside the household), as a result of which women are less willing to invest their time and energy in experimental activities outside the household (Scott \& Foster, 2008), when they can invest their time in industries they already have relevant 
knowledge of. However, this cannot be applied unconditionally, since most of the women reported that they were confined to their homes now more than before.

Regardless of the underlying cause, what is important to realise is that women's essential knowledge about agriculture and natural resource usage is being rapidly lost, as it no longer appears to be economically viable. However, it is worth mentioning here that to say that knowledge is being lost does not mean that the knowledge-base of the community is shrinking as a result. It is to imply that the traditional knowledge is replaced by more contemporary, modern knowledge.

\section{Socio-Cultural Dimensions}

Lifestyles have become more sedentary as women find themselves confined to their homes. Gender roles and responsibilities have become markedly specialised. Where women earlier helped both in the field and in the household to secure food and earn livelihoods, now they are looking only after their households and domestic livestock. Gender segregation seems to have become more marked than before. Part of the reason may lie in women's decreased mobility which decreases opportunities of socialisation. Social norms appear to have evolved over the years to adjust to the new social dynamics. This has had some negative impacts, as women reported a greater perception of insecurity and social isolation now.

Alternative approaches in development thinking associate increased economic prosperity with increased empowerment of women. However, this research reveals that women became more confined to their homes as the economic prosperity of their households increased. From contemporary development perspectives, it appears that women have become less empowered despite having improved access to amenities, facilities, education, health, wealth, market, and the like. Or, perhaps, existing development approaches overlook localised, culturally-determined concepts of empowerment?

Women felt that they were better off economically and socially than before, even though their social mobility seems to have decreased. Women felt that they no longer needed to go out in the fields and earn incomes when they had better access to basic necessities. They were generally more aware thanks to a revolution in communication and information technology. 
From the findings it appears that, firstly, economic prosperity is not always positively correlated to greater social mobility. Depending on the local context, greater wealth can mean women have more personal time to dedicate to their priorities (which in this case seem to be inside the household). Women earlier moved out of their homes out of necessity to fetch resources and earn extra income. In this regard, social mobility cannot always be directly related to the level of independence practiced by women. What needs to be clarified is whether women are dedicating more time now to the household out of choice, or pressurised to conform to changing gender roles.

It is apparent from the research that knowledge has traditionally been disseminated orally or through observation to the younger generations where the elders act as 'intermediaries' or 'gatekeepers' of vast, useful knowledge (Smith et al., 2000). Advancements in telecommunications and access to media serve as new gateways to knowledge in this era. This is fast becoming a reality in rural communities too, where social changes are challenging the existing status quo that was originally granted to the elderly, as they were the sole sources of vast knowledge - and power. In other words, modernisation challenges conventional norms and power structures in rural households which is significantly affecting rural dynamics.

Although it is difficult to verify to what extend women's sustainable traditional practices were guided by their actual belief systems (Kalland, 2000), it is safe to say that traditional knowledge played some constructive role in contributing to rural sustainability.

Another example of how women's traditional knowledge has evolved and adapted to changing social contexts is present in their social 'evaluation system'. Women have cleverly developed socio-economic indicators that help them instantly assess useful information. For example, mud houses were seen as an indicator of poverty; access to ample supply of water an indicator of wealth; know-how of stitchery a sign of efficiency (especially in households dependent on it as a livelihood); rapidly changing social mores a sign of immorality. Indicators were also used for other means. What is interesting to note is how the indicators have evolved over time. Elderly women felt that the inability to acquire traditional skills such as craft-making, resource-gathering (such as fuel), were indicative of inefficiency of a woman. However, these indicators are hardly relevant 
nowadays, when girls' formal education is given greater preference over informal knowledge.

Demographic changes in rural communities affect traditional knowledge systems. More people seek to migrate out of the rural areas for better opportunities. This has resulted in less people being able to utilise traditional knowledge and disseminate it. Additionally, with increased out-migration, industrialisation, urbanisation, and globalisation, traditional knowledge is becoming hybridised with 'external' knowledges. The villagers' resilience in coping with such rapid changes can be assessed from their adoption of both the modern and the traditional in their everyday living. They live in mud-lined houses where their televisions display international media channels.

\section{Economic Dimensions}

The villages are moving away from a value-based to a market-based society. This is exemplified by the evolution of social standards over time. Villagers complained that moral standards have been displaced by monetary values, especially when it came to evaluating human well-being. Clearly, local perceptions of prosperity are becoming increasingly hybridised with capitalist perceptions of well-being. Some of the factors contributing to this could be the greater integration of rural communities with markets and urban centres, out-migration, access to international media, and government policies.

Interestingly, women relied greatly on traditional know-how when other opportunities were limited. Poverty and lack of basic facilities pressed women to work for longer hours, to go further to fetch resources (like water, wood and useful plants), to diversify their means of earning livelihoods, and to work harder, often at a par with men, on farms (Briggs et al., 2003).

They also invested extra time and efforts to diversify their pool of livelihood sources for income generation. This has been recognised in literature elsewhere which indicates that rural women invest in a diverse range of skills which help them secure livelihoods from multiple sources (Pretty, 2008; Scott \& Foster, 2008; Zoomers, 2008; Briggs et al., 2003). This is particularly so when opportunities are limited. This practice serves as a 'hedge' 
against financial shocks, to sustain themselves and their families, rendering them less vulnerable (Zoomers, 2008; Briggs et al., 2008).

Women developed extensive knowledge about cheaper natural resources, especially when they were constrained by a lack of other opportunities or resources. This may have been due to a lack of awareness of and/or accessibility to better natural resources. However, previous research studies agree that poorer segments of community have to depend on less desirable resources, because of their economic disadvantage, but their knowledge about cheaper resources becomes specialised (Briggs et al., 2003).

Economic trends and livelihoods affect environmental resource base. For example, women reported that crafts industry had served as a major source of income generation (beside agriculture) a generation ago. Its great reliance on cotton crop was evident by the great amount of knowledge elderly women held (about spinning, weaving, and the like). However, with technological revolution in the agricultural sector, rural communities switched to newer, more profitable crops. This has resulted not only in loss of local biodiversity but has also resulted in a loss of livelihoods from the cottage industry, and erosion of huge knowledgebase. Changing livelihood trends and depleting environmental resource indirectly affect traditional knowledge associated with it.

Existing multilateral and donor-funded projects blame the poor for local environmental degradation and their economic deprivation (see Hope, 2008). It suggests that the poor are bounded in a poverty trap where the poor exploit environmental resources to move out of poverty, but in their quest, disrupt environmental sustainability, further dragging themselves into poverty. This research, however, suggests quite the opposite, but the argument remains the same: environmental balance is seriously disrupted when economic priorities overlook environmental sustainability.

The introduction of economically profitable alternatives, and the seduction of handsome incomes, has prompted locals to invest in new knowledges and practices, some of which are unsustainable and even detrimental to the environment. Undeniably, better opportunities come at a price (Briggs et al., 2003). Take the case of chemical fertilisers: their easy availability has encouraged its indiscriminate use in agriculture. The increased yields that wealthier locals expect in return are more than an incentive. The poor on the 
other hand are left to use less economically desirable alternatives, such as using traditionally-prepared organic manure. The prolonged use of artificial fertilisers has resulted in a loss of soil productivity, and according to the villagers, resulted in innutritious and unhealthy crops.

The allure of technological solutions tempts locals to assume that environmental problems will be easily-fixed and they no longer have to look after the 'health' and quality of the soil. Traditional agri-practices such as crop rotation, slash-and-burn, and adding of organic manure to the soil, have been slowly lost, with the introduction of new, costly technology. This has had a direct impact on biodiversity, knowledge systems and livelihoods related to it. All has been overlooked in the quest of economic prosperity. Undeniably, increased prosperity (and the quest for more), rather than poverty or subsistence, appears to be the driving force that has led to the current state of environmental deterioration in these areas.

The 'quality' of a product was determined by the value attached to it. Hand-made products were highly valued because of the personal time, effort and skill that went into making them. Women felt home-made products were of greater quality, because they knew how to make those products, and made them at home. This showed how knowledge was complexly intertwined with indicators and standards to maintain selfsufficiency of the community. This is consistent with similar findings in other places (e.g. see Kater's work carried out in Thai villages working for the crafts industry, and their valuing of indigenously produced crafts by locals as higher in quality, 1993). Quality, thus, was a subjective local concept that valued and privileged self-sufficiency over dependency on the extra-local.

\section{Environmental Dimensions}

The relationship between women and their environment is intricately interdependent, and their traditional environmental knowledge is indeed a depiction of this (Murdoch \& Clark, 1994). Rural women have relied on their natural environment as a source of sustenance for meeting their needs and fulfilling responsibilities in a sustainable way. They have done this through: (i) sustainably using and managing their resources; and, 
(ii) conserving them for future use, especially when the primary resource was of economic importance.

This, however, took place unconsciously. Saan, or flax plant, was originally cultivated as a source of livelihood, but it inadvertently also conserved the indigenous plant species. It has now disappeared from the local topography especially after the introduction of other non-local crops and plant species.

Niamir (1989) argues that indigenous knowledge systems are designed in a way that they allow equitable access to resources by the poorer and weaker sections of the society (in Marsden, 1994). Her argument seems to hold true in this case where women, forming the weaker segment of their communities, felt more secure accessing resources collectively through indigenous ways. Working in social groups gave them a sense of security when they laboured outside their homes. Presumably, access to resources was better when women accessed it collectively. This would be in agreement with similar work carried out with rural women in other developing areas (Jacobs, 2008). This equitable access to resources is an essential feature of sustainable development that, Marsden argues, is lacking in top-down development approaches (1994).

A changing natural resource base affected women in various ways. Their traditional knowledge adapted to accommodate new information about the changed resources. It also impacted their lifestyles, roles and responsibilities, especially when the changes were drastic (Briggs et al., 2003). Women complained that their lives had become relatively sedentary now. A few decades ago, when access to water was limited to natural sources, women travelled as far as 2-4 kilometres to fetch water. In contemporary times, shrinking water bodies, complimented by easy access to government-supplied water at home had indirectly resulted in a decrease in women's social mobility. Their confinement to the home, as an indirectly consequence of changed resource base, has given way to social segregation. There was agreement among the villagers that gender segregation had become more marked than before. As a result, gender roles had become more 'specialised' as women worked 'inside' the household and men worked 'outside. In other words, women and their traditional knowledge have 
become spatially restricted following major changes in natural resource base (Briggs et al., 2003).

The accessibility of a resource affected how it was used. This included the proximity and quantity of resource, which determined the amount of time and effort that would go into fetching it. For example, easy accessibility of flowing water at home resulted in higher consumption, and sometimes in its indiscriminate use.

The more difficult a basic resource was to access, the more complex the knowledge about it became. This was as a result of the amount of effort and time that went into acquiring the resource. Overtime, villagers' traditional knowledge adapted to locate most suitable and efficient ways to access these. When water had to be accessed from a distant source, women's knowledge about it deepened to adapt ways to best access the resource (and purify it). Similarly, when agricultural mechanisation, irrigation and fertilisers were unheard of, women (and men) prepared organic manure to make the soil more productive and fertile. Local knowledge about this was complex, involving knowhow about the raw materials to be used, ways to collect them, its preparation. The personal time and effort that went into accessing it correlated directly with the depth of knowledge women held about it.

Women seem to be keenly conscious of their time and labour efforts. However, when the scarce resource was non-basic, like cotton and saan, knowledge about it eroded over time; women found it suitable to invest their time in less profitable activities, rather than investing it in a hard-to-access resource that consumed much of their labour and time.

Locals have intelligently adapted their traditional knowledge to utilise common natural resources. An example of this is the traditional housing, which is a unique innovation that is suited to the local environmental conditions. Despite its flaws, traditional housing provided shelter to the villagers at minimal cost using organic resources. However, because of easy affordability, it has come to be associated with poverty, and hence, low social status granted to it. Because modern housing has become more socially respected and looked upon, traditional shelters, and related knowledge, are fast disappearing. 


\section{Challenges \& Implications}

There are several challenges to local development that need to be addressed. As indicated in the global literature, livelihood needs (and wants) and environmental sustainability are sometimes in conflict with each other. Local development planning not only needs to integrate economic objectives with environmental targets, but also needs to take into account informal traditional epistemologies of women that support sustainability. Traditional knowledge systems in the communities studied are being marginalised due to inadequate national policies and aggressive international targets, such as the MDGs, which place emphasis on the acquisition of formal education only, while ignoring the innovative capacities of indigenous knowledge systems.

Despite awareness at the international forums that traditional knowledge holds essential clues for local sustainability and must be preserved, little is done at the grass-roots level to prevent its erosion and loss. From the research it is evident that traditional knowledge contributes to sustainable development, but by its loss and constant erosion, sustainability is being challenged. The eroding traditional knowledge base of the villages surveyed can seriously impact the villagers' sense of identity and belonging, besides challenging sustainability. As the knowledge is rapidly being lost and replaced by newer knowledges, villagers are re-negotiating their identity as well as finding new means to sustain themselves in the radically changing environments.

The research confirms that social networks are important in rural communities because they help the vulnerable segments to meet their needs. This also gives them a space where they can acquire, transfer and reinforce traditional knowledge and skills. However, with rapid socioeconomic change, this is being challenged. Social interaction for women seems to have declined with increasingly sedentary lifestyles. Villagers now prefer to buy products from the urban market, rather than indigenously produce them. The rural principle of self-sufficiency is being replaced by a greater dependency on the urban market. The implications on social dynamics are significant. Decreased dependency on the community and increasing reliance on the 'outside world' is making the society increasingly individualistic. The change is resulting not only in the erosion and loss of traditional knowledge, but also in an increased feeling of social isolation among the villagers. 
This research also shows that the villages surveyed, like other indigenous communities, are challenged by their own emotional dependency on the outside world: on the urban, the global, the Western, and/or the modern. This trend is pronounced in Pakistan's national sustainability and development policies and in Pakistan's international affairs as well. A prolonged dependency on foreign aid has negatively impacted the common psyche, which is noticeable at the local level too. The locals hardly seem to present their indigenous solutions for sustainable development to outsiders; instead they have become dependent on external input for the solution of their problems. This low confidence in local innovation reflects the villagers' lack of trust and pride in their indigenous knowledge systems. This is similar to what is occurring in other indigenous communities that have become dependent on external 'solutions' to deliver them from their current state of deprivation, after having lost traditional solutions to their problems (Grenier, 1998).

From the study it is evident that the older women have knowledge about a diversity of skills compared to the younger generations. An important question that the local government needs to address is how to devise development programmes that target and engage women, while also recognising and productively using their traditional know-how in the cottage industry, agriculture and resource management.

Advocates of sustainable indigenous development critique that indigenous communities, like the ones surveyed, are fast becoming extra-localised with globalisation, and hence are losing some of the inherent vital features that are crucial to sustainability (see Smith et al., 2000). The issues of out-migration, urbanisation and media revolution are challenging conventional indigenous knowledge systems, since locals are no longer as locally-rooted. Increased market-integration and agrarian commercialisation present more profitable prospects to local villagers, which is why they are exchanging their traditional know-how with the non-indigenous. Traditional knowledge systems find it hard to evolve and negotiate with change in such contexts, and hence are becoming locally displaced and eroded. 


\section{Conclusions}

The research shows that the indigenous knowledge of women in the villages surveyed is being eroded as a result of rapid socioeconomic change. This has had a major impact on women's sustainable livelihoods. Research shows that women's traditional knowledge is interrelated with environmental, economic and social sustainability, since the loss of knowledge is directly correlated with a loss of biodiversity, sustainable income and traditional way of living. The problem is worsened by a lack of recognition of this vital resource of knowledge at the governmental and non-governmental level, resulting in policy discrepancies. Additionally, issues such as globalisation, out-migration, marketintegration and livelihood needs are challenging indigenous knowledge systems and their integration in the development process. Given these challenges, the following chapter offers a number of policy recommendations for enhancing sustainability efforts at the local and global level by employing traditional knowledge systems. 


\section{CHAPTER 8: The way forward}

\section{Concluding the research}

This study has endeavoured to demonstrate that traditional knowledge systems have a lot to offer to multiple dimensions of sustainable development. The underlying conviction of this research was that although indigenous knowledge cannot be seen as a panacea for development (Nygren, 1999), it certainly offers some useful insights on sustainability that conventional development thinking overlooks. The thesis began by contextualising sustainable development and traditional knowledge systems within the wider development rhetoric. The thesis examined the existing concepts and theories in sustainable development and traditional knowledge systems. After giving a brief historical background, it looked at some of the dominant theories in development, sustainable development and gender studies related to indigenous knowledge systems. Critical of the neo-liberal paradigm that dominates conventional development thinking and programmes, the thesis supported participatory development of neo-populist school of thought, which gives credence to local needs and insights in development. Important debates that sometimes divide traditional knowledge studies were discussed; these included dichotomies between the traditional, indigenous or local, and the Western, modern, scientific, or global. The research literature covered three most important aspects of sustainability - the environmental, economic and social - covering subject areas of natural resource usage, agriculture and handicrafts industry. Later, the challenges that face the integration of traditional knowledge studies in sustainable development were outlined, before discussing the gaps in existing literature.

The focus of the study then shifted to the local level. To contextualise the research, Pakistan's environmental legislation was discussed, before discussing the agricultural and natural resource sector policies.

The findings from the field research show that women contribute to rural sustainability, and are active agents in the development process, but this is unfortunately not always recognised. This is partly because women's contribution is most usually informal and home-based in important sectors such as agriculture, natural resource management and 
cottage industry. The research clearly shows that women are in an intricate relationship with their environment - dependent upon it to meet their household needs, and in doing so, sustainably managing the natural resource base for future use. It also shows that women's traditional knowledge is affected by, and influences, their evolving gender roles. In terms of rural economy, communities placed great value on rural self-sufficiency. Community members were interdependent on one another and social ties were important especially for the more vulnerable segments of society. Women collectively accessed resources and undertook economic activities that ensured equitable access to resources especially for the poor and vulnerable. All of this is being challenged now by the onslaught of urbanisation, industrialisation, out-migration and globalisation in a rapidly changing socioeconomic context. Such issues, also reflected the global level, challenge the successful integration of indigenous knowledge research in sustainable development in the national and the international arena.

\section{Recommendations}

The answers and solutions to development problems lie within communities. Better results can be achieved by gender mainstreaming and engaging the local communities in policy-making and planning. A strong will is needed on behalf of the authorities to genuinely involve the locals and their value systems in the development process.

Local people's perspectives are important to local development, and hence, should be integrated in sustainable rural development policy. Some mechanism should be put in place to take into account local voices, which otherwise are usually marginalised in national policies. Assistance, input and skills should not be left to the outsiders alone to decide and transfer (Scott \& Foster, 2008). For this, there is a need for creating enabling institutional framework and administrative system, which allows people to voice their needs and wants, and allows them to practice options concerning their community's management and conservation (Hussain \& Karki, 2004). This would be in line with the UNCED's Agenda 21 which recommends the involvement of local and indigenous groups in drafting local policies which set guidelines for resource management and conservation of biodiversity for sustainable development. 
There is a need to broaden the national perspective on sustainable development to promote a more holistic development, which equally acknowledges the environmental, socio-cultural, and economic spheres of human welfare. This could be done by allowing a more equitable participation in policy-making process by engaging all concerned stakeholders, especially the rural poor women whose voices are already marginalised.

Women's contribution to sustainable development is unique, yet, goes unrecognised, often becoming invisible in development policy, and as a consequence, sidelined in government programmes. Policy and interventions should be so designed that they serve the interest of women (along with men) in a meaningful and useful way, adding to their incomes without adding to their burdens, in ways which are culturally appropriate (Scott \& Foster, 2008). Taking advantage of the roles that rural women already play in their communities, policies should be devised in a way that they best suit women's needs and wants (Dove, 1992), and integrate well with their everyday lives. The draft Home-Based Workers Policy of Pakistan is a positive step forward. It should be effectively implemented so benefits could reach out to the intended beneficiaries.

Table 4: List of main recommendations

\begin{tabular}{|l|l|}
\hline Recommendation & Purpose \\
\hline $\begin{array}{l}\text { Adult literacy programmes targeted at } \\
\text { rural women (basic reading and } \\
\text { writing skills) }\end{array}$ & $>$ Increased adult literacy \\
& $>$ Documentation of indigenous \\
& knowledge by the indigenous
\end{tabular}




\begin{tabular}{|c|c|}
\hline & $\begin{aligned}> & \text { Greater recognition of home-based } \\
& \text { women workers } \\
> & \text { Income generation } \\
> & \text { Traditional knowledge revival } \\
> & \text { Biodiversity conservation }\end{aligned}$ \\
\hline $\begin{array}{l}\text { Establishment of a } \quad \text { national } \\
\text { Traditional Knowledge } \\
\text { Centre }\end{array}$ & $\begin{aligned} &> \text { Collect, document \& disseminate data } \\
& \text { on traditional knowledges } \\
&>\text { Advocate for traditional knowledge } \\
& \text { systems in all major development } \\
& \text { sectors (e.g. education, health, } \\
& \text { environment, women development, } \\
& \text { agriculture) } \\
&>\text { Serve as a research centre on national } \\
& \text { and international traditional knowledge } \\
& \text { systems between academic, } \\
&>\text { Academic collaboration with reputed } \\
& \text { academic centres and institutes } \\
&>\text { Intermediary bon-governmental } \\
& \text { governmental and noties } \\
& \text { bodis }\end{aligned}$ \\
\hline
\end{tabular}

It is recommended that adult literacy programmes be established for the rural women by the local or provincial government. This will allow women to document and disseminate their traditional knowledge, and hopefully, open up better opportunities for employment in the formal sector.

With the involvement of NGOs, such as the Sunghi and Lok Sanjh, women should be provided a platform, where they can share their knowledge with other women in the agriculture and cottage industry. Besides ensuring continuity of traditional knowledge and revival of important sectors, it will also provide a venue for social exchange. 
The government should re-organise the local cottage industry through home-based 'workshop system' (which has proved successful in Thailand and other East Asian countries) for easier governmental support and management. This will help in income generation, knowledge revival, biodiversity conservation (especially if the raw products are indigenously cultivated), and community cohesion. At the same time, it will allow the local government to standardise local crafting skills with modern quality standards.

A National Traditional Knowledge Resource Centre should be established (similar to those already setup in many developing countries), which should aim to collect and document traditional knowledges in Pakistan. It should collaborate with academic, governmental and non-governmental organisations to coordinate research on TK in sustainable development initiatives. It should also advocate for the integration of traditional knowledges in major development sectors (especially in formal education).

\section{Future prospects}

This research indicates that paths to development are many and diverse. To believe that development is uni-linear or uni-dimensional, or has only specific paths using which goals of development can be achieved, would a misguided conjecture. However, in order to achieve a broader (and more culturally appropriate) outlook on sustainable development, a better understanding of traditional concepts of sustainability, as opposed to the current Western-influenced notions of sustainable development, is needed.

A development that is culturally sound and environmentally sustainable is likely to bring more fruitful and sustainable results especially where local knowledge is acknowledged and integrated into development programmes. Given the complex nature of development, participatory development seems to be most promising in its ability to contextualise itself in the local context, its respect for local peoples' knowledge and belief systems, and its representation of local voices in development policy and practice.

Although critics may charge that indigenous knowledge research is losing relevance and is on the demise in development, there is still a lot that development can learn from traditional knowledge systems. Interest in the subject area needs to be reinforced by studying indigenous communities more closely and learning how they adapt culturally appropriate ways of sustaining their environment, economy, and society. The intended 
purpose is not to revert back to the past, as some may fear, but rather pick up the more useful, constructive aspects of traditional wisdom which can help us sustain a better future. The quest for global sustainability should begin with small yet appropriate sustainable steps at the local level.

An ideal form of development should seek to move towards a more 'hybrid' society, where the traditional and the modern, the Western and the indigenous, and the objective and subjective, are in harmony with each other, rather than either being mutually exclusive or at opposite ends. It is hoped that such a society will offer the younger and older generations, Western and non-Western communities, and scientific and 'non-scientific' academia to learn from each other through hybrid diffusion of knowledge. Such societies, it is hoped, will offer more integrated and balanced approaches to sustainable development. 


\section{REFRENCES}

Agrawal, A. (1995). Dismantling the Divide Between Indigenous and Scientific Knowledge. Development and Change, 26 (3), 413-439.

Agrawal, A. (2002). Indigenous knowledge and the politics of classification. UNESCO. Oxford: Blackwell.

Ahmad, M. (2001). Agricultural Productivity Growth Differential in Punjab, Pakistan: A Districtlevel Analysis. The Pakistan Development Review, 40 (1), 1-25.

Ahmed, Z. U. (2006). Community consultation dialogues on the GoP's Poverty Reduction Strategy Paper (PRSP). Islamabad: Rural Support Programmes Network (RSPN) in collaboration with DFID. Retrieved December 8, 2009, from http://www.rspn.org/Publications/1.2.1\%20PRSPII\%20Report.pdf

Ajmal, M. (2008). Brainstorming Session on the National Sustainable Development Strategy [Electronic version]. SDPI Research and News Bulletin, 15 (4).

Aken, J. V. (2008, Winter). Key report calls for shift to sustainable farming. Pacific ecologist (16), p. 46.

ANKN. (2008, November 13). Indigenous Knowledge Systems and Higher Education: Preparing Alaska Native PhD's for Leadership Roles in Research. Retrieved November 28, 2009, from Alaska Native Knowledge

Network: http://www.ankn.uaf.edu/curriculum/Articles/RayBarnhardt/PreparingPhDs.html

Appleton, H. E., \& Hill, C. L. (1994). Gender and indigenous knowledge in various organizations. Indigenous Knowledge and Development Monitor, 2 (3).

Azid, T., Aslam, M., \& Chaudhary, M. O. (2001). Poverty, Female Labour Force Participation, and Cottage Industry: A Case Study of Cloth Embroidery in Rural Multan. Pakistan Development Review, 40 (4), 1105-1118.

Becker, C. D., \& Ghimire, K. (2003). Synergy between traditional ecological knowledge and conservation science supports forest preservation in Ecuador. Conservation Ecology, 8 (1), Retrieved May 3, 2009, from http://www.consecol.org/vol8/iss1/art1 
Bicker, A., \& Sillitoe, P. (2004). Introduction: Hunting for theory, gathering ideology. In A. Bicker, P. Sillitoe, \& J. Pottier (Eds.), Development and Local Knowledge: New Approaches to Issues in Natural Resources Management, Conservation, and Agriculture (pp. 1-18). Abingdon, UK: Routledge.

Bicker, A., Sillitoe, P., \& Pottier, J. (Eds.). (2004). Investigating Local Knowledge: New Directions, New Approaches. Hants, England: Ashgate.

Boven, K., \& Morohashi, J. (Eds.). (2002). Best Practices using Indigenous Knowledge. The Hague and Paris: Nuffic and UNESCO-MOST.

Breidlid, A. (2009). Culture, indigenous knowledge systems and sustainable development: A critical view of education in an African context. International Journal of Educational Development, 29, 140-148.

Briggs, J. (2008). Indigenous knowledge and development. In V. Desai, \& R. B. Potter (Eds.), The Companion to Development Studies (2nd ed., pp. 107-110). London: Hodder Education.

Briggs, J. (2005). The use of indigenous knowledge in development: problems and challenges. Progress in Development Studies, 5 (2), 99-114.

Briggs, J., Sharp, J., Hamed, N., \& Yacoub, H. (2003). Changing Women's Roles, Changing Environmental Knowledges: Evidence from Upper Egypt. The Geographical Journal, 169 (4), 313325.

Briggs, J., Sharp, J., Yacoub, H., Hamed, N., \& Roe, A. (2007). The Nature of Indigenous Environmental Knowledge Production: Evidence from Bedouin Communities in Southern Egypt. Journal of International Development, 19, 239-251.

Brokensha, D., Warren, D. M., \& Werner, O. (Eds.). (1980). Indigenous Knowledge Systems and Development. Washington D.C.: University Press of America.

Bruyere, G., \& Bergland, E. (n.d.). Module 4: Traditional Knowledge. University of the Arctic, Cicumpolar studies. University of the Arctic.

Burford, G., Rafiki, Y., \& Ngila, G. O. (2003, March). Education, indigenous knowledge and globalisation. Retrieved April 11, 2009, from Science in Africa: http://www.scienceinafrica.co.za/2003/march/ik.htm 
Burgess, J. (2006). Participatory action research: First-person perspectives of a graduate student. Action Research, 4, 419-437.

Chaudhry, M. G., \& Chaudhry, G. M. (1997). Pakistan's Agricultural Development since Independence: Intertemporal Trends and Explanations [Electronic version]. The Pakistan Development Review, 36 (4), 593-612.

Costa-Neto, E. M. (2000). Sustainable development and traditional knowledge: A case study in a Brazilian artisanal fishermen's community. Sustainable Development, 8, 89-95.

Desai, V., \& Potter, R. B. (Eds.). (2008). The Companion to Development Studies (2nd ed.). London: Hodder Education.

Dove, M. R. (2003). Bitter Shade: Throwing Light on Politics and Ecology in Contemporary Pakistan. Human Organization, 62 (3), 229-241.

Dove, M. R. (2000). The Life-Cycle of Indigenous Knowledge, and the Case of Natural Rubber Production. In R. Ellen, P. Parkes, \& A. Bicker (Eds.), Indigenous Environmental Knowledge and its Transformations: Critical Anthropological Perspectives (pp. 213-252). Amsterdam: Harwood Academic Publishers.

Dove, M. R. (1994). The Existential Status of the Pakistani Farmer: Studying Official Constructions of Social Reality. Ethnology , 33 (4), 331-351.

Dove, M. R. (1992). Foresters' beliefs about farmers: a priority for social science research in social forestry. Agroforestry Systems , 17 (1), 13-41.

Dowling, R. (2004). Power, Subjectivity and Ethics in Qualitative Research. In I. Hay (Ed.), Qualitative Research Methods in Human Geography (pp. 19 - 29). Melbourne: Oxford University Press.

Delegation of the European Commission to Pakistan. (2007). Pakistan-Europe Community: Country Strategy Paper for 2007-2013. Retrieved April 27, 2009, from http://www.delpak.ec.europa.eu/Documents/CSP07_13_en.pdf

Ellen, R., \& Harris, H. (2000). Introduction. In R. Ellen, P. Parkes, \& A. Bicker (Eds.), Indigenous Environmental Knowledge and its Transformations: Critical Anthropological Perspectives (pp. 134). London: Routledge.

Elliott, J. A. (1999). An Introduction to Sustainable Development (2nd ed.). London: Routledge. 
Ellis, D., \& West, P. (2004). Local History as 'Indigenous Knowledge': Aeroplanes, Conservation and Development in Haia and Maimafu, Papua New Guinea. In A. Bicker, P. Sillitoe, \& J. Pottier (Eds.), Investigating Local Knowledge: New Directions, New Approaches (pp. 105-128). Hants, England: Ashgate.

Escobar, A. (1998). Whose Knowledge, Whose Nature?: Biodiversity Conservation and the Political Ecology of Social Movements. Journal of Political Ecology, 5, 53-82.

Fals-Borda, O. (2001). Participatory (action) research in social theory: Origins and challenges. In P. Reason, \& H. Bradbury (Eds.), Handbook of action research: Participative inquiry and practice (pp. 27-37). London: Sage.

Fernández, M. E. (1994). Gender and indigenous knowledge [Electronic source]. Indigenous Knowledge and Development Monitor, 2 (3).

Food and Agriculture Organisation. (2006). Food Outlook: Global Market Analysis. FAO. Retrieved June 20, 2009, from http://www.fao.org/docrep/009/J7927e/j7927e00.htm

Friel, M., \& Santagata, W. (2008). Making material cultural heritage work: From traditional handicrafts to 'soft' industrial design. In H. Alheier \& Y. R. Isar (Eds.), The Cultural Economy: The Cultures and Globalisation Series II. London: Sage.

Glatthorn, A. A., \& Joyner, R. L. (2005). Writing the Winning Thesis or Dissertation: A Step-by-Step Guide (2nd ed.). Thousand Oaks, CA: Corwin Press.

Government of Pakistan. (n.d.). Brief on NSDS process in Pakistan [Electronic source]. Retrieved April 24, 2009, from: http://www.pakistan.gov.pk/divisions/environmentdivision/media/BRIEF_ON_THE_NSDS_PROCESS_IN_PAKISTAN.pdf

Government of Pakistan. Federal Bureau of Statistics. (n.d.). Agriculture Statistics. Retrieved December 12 , 2009, fromhttp://www.statpak.gov.pk/depts/fbs/statistics/agriculture_statistics/agriculture_statistics.h $\mathrm{tml}$

Government of Pakistan. Ministry of Environment. (2005). National Environmental Policy. Islamabad: The Government of Pakistan.

Government of Pakistan. Ministry of Environment. (n.d.)State of Environment Report 2005 (Draft). Pakistan Environmental Protection Agency, Islamabad. 
Grenier, L. (1998). Working with Indiegnous Knowledge: A Guide for Researchers. Ottawa, ON.: International Development Research Centre (IDRC).

Guchteneire, P., Krukkert, I., \& Liebenstein, G. (Eds.). (1999). Best Practices on Indigenous Knowledge. UNESCO-MOST \& CIRAN. Retrieved May 3, 2009, from http://www.unesco.org.

Hanson, A. J., Bass, S., Bouzaher, A., \& Samdani, G. M. (2000). Pakistan's National Conservation Strategy: Renewing the commitment to action - Report of Mid-Term Review. IUCN.

Hanson, L., \& Hanson, C. (2001). Transforming participatory facilitation: Reflections from practice. PLA Notes, 41, pp. 29-32.

Harris, J. M. (2000). Basic Principles of Sustainable Development. Working Paper, Tufts University, Global Development and Environment Institute, Medford, MA.

Hoggart, K., Lees, L., \& Davis, A. (2002). 'Close encounters: interviews and focus groups. In K. Hoggart, L. Lees, \& A. Davis (Eds.), Researching Human Geography (pp. 201-250). London: Arnold. HomeNet Pakistan. (n.d.). The Movement toward a National Policy on Homebased Workers. Retrieved September 29, 2009, from HomeNet SouthAsia: www.homenetsouthasia.org/downloads/28.ppt

Hope, K. R. (2008). Poverty, Livelihoods and Governance in Africa: Fulfilling the Development Promise. New York: Palgrave.

Howes, M. (1979). The Uses of Indigenous Technical Knowledge in Development. The IDS Bulletin, $10(2), 12-23$.

Howes, M., \& Chambers, R. (1979). Indigenous Technical Knowledge: Analysis, Implications and Issues. The IDS Bulletin, 10 (2), 5-11.

Hussain, K., \& Karki, M. (2004). Linking Research to Development in Medicinal Plants-based Livelihood Development (Unique partnership building initiative in Pakistan highlands between ICIPRP and IDRC-MAPPA). Intercooperation Pakistan. Retrieved from http://www.intercooperation.org.pk.

Ibrar, M. (2003). Conservation of indigenous medicinal plants and their traditional knowledge found in moist temperate Himalayas Pakistan. PhD Thesis. Quaid-i-Azam University, Islamabad. Retrieved May 21, 2009, from Pakistan Research Repository. 
International Fund for Agricultural Development. (2009, November 17). Indigenous Peoples. Retrieved December 11, 2009, from IFAD: http://www.ifad.org/english/indigenous/index.htm Isbister, J. (2003). Promises Not Kept: Poverty and the Betrayal of Third World Development (6th ed.). Bloomfield, CT: Kumarian.

Jabbar, A., Raza, M. A., Iqbal, Z., \& Khan, M. N. (2006). An inventory of the ethnobotanicals used as anthelmintics in the southern Punjab (Pakistan). Journal of Ethnopharmocology, 108, 152-154.

Jacobs, S. (2008). Livelihood strategies and their environmental impacts. In V. Desai, \& R. B. Potter (Eds.), The Companion to Development Studies (2nd ed., pp. 334-340). London: Hodder Education.

Johnson, M. (1992). Research on Traditional Environmental Knowledge: Its Development and Its Role [Electronic version]. In M. Johnson (Ed.), LORE: Capturing Traditional Environmental Knowledge (pp. 3-20). Ottawa, Ont.: IDRC.

Kalland, A. (2000). Indigenous Knowledge: Prospects and Limitations. In R. Ellen, P. Parkes, \& A. Bicker (Eds.), Indigenous Environmental Knowledge and its Transformations: Critical Anthropological Perspectives (pp. 319-336). Amsterdam: Harwood Academic Publishers.

Kater, A. (1993). Indigenous Learning in Crafts: A Pilot Research Effort [Electronic version]. Indigenous Knowledge and Development Monitor, 1 (1).

Kincheloe, J. L., \& Steinberg, S. R. (2008). Indigenous Knowledges in Education. In N. K. Denzin, Y. S. Lincoln, \& L. T. Smith (Eds.), Handbook of Critical and Indigenous Methodologies (pp. 135-156). Los Angeles: Sage.

Kumar, S. (2002). Methods for Community Participation: A Complete Guide for Practitioners. London: ITDG Publishers.

Kwa, E. L. (2005). Traditionalizing Sustainable Development: The Law, Policy, and Practice in Papua New Guinea. PhD Thesis, University of Auckland. Retrieved March 31, 2009,fromNational Libraries' of New Zealand.

Lalonde, A. (1993). Indigenous Knowledge Systems and Sustainable Development: IDRC program development. IDRC.

Lammerink, M. P. (2006). Enhancing Indigenous People's Forest Knowledge. Paper presented at the 2006 'International Conference on Endogenous Development and Bio-Cultural Diversity' 
inGeneva, Switzerland. Retrieved July 30, 2009, from http://www.bioculturaldiversity.net/Downloads/Papers\%20participants/Lammerink.pdf

Malik, S. (1996). Determinants of Rural Poverty in Pakistan: A Micro Study [Electronic version]. The Pakistan Development Review, 35 (2), 171-187.

Marsden, D. (2007). [Review of the book Local science vs global science: approaches to indigenous knowledge in international development]. Journal of the Royal Anthropological Institute, 13 (4), 1028-1029.

Marsden, D. (1994). Indigenous management and management of indigenous knowledge. In S. Wright (Ed.), The Anthropology of Organizations (pp. 39-53). London: Routledge.

Marshall, C., \& Rossman, G. B. (2006). Designing Qualitative Research (4th ed.). Thousand Oaks: Sage.

Mathez-Stiegel, S.-L., Boillat, S., \& Rist, S. (2006). Promoting the diversity of worldviews: An ontological approach to bio-cultural diversity. Paper presented at the 2006 'International Conference on Endogenous Development and Bio-Cultural Diversity' in Geneva, Switzerland. $\begin{array}{llll}\text { Retrieved July } 30, & \text { 2009, from }\end{array}$ http://www.bioculturaldiversity.net/Downloads/Papers\%20participants/Mathez_et_al.pdf Mazzucato, V. (1996). Indigenous economies: bridging the gap between economics and anthropology [Electronic version]. Indigenous Knowledge and Development Monitor, 5 (1).

McCright, A. M., \& Clark, T. N. (Eds.). (2006). Dimensions of Local Sustainability (Vol. 10: Research in Urban policy). Oxford: Elsevier.

McGregor, D. (2004). Traditional Ecological Knowledge and Sustainable Development: Towards Coexistence [Electronic version]. In M. Blaser, H. A. Feit, \& G. McRae (Eds.), In The Ways of Development: Indigenous Peoples, Life Projects and Globalization (pp. 72-81). London/Ottawa: Zed/IDRC.

Mebratu, D. (1998). Sustainability and sustainable development: Historical and conceptual review. Environmental Impact Assessment Review, 18 (6), 493-520.

Mikkelsen, B. (2005). Methods for Development Work and Research: A New Guide for Practitioners (2nd ed.). New Delhi: Sage. 
Mikkelsen, C. (2005). Report on the interplay between indigenous peoples, gender and natural resource management. (DIIS Working Paper 2005/5). Copenhagen: Vesterkopi.

Miller, M. B., Greenwood, D., \& Maguire, P. (2003). Why Action Research? Action Research, 1 (9), 9-28.

Mishra, S. (1994). Women's indigenous knowledge of forest management in Orissa (India) [Electronic source]. Indigenous Knowledge and Development Monitor, 2 (3).

Mohan, G. (1999). Not so distant, not so strange: the personal and political in participatory research. Ethics Place and Environment, 2, 41-54.

Munasinghe, M. (1992). Environmental Economics and Sustainable Development[Environment Paper No.3]. Paper presented at the UN Earth Summit, Rio de Janeiro. Washington DC: World Bank.

Murdoch, J., \& Clark, J. (1994). Sustainable Knowledge. Geoforum, 25 (2), 115-132.

Nakashima, D., \& Roue, M. (2002). Indigenous Knowledge, Peoples and Sustainable Practice. In P. Timmerman (Ed.), Encyclopedia of Global Environmental Change (Vol. 5: Social and Economic dimensions of Global Environmental Change, pp. 314-324). Chichester: John Wiley \& Sons.

Nazhar, B. (1995). Rural Savings: Their Magnitude, Determinants, and Mobilisation. The Pakistan Development Review, 34 (4), 779-788.

NSDS to offer opportunity to integrate sustainable development related policies, strategies. (2008, February 27). Pakistan Press International.

Nuffic-CIRAN. (1993). Background to the International Symposium on Indigenous Knowledge and Sustainable Development [Electronic version]. Indigenous Knowledge and Development Monitor, $1(2)$.

Nygren, A. (1999). Local Knowledge in the Environment-Development Discourse. Critique of Anthropology, 19 (3), 267-288.

O'Brien, R. (2001). An Overview of the Methodological Approach of Action Research (English version). In R. Richardson (Ed.), Theory and Practice of Action Research. Brazil: Universidade Federal da Paraíba. 
Oplinger, E., Oelke, E., Doll, J., Bundy, L., \& Schulerl, R. (1997, November 18). Flax. In Alternative Field Crops Manual. Retrieved June 4, 2009, from New Crops Resource Online Program, Purdue University: http://www.hort.purdue.edu/newcrop/afcm/flax.html

Osseweijer, M. (2000). 'We Wander in Our Ancestors' Yard': Sea Cucumber Gathering in Aru, Eastern Indonesia. In R. Ellen, P. Parkes, \& A. Bicker (Eds.), Indigenous Environmental Knowledge and its Transformations: Critical Anthropological Perspectives (pp. 55-78). Amsterdam: Harwood Academic Publishers.

Pandey, R. (2009, April 9). Etymology of Flax. Retrieved May 7, 2009, from Agropedia: http://agropedia.iitk.ac.in/?q=content/etymology-flax

Parkes, P. (2000). Enclaved knowledge: Indigent and indignant representations of environmental management and development among the Kalasha of Pakistan. In R. Ellen, P. Parkes, \& A. Bicker (Eds.), Indigenous Environmental Knowledge and its Transformations: Critical Anthropological Perspectives (pp. 253-292). Amsterdam: Harwood Academic Publishers.

Parnwell, M. J. (2008). Agropolitan and bottom-up development. In V. Desai, \& R. B. Potter (Eds.), The Companion to Development Studies (2nd ed., pp. 111-115). London: Hodder Education.

Pelling, M. (2008). The Rio Earth Summit. In V. Desai, \& R. B. Potter (Eds.), The Companion to Development Studies (2nd ed., pp. 288-292). London: Hodder Education.

Pike, J. (n.d.). Pakistan Special Weapons Facilities. Retrieved December 9, 2009, from Federation of American Scientists: http://www.fas.org/nuke/guide/pakistan/facility/index.html

Posey, D. A. (2000). Ethnobiology and ethnoecology in the context of national laws and international agreements affecting indigenous and local knowledge, traditional resources and intellectual propery rights. In R. Ellen, P. Parkes, \& A. Bicker (Eds.), Indigenous Environmental Knowledge and its Transformations: Critical Anthropological Perspectives. Amsterdam: Harwood Academic Publishers.

Pottier, J. (2003). Negotiating Local Knowledge: An Introduction. In J. Pottier, P. Sillitoe, \& A. Bicker (Eds.), Negotiating Local Knowledge: Identity and Power in Development (pp. 1-29). London: Pluto.

Pretty, J. (2008). Agricultural sustainability. In V. Desai, \& R. B. Potter (Eds.), The Companion to Development Studies (2nd ed., pp. 165-169). London: Hodder Education. 
Qureshi, R. A., Ahmed, M., \& Ghufran, M. A. (2007). Indigenous knowledge of some important wild plants as a folk medicines in the area of Chhachh (Distt. Attock) Punjab (Pakistan). Electronic Journal of Environmental, Agricultural and Food Chemistry , 6 (11), 2500-2511.

Rajasekaran, B., \& Warren, D. M. (1994). IK for socioeconomic development and biodiversity conservation: The Kolli hills [electronic version]. Indigenous Knowledge and Development Monitor, 2 (2).

Rajasekaran, B., Martin, R., \& Warren, D. M. (1993). A framework for incorporating indigenous knowledge systems into agricultural extension [electronic version]. Indigenous Knowledge and Development Monitor, 1 (3).

Redclift, M. (2008). Sustainable development. In V. Desai, \& R. B. Potter (Eds.), The Companion to Development Studies (2nd ed., pp. 279-282). London: Hodder Education.

Redclift, M. (1992). The Meaning of Sustainable Development. Geoforum, 23 (3), 395-403.

Retting. (2009). In Encyclopædia Britannica Online. Retrieved May 29, 2009, from Encyclopædia Britannica Online: http://www.britannica.com/EBchecked/topic/500159/retting Review of National Policy for Home-Based Workers. (2008, April 11). Daily Times .

Robeyns, I. (2005). The Capability Approach: a theoretical survey. Journal of Human Development, $6(1), 93-117$.

Sardar, A. A., \& Khan, Z. (2009). Ethnomedicinal studies on plant resources of tehsil Shakargarh, District Narrowal, Pakistan. Pakistan Journal of Botany , 4 (1), 11-18.

Scott, A., \& Foster, M. (2008). Gender, technology and livelihoods. In V. Desai, \& R. B. Potter (Eds.), The Companion to Development Studies (2nd ed., pp. 369-373). Londer: Hodder Education. Sen, A. (2000). Development as Freedom. New Delhi: Oxford University Press.

Shaw, R., Takeuchi, Y., Uy, N., \& Sharma, A. (2009). Indigenous Knowledge for Disaster Risk Reduction: Policy Note. UN/ISDR/EU.

Shinwari, M. I., \& Khan, M. A. (2000). Folk use of medicinal herbs of Margalla Hills National Park, Islamabad. Journal of Ethnopharmacology , 29, 45-56.

Sillitoe, P. (1996). A Place Against Time: Land and Environment in the Papua New Guinea Highlands. Amsterdam: Harwood Academic Publishers. 
Sillitoe, P. (1998a). The Development of Indigenous Knowledge: A New Applied Anthropology. Current Anthropology, 39 (2), 223-252.

Sillitoe, P. (1998b). What, know natives? Local knowledge in development. Social Anthropology, 6 (2), 203-220.

Sillitoe, P., \& Marzano, M. (2009). Future of indigenous knowledge research in development. Futures, 41, 13-23.

Sillitoe, P., Barr, J., \& Alam, M. (2004). Sandy-clay or clayey-sand? Mapping indigenous and scientific knowledge on the Bangladesh floodplains. In A. Bicker, P. Sillitoe, \& J. Pottier (Eds.), Development and Local Knowledge (pp. 174-201). Abingdon, UK: Routledge Harwood.

Silverman, D. (2006). Interpreting Qualitative Data (3rd ed.). London: Sage.

Smith, C., Burke, H., \& Ward, G. K. (2000). Globalisation and Indigenous Peoples: Threat or Empowerment? In C. Smith, \& G. K. Ward (Eds.), Indigenous Cultures in an Interconnected World (pp. 1-26). Sydney: Allen \& Unwin.

Stonebanks, C. D. (2008). An Islamic Perspective on Knowledge, Knowing, and Methodology. In N. K. Denzin, Y. S. Lincoln, \& L. T. Smith (Eds.), Handbook of Critical and Indigenous Methodologies (pp. 293-321). Los Angeles: Sage.

Sundar, N. (2000). The Construction and Deconstruction of 'Indigenous' Knowledge in India's Joint Forest Management Programme. In R. Ellen, P. Parkes, \& A. Bicker (Eds.), Indigenous Environmental Knowledge and its Transformations: Critical Anthropological Perspectives (pp. 79100). Amterdam: Harwood Academic Publishers.

Swift, J. (1979). Notes on Traditional Knowledge, Modern Knowledge and Rural Development. The IDS Bulletin, 10 (2), 41-43.

Turning blight into bloom (editorial). (2008, September 11). Nature, 455 (7210), p. 137.

Ulluwishewa, R. (1993). Indigenous knowledge, national IK resource centres and sustainable development [Electronic source]. Indigenous Knowledge and Develpoment Monitor, 1 (3).

UN population report: Culture is key to progress. (2008, December 11). Retrieved December 26, 2008, from GMA News: http://www.gmanews.tv/story/133114/UN-population-report-Culture-iskey-to-progress 
UNIFEM. (2000). Women workers in the informal sector in South Asia: Creating an enabling environment. Regional Policy Seminar (pp. 1-14). Kathmandu: UNIFEM, Government of Nepal, IDRC, WIEGO.

United Nations Development Programme. (2009). Human Development Report 2009 - Country fact sheets - Pakistan. Retrieved September 29, 2009, from Human Development Reports: http://hdrstats.undp.org/en/countries/country_fact_sheets/cty_fs_PAK.html

United Nations Educational, Scientific and Cultural Organization. (2009, March 23). What is Intangible Cultural Heritage? Retrieved March 26, 2009, from UNESCO: http://www.unesco.org/culture/ich/index.php?pg=00002

United Nations Educational, Scientific and Cultural Organization. (n.d.). What is Local Knowledge? Retrieved May 3, 2009, from LINKS Programme (UNESCO): http://portal.unesco.org/science/en/ev.phpURL_ID=2034\&URL_DO=DO_TOPIC\&URL_SECTION=201.html

United Nations Environment Programme. (2009). National Sustainable Development Strategy of Pakistan. UNEP Regional Workshop, (p. 16). Bangkok.

United Nations Environment Programme. (2004). Women and the Environment. Nairobi: UNEP.

United Nations Population Fund. (2008). State of World Population 2008 - Reaching Common Ground: Culture, Gender and Human Rights. New York: UNFPA.

United States Department of Agriculture. (2009). Pakistan Agriculture Economy and Policy. Foreign Agricultural Service. USDA.

Wadsworth, Y. (1998). What is Participatory Action Research? [Electronic version]. Action Research International, Paper 2.

Warren, D. M. (1996). Indigenous Knowledge, Biodiversity Conservation, and Development. In V. U. James (Ed.), Sustainable Development in Third World Countries: Applied and Theoratical Perspectives (pp. 81-88). Westport, CT: Praeger.

WIPO. (n.d.). Traditional Knowledge, Genetic Resources and Traditional Cultural Expressions/Folklore. Retrieved December 5, 2009, from World Intellectual Property Organisation: http://www.wipo.int/tk/en 
Wolff, N. H., \& Wahab, B. (1995). Learning from craft taxonomies: development and a Yoruba textile tradition [Electronic version]. Indigenous Knowledge and Development Monitor, 3 (3).

World Bank. (2008). Key Development Data \& Statistics: Pakistan. Retrieved September 27, 2009, from World Bank: http://web.worldbank.org/WBSITE/EXTERNAL/DATASTATISTICS/0,,contentMDK:20535285 menu PK:1192694 pagePK:64133150 piPK:64133175 theSitePK:239419,00.html

World Bank. (1997). Rural development: From vision to action. Washington DC: World Bank.

World Bank. (n.d.). What is Indigenous Knowledge? Retrieved March 28, 2009, from WB: http://www.worldbank.org/afr/ik/basic.htm

World Commission on Environment and Development. (1987). Our Common Future. Oxford: Oxford University press.

World Resources Institute in collaboration with United Nations Development Programme, United Nations Environment Programme, and World Bank. (2008). World Resources 2008: Roots of Resilience - Growing the Wealth of the Poor. Washington, DC: World Resources Institute.

Zoomers, A. (2008). Rural livelihoods. In V. Desai, \& R. B. Potter (Eds.), The Companion to Development Studies (2nd ed., pp. 147-151). London: Hodder Education.

Zweifel, H. (1996). Biodiversity and the appropriation of women's knowledge [Electronic version]. Indigenous Knowledge and Development Monitor, 5 (1). 


\section{APPENDIX: Ethics forms}

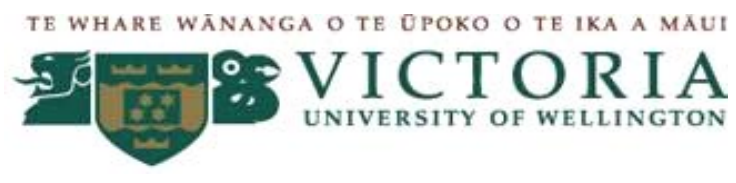

\section{Information sheet: 'Traditional Wisdom \& Sustainable Development in Rural Pakistan}

I am carrying out this research as part of my thesis for Masters of Development Studies degree, at Victoria University of Wellington, New Zealand. The purpose of this research is to explore the linkages between traditional wisdom and sustainable development. The University regulations require me to inform you about this research before gaining your consent to participate in it. You are under no obligation to participate if you do not wish to.

The information provided will be used to seek the following objectives: (a) how traditional wisdom helps contribute to sustainable development; (b) how this helps in sustaining sustainable livelihoods, if at all; and (c) how this information may be useful for New Zealand.

The anticipated length of the interviews will be about 45 minutes to 1 hour. During the length of this interview, I will ask questions related to folklores, stories, oral histories that your mother, grandmothers or other close family members may be passed on to you. I will also be interested in finding out how this vast knowledge has helped (or helps) you in implementing sustainable practices. And how this contributes (or has contributed) to your daily earning.

In case you volunteer to be interviewed, the information you provide will be used in the research in way so as to maintain your confidentiality. In no way your name or personal description will be revealed. The information you give will be used in my thesis and possibly personal publication for educational purposes only. Any information you provide will be accessible to me and my supervisor only. The data recorded will be kept in a secure place until one year after the completion of the research and final publication of my thesis.

You may withdraw from this research at any stage. Just let the key-informant / translator know. You may contact me directly too on my contact number (below).

Thank you for your time and consideration. I shall look forward to talk to you soon. Should you have any queries or concerns, please do not hesitate to contact me or my supervisor at the contact number below.

Sincerely,

Sadia Munawar

(R) +64-4-382-9736; (M) +64-21-053-2725

Email:munawar.sadia@gmail.com

Supervisor: John Overton

Tel: +64-4-463-5281

Email: John.Overton@vuw.ac.nz 


\section{Interview Questions}

Personal information:(To be recorded by interviewer as participants will not be able to read or write in English or Urdu)

Name (and pseudonym):

Age\& Gender:

Village:

Education (if any):

Other (optional):

Interview questions

(Please note: As all interviews will be semi-structured, the following questions are subject to change during translation and during the course of the conversation/interview.)

$\rightarrow$ What do you understand by 'sustainable development'?

$\rightarrow$ What stories do you remember from your childhood that your mother, grandmother, or any other relative may have narrated to you, which influenced your thinking about the environment/nature and your connection to it? How do you see them connect to the daily lifestyles you have adapted now?

$\rightarrow$ Do you think these stories and/or folklore may have a role in contributing to the environmentally sustainable practices common in your life or your village today? If yes, can you specify what practices these are?

$\rightarrow \quad$ How do you see it practiced in your household and/or village today? In what ways it may not be practiced? Is there any specific incidence that comes to mind when we talk about sustainable development / practice?

$\rightarrow$ Do you think your living lifestyle and your use of land, water, vegetation, etc has any impact on this area in the long- or short-run? Do you think it may have an impact on the wider society and on the planet we live on? Please elaborate.

$\rightarrow$ Does this vast knowledge about sustainable practices contribute to your daily earning? If yes, which one of these practices help you feed for yourself/family, or help earn you a living?

$\rightarrow$ How do you make use of natural resources (water, soil, plants, animals, sunlight, etc.)?

$\rightarrow$ What about garbage disposal? Sanitation system?

$\rightarrow$ How do you see your village approaches to be unique from other rural communities? Do you believe some of the sustainable practices of your villages may have been overlooked from which others could learn lessons to live sustainably?

$\rightarrow \quad$ What do you see as the ideal kind of project for this region that can help encourage sustainable development and living for the locals? What kinds of projects, policies you think would take local views about the traditional knowledge, environment and development into consideration?

$\rightarrow$ How do you spend your free time?

$\rightarrow \quad$ Is there anything else you would like to add? 
